Utah State University

DigitalCommons@USU

\title{
$5-2013$
}

\section{Lunar Tidal Effects in the Electrodynamics of the Low-Latitude Ionosphere}

Brian David Tracy

Utah State University

Follow this and additional works at: https://digitalcommons.usu.edu/etd

Part of the Atmospheric Sciences Commons, and the Physics Commons

\section{Recommended Citation}

Tracy, Brian David, "Lunar Tidal Effects in the Electrodynamics of the Low-Latitude lonosphere" (2013). All Graduate Theses and Dissertations. 1968.

https://digitalcommons.usu.edu/etd/1968

This Thesis is brought to you for free and open access by the Graduate Studies at DigitalCommons@USU. It has been accepted for inclusion in All Graduate Theses and Dissertations by an authorized administrator of DigitalCommons@USU. For more information, please contact digitalcommons@usu.edu.

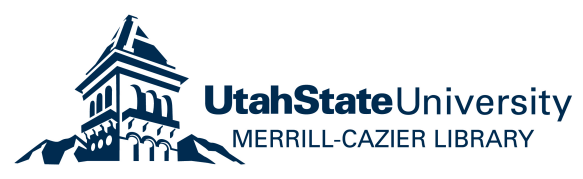




\title{
LUNAR TIDAL EFFECTS IN THE ELECTRODYNAMICS OF THE LOW-LATITUDE IONOSPHERE
}

\author{
by \\ Brian D. Tracy \\ A thesis submitted in partial fulfillment \\ of the requirements for the degree \\ of \\ MASTER OF SCIENCE \\ in \\ Physics
}

Approved:

Bela G. Fejer

Ludger Scherliess

Major Professor

Committee Member

David Peak

Committee Member

Mark McLellan

Vice President for Research and

Dean of the School of Graduate Studies

UTAH STATE UNIVERSITY

Logan, Utah 
Copyright @ Brian D. Tracy 2013

All Rights Reserved 


\author{
ABSTRACT \\ Lunar Tidal Effects in the Electrodynamics of the \\ Low-Latitude Ionosphere \\ by \\ Brian D. Tracy, Master of Science \\ Utah State University, 2013
}

Major Professor: Dr. Bela G. Fejer

Department: Physics

We used extensive measurements made by the Jicamarca Unattended Long-Term Investigations of the Ionosphere and Atmosphere (JULIA) and Incoherent Scatter Radar (ISR) systems at Jicamarca, Peru during geomagnetic quiet conditions to determine the climatologies of lunar tidal effects on equatorial vertical plasma drifts. We use, for the first time, the expectation maximization (EM) algorithm to derive the amplitudes and phases of the semimonthly and monthly lunar tidal perturbations. Our results indicate, as expected, lunar tidal effects can significantly modulate the equatorial plasma drifts. The local time and seasonal dependent phase progression has been studied in much more detail than previously and has shown to have significant variations from the average value. The semimonthly drift amplitudes are largest during December solstice and smallest during June solstice during the day, and almost season independent at night. The monthly lunar tidal amplitudes are season independent during the day, while nighttime 
monthly amplitudes are largest and smallest in December solstice and autumnal equinox, respectively. The monthly and semimonthly amplitudes decrease from early morning to afternoon and evening to morning with moderate to large increases near dusk and dawn.

We also examined these perturbation drifts during periods of sudden stratospheric warmings (SSWs). Our results show, for the first time, the enhancements of the lunar semimonthly tidal effects associated with SSWs to occur at night, as well as during the day. Our results also indicate during SSWs, monthly tidal effects are not enhanced as strongly as the semimonthly effects. 


\section{PUBLIC ABSTRACT}

\section{Lunar Tidal Effects in the Electrodynamics of the Low-Latitude Ionosphere \\ Brian D. Tracy, Master of Science \\ Utah State University, 2013}

In order to model and perform better forecasts of the upper atmosphere, we have studied variations in the equatorial ionosphere due to lunar tidal forcing. We used extensive measurements made by the Jicamarca Unattended Long-Term Investigations of the Ionosphere and Atmosphere (JULIA) and Incoherent Scatter Radar (ISR) systems at Jicamarca, Peru during geomagnetic quiet conditions to determine the season, local time, and lunar age-dependent lunar tidal effects on equatorial vertical plasma drifts. The amplitudes and phases of the semimonthly and monthly lunar tidal perturbations were derived using a least squares method. Our results indicate that, as expected, lunar tidal effects can significantly modulate the equatorial plasma drifts. The local time and seasonal dependent phase progression has been studied in much more detail than previously and has shown to have significant variations from the average value. The semimonthly drift amplitudes are largest during December solstice and smallest during June solstice during the day and almost season independent at night. The monthly lunar tidal amplitudes are season independent during the day, while nighttime monthly amplitudes are largest and smallest in December solstice and autumnal equinox, respectively. The monthly and semimonthly amplitudes decrease from early morning to afternoon and evening to morning with moderate-to-large increases near dusk and dawn. 
We also examined these perturbation drifts during periods of sudden stratospheric warmings (SSWs), which is a meteorological event where the polar vortex is displaced or splits and which has been known to be associated with a large increase in planetary wave activity. Our results show, for the first time, the enhancements of the lunar semimonthly tidal effects associated with SSWs to occur at night, as well as during the day. Our results also indicate during SSWs monthly tidal effects are not enhanced as strongly as the semimonthly effects. 


\section{ACKNOWLEDGMENTS}

I would like to thank Dr. Fejer for providing me with his time, thoughts, and guidance throughout this process, for making the data available, and for funding my research efforts. Specifically, thank you for helping me to learn coding, figure design and presentation, data analysis, and to improve my writing skills (even if I have a long ways to go). His patience, efforts, and guidance throughout this process have been, and are, greatly appreciated. I would also like to thank my committee members, Dr. Peak and Dr. Scherliess; each has helped me to learn things I consider important. Dr. Peak, thank you for always having a fun and educational class. I learned a lot about physics, as well as about future career opportunities from your classes. Also thanks for helping me to apply for and receive national awards. Dr. Scherliess, thanks for helping me to learn numerical methods and coding. I can see how this will be a great asset in my future work.

I would like to give special thanks to those who have been with me through this from the beginning. I have been asking questions since I was young. I know this could be taxing. I thank my parents for developing this into a healthy talent instead of squishing it, as so many would have. I also would like to give a special thank you to my wife. She has only known me for a short while, but already she has taught me things I would not learn from anyone else. I look forward to many years ahead. I also have learned through the years that I do not do this alone. I would like to thank God for the gifts and talents He has given me to bless His children, which includes furthering our knowledge of His creations. Finally, I would like to thank my friends, family, and other professors and teachers I have had while growing up; each one has helped me along the path. 
I would also like to acknowledge this work was supported by the Aeronomy Program, division of Atmospheric Sciences of the National Science Foundation through Grant AGS-1068104 and by NASA through Grants NNH12C02C and NNX09ANSSG. The Jicamarca Radio Observatory is a facility of the Instituto Geofisico del Peru, and is operated with support from the NSF cooperative agreement AGS-0905448 through Cornell University.

Brian D. Tracy 
CONTENTS

Page

ABSTRACT.

iii

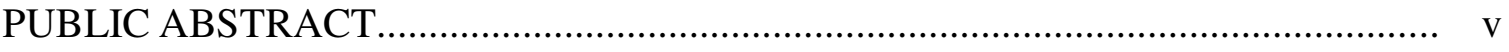

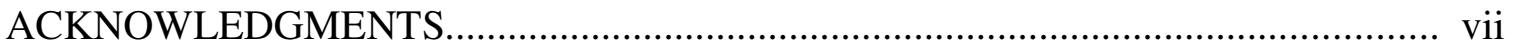

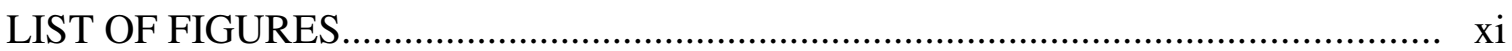

CHAPTER

1. INTRODUCTION ...................................................................

1.1. The Earth's Atmosphere............................................................ 1

1.2. The Earth's Ionosphere............................................................... 2

1.3. Overview of This Work................................................................. 4

2. LOW-LATITUDE IONOSPHERIC PLASMA DRIFTS..................... 6

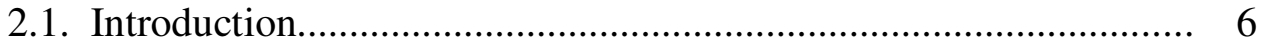

2.2. E- and F-region Dynamo and Polarization Fields....................... 7

2.3. Quiet-Time Plasma Drifts..................................................... 9

2.4. Longitude Dependence of the Vertical and Zonal Plasma Drift..... 17

2.5. Ionospheric Weather............................................................. 31

3. LUNAR TIDAL EFFECTS ON THE EQUATORIAL PLASMA DRIFTS......................................................................... 33

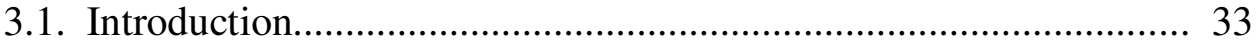

3.2. Data and Methodology........................................................ 38

3.3. Lunar Tidal Effects................................................................ 41

3.3.1. Luni-Solar Semimonthly Tidal Effects.............................. 43

3.3.2. Luni-Solar Monthly Tidal Effects..................................... 57

3.4. Lunar Tidal Effects During Sudden Stratospheric Warmings.......... 73

3.5. Equatorial Spread F Short-Term Variability.................................. 79

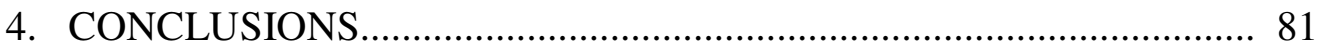


4.1. Summary of Results.............................................................. 81

4.2. Suggestions for Future Work................................................... 82

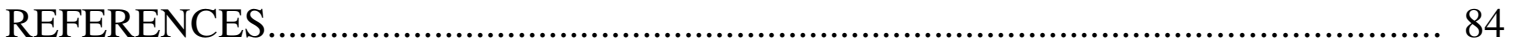

APPENDIX 


\section{LIST OF FIGURES}

Figure

1-1. Typical profiles of neutral atmosphere temperatures and plasma densities as a function of height.

2-1. Jicamarca F-region average season and solar-flux-dependent vertical (positive upward) plasma drifts.

2-2. Jicamarca prereversal peak velocity for three seasons as a function of solar flux

2-3. Jicamarca average quiet-time vertical plasma drifts as a function of season for moderate solar flux conditions as derived from ISR F-region and JULIA $150 \mathrm{~km}$ measurements.

2-4. Jicamarca average season and solar-flux-dependent zonal (positive eastward) plasma drifts.

2-5. Solar flux dependence of the nighttime F-region eastward peak velocity.....

2-6. Average vertical plasma drifts as a function of season and local time from the ROCSAT Fejer et al. (2008) and Jicamarca ISR/ AE-E from Scherliess and Fejer (1999) empirical models.

2-7. Local time, season and longitude-dependent vertical plasma drifts (positive upward) as derived from ROCSAT-1 satellite measurements

2-8. Local time, longitude and solar flux variation of the quiet-time vertical plasma drift for eight longitude sectors and three seasons as derived from ROCSAT-1 data.......

2-9. Longitude dependence of the vertical plasma drift for three seasons and two local time sectors as derived from ROCSAT-1 data.

2-10. Longitude dependence of the prereversal enhancement for three seasons as derived from ROCSAT-1 data.

2-11. Average F-region quiet-time zonal (positive eastward) plasma drift as a function of local time and season from C/NOFS VEFI measurements over the Peruvian equatorial region and from the Jicamarca radar. 
2-12. Local time, season, and longitude-dependent average zonal plasma drifts from VEFI measurements onboard the C/NOFS satellite.

2-13. Local time and longitude variation of the average low-solar-flux quiet-time zonal plasma drift for eight longitude sectors and three seasons from VEFI measurements onboard the C/NOFS satellite.

2-14. Longitude and seasonal dependence of the zonal plasma drift for two local time sectors as measured by VEFI onboard the C/NOFS satellite

2-15. Longitude and seasonal dependence of the zonal plasma drift for two local time sectors, including prereversal enhancement, as measured by VEFI on board the $\mathrm{C} / \mathrm{NOFS}$ satellite

3-1. Local solar time, $t$, local lunar time, $\tau$, lunar age, $v$, and the relationship between them is shown for a point, $\mathrm{P}$, on the Earth, E

3-2. Days of data during each day of the lunar cycle from the ISR and JULIA radar systems at Jicamarca, Peru.

3-3. Equatorial vertical plasma drift perturbations (positive upward) as a function of local time and day after the new moon derived from Jicamarca incoherent scatter radar measurements during December solstice

3-4. Daytime vertical plasma drift perturbations as function of local time and day after new moon for November-February derived from JULIA data (top panel) and bihourly average of the daytime perturbation vertical drifts (center and bottom panels).

3-5. Daytime maximum likelihood luni-solar semimonthly lunar drifts as derived from JULIA data for three seasons.

3-6. Daytime maximum likelihood luni-solar semimonthly lunar drifts as derived from JULIA data for six bimonthly periods

3-7. Bimonthly variation of the amplitudes and phases of daytime (9-15 LT) maximum likelihood luni-solar semimonthly vertical perturbation drifts as derived from JULIA data.

3-8. Local time variation of the amplitudes and phases of maximum likelihood lunisolar semimonthly daytime drifts during July-August from JULIA data.....

3-9. Day and nighttime maximum likelihood luni-solar semimonthly perturbation drifts as derived from ISR data for three seasons 
3-10. Daytime maximum likelihood luni-solar semimonthly perturbation drifts as derived from ISR data for six bimonthly periods

3-11. Nighttime maximum likelihood luni-solar semimonthly perturbation drifts as derived from ISR data for six bimonthly periods.

3-12. Day and nighttime maximum likelihood luni-solar semimonthly perturbation drifts as derived from ISR data for January-February and the calculated and expected phase.

3-13. Bimonthly variation of the amplitudes and phases of daytime (9-15 LT) maximum likelihood luni-solar semimonthly vertical perturbation drifts as derived from ISR data.

3-14. Bimonthly variation of the amplitudes and phases of nighttime (20-06 LT) maximum likelihood luni-solar semimonthly vertical perturbation drifts as derived from ISR data.

3-15. Local time variation of the yearly average amplitudes of the luni-solar semimonthly perturbation drifts as derived from the ISR data.

3-16. Comparison of the bimonthly variation of the amplitudes and phases of daytime (9-15 LT) maximum likelihood luni-solar semimonthly vertical perturbation drifts as derived from JULIA and ISR data.

3-17. Local time variation of average ISR vertical drift velocities for periods starting close to new and full moon....

3-18. Daytime maximum likelihood luni-solar monthly perturbation drifts as derived from JULIA data for three seasons.

3-19. Daytime maximum likelihood luni-solar monthly perturbation drifts as derived from JULIA data for six bimonthly periods.

3-20. Bimonthly variation of the amplitudes and phases of daytime (9-15 LT) maximum likelihood luni-solar monthly vertical perturbation drifts as derived from JULIA data......

3-21. Local time variation of the average amplitudes and phases of the luni-solar monthly perturbation drifts as derived from JULIA data.

3-22. Day and nighttime maximum likelihood luni-solar monthly perturbation drifts as derived from ISR data for three seasons. 
3-23. Daytime maximum likelihood luni-solar monthly perturbation drifts as derived from ISR data for six bimonthly periods.

3-24. Nighttime maximum likelihood luni-solar monthly perturbation drifts as derived from ISR data for six bimonthly periods.....

3-25. Day and nighttime maximum likelihood luni-solar monthly perturbation drifts as derived from ISR data for January-February and the calculated and expected phase.

3-26. Bimonthly variation of the amplitudes and phases of daytime (9-15 LT) maximum likelihood luni-solar monthly vertical perturbation drifts as derived from ISR data.

3-27. Bimonthly variation of the amplitudes and phases of nighttime (20-06 LT) maximum likelihood luni-solar monthly vertical perturbation drifts as derived from ISR data.

3-28. Local time variation of the average amplitudes of the luni-solar semimonthly and monthly perturbation drifts as derived from ISR data.

3-29. Comparison of the bimonthly variation of the amplitudes and phases of daytime (9-15 LT) maximum likelihood luni-solar monthly vertical perturbation drifts as derived from JULIA and ISR data....

3-30. Day and nighttime maximum likelihood luni-solar semimonthly perturbation drifts as derived from ISR data for periods with (bottom panel) and without (top panel) ssw.

3-31. Jicamarca bimonthly averaged vertical plasma drift perturbations and highlatitude temperatures and winds during the 2010 SSW event.

3-32. Average vertical plasma drifts (positive upward) derived from ROCSAT-1 (top panel) and ISR (bottom panel) measurements for periods starting close to the new and full moons, 3-17 and 18-2 days after the new moon, respectively.... 


\section{CHAPTER 1}

\section{INTRODUCTION}

\subsection{The Earth's Atmosphere}

The Earth's atmosphere extends from the surface of the Earth to many thousands of kilometers. The composition, temperature, pressure, and charge density of the atmosphere are season, local time, altitude, latitude, and longitude dependent. The characteristics of these parameters were discussed in detail by several authors [e.g., Schunk and Nagy, 2009; Kelley, 2009]. The classification of the neutral atmosphere by temperature for a typical midlatitude is displayed in Figure 1-1. From the ground to about $10 \mathrm{~km}$, the temperature decreases with a lapse rate of about $7 \mathrm{~K} / \mathrm{km}$ in the troposphere. The temperature trend reverses at the tropopause leading to an increase in the stratosphere, which is largely due to the absorption of ultraviolet radiation by ozone. The temperature trend reverses again at the stratopause, at about $50 \mathrm{~km}$. Radiative cooling in the mesosphere creates a very sharp temperature decrease that leads to the coolest atmospheric temperatures (about 130-190 K) at the mesopause (about $95 \mathrm{~km}$ ). Above the mesopause, in the thermosphere, the temperature increases drastically due to the absorption of extreme ultraviolet and ultraviolet radiation to values that vary considerably, but are often above $1000 \mathrm{~K}$.

The neutral atmosphere is well mixed below about $100 \mathrm{~km}$ (homosphere) with a composition of $78 \% \mathrm{~N} 2,21 \% \mathrm{O} 2$, and $1 \%$ trace gases. Above the turbopause (heterosphere), the various gases begin to separate according to mass into different layers with heavier molecules at lower altitudes and lighter atoms at higher altitudes. Above 


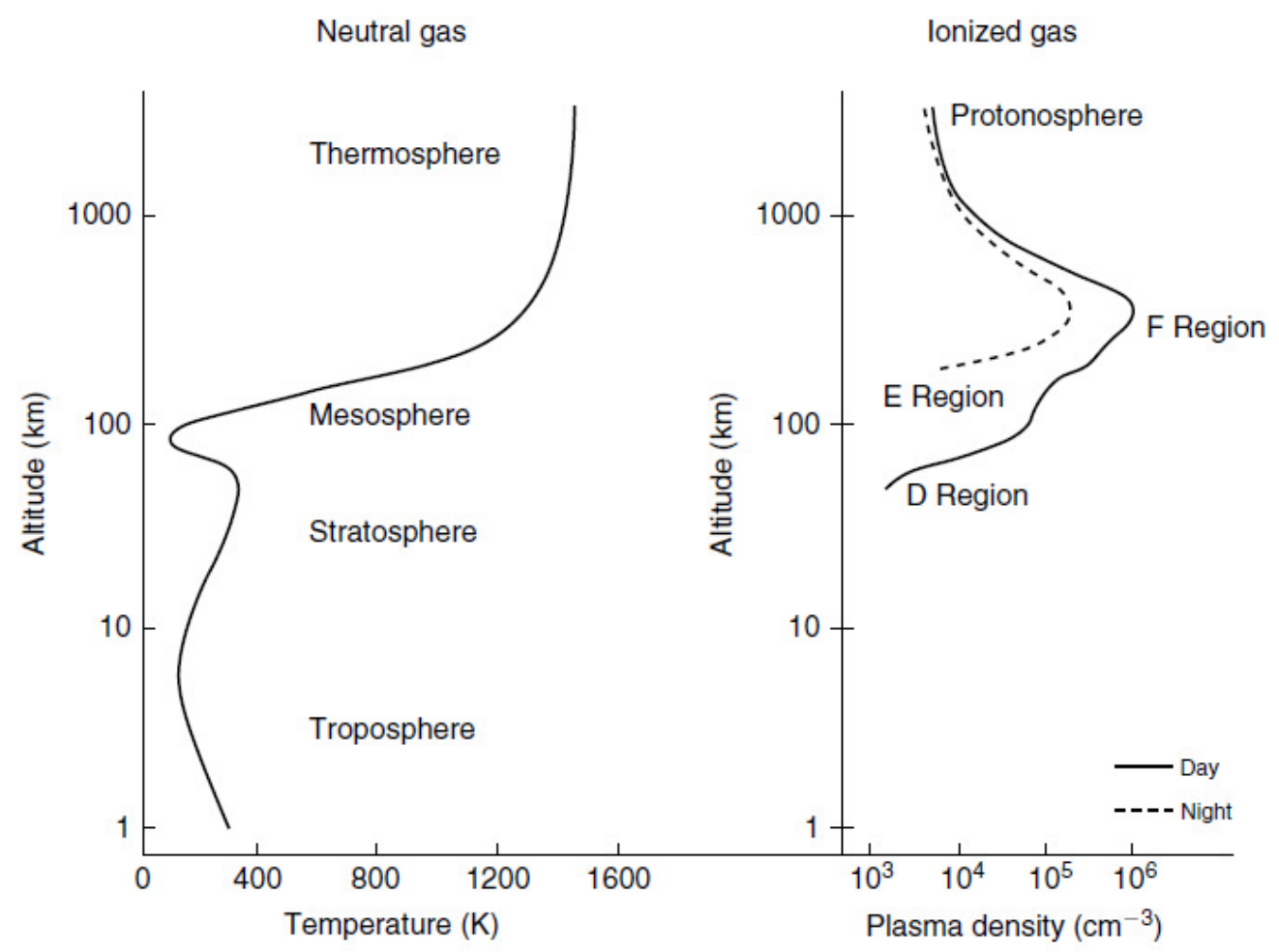

Figure 1-1. Typical profiles of neutral atmosphere temperatures and plasma densities as a function of height [from Kelley, 2009].

$500 \mathrm{~km}$, in the exosphere, the neutral densities are low enough that, although the temperature trend does not change, collisions are no longer important and individual particles follow ballistic-style motions.

\subsection{The Earth's Ionosphere}

The ionosphere, the ionized portion of the upper atmosphere, extends from about 60 to $1000 \mathrm{~km}$, covers the whole Earth, and is formed primarily by ionization of the atmospheric gases by solar EUV and soft X-ray radiation. Like the neutral atmosphere, the ionosphere is local time, season, latitude and longitude dependent. The plasma, thus formed, is balanced by the recombination of electrons and ions and loss due to transport 
to other regions. Typical ionospheric plasma densities are less than $1 \%$ of typical neutral densities. Despite the relatively low density of the plasma, the resultant currents and electric fields produced have a profound impact on the region.

The ionosphere displays a layered structure with different composition, reaction rates, and dynamics at different altitudes (see Figure 1-1). The D-region extends from about $60 \mathrm{~km}$ to $90 \mathrm{~km}$ and is heavily dominated by chemical production and loss processes and collisions with the neutral atmosphere. The dominant ions here are $\mathrm{NO}^{+}$ from Lyman series-alpha hydrogen radiation at a wavelength of $122 \mathrm{~nm}, \mathrm{O}_{2}{ }^{+}$, and other positive and negative molecular ions from X-ray radiation and water cluster ions from hydration primarily with $\mathrm{NO}^{+}$and $\mathrm{O}_{2}{ }^{+}$. The $\mathrm{E}$ region is defined from about $90 \mathrm{~km}$ to 150 $\mathrm{km}$ and is also heavily dominated by chemical loss processes. The major ions are $\mathrm{NO}^{+}$, $\mathrm{O}_{2}{ }^{+}$, and $\mathrm{N}_{2}{ }^{+}$. As the loss processes for both the $\mathrm{D}$ and $\mathrm{E}$ regions are quite fast, the plasma densities in these regions decrease quickly after sunset.

The F region is the region from about $150 \mathrm{~km}$ to $500 \mathrm{~km}$. During the day, this region has two subregions, $F_{1}(150-250 \mathrm{~km})$ and $F_{2}(250-500 \mathrm{~km})$. In the $F_{1}$ region, chemical production and loss processes are still dominant, whereas in the $\mathrm{F}_{2}$ region, both chemical loss and transport processes are important. The main ion in this region is $\mathrm{O}^{+}$. The peak plasma density occurs in this region as a result of a balance between chemical production and loss processes and plasma transport. The daytime peak plasma density $\left(10^{6} \mathrm{~cm}^{-3}\right)$ is roughly a factor of ten greater than that in the E region and two orders of magnitude smaller than that of the neutral density. At night, the F region does not die out due to the high composition of atomic ions; however, the nighttime peak plasma densities 
can be as low as $10^{4} \mathrm{~cm}^{-3}$ in the post-midnight period. The topside ionosphere is generally defined to be the region above the F-region peak $(500-800 \mathrm{~km})$, while the protonosphere, above about $800 \mathrm{~km}$, is the region where the lighter atomic ions $\left(\mathrm{H}^{+}\right.$and $\left.\mathrm{He}^{+}\right)$are the primary constituents of the plasma.

The ionosphere is further classified according to geomagnetic latitude. At high latitudes the magnetic field lines are almost vertical and electric fields and currents due to the solar wind-magnetosphere interaction are imposed on the ionosphere and form the primary drivers of plasma drifts and currents. At midlatitudes the magnetic field lines have sizable inclinations, but generally do not link the ionosphere with the hot, tenuous plasmas of the magnetosphere and solar wind. Here electric fields from high and low latitudes, atmospheric tides, and planetary and gravity waves play major roles in the dynamics. At low latitudes the magnetic field lines are almost horizontal, and as a result, the ionosphere is primarily driven by dynamo electric fields of tidal origin; however, storm-time effects can, and often do, play a large role in the dynamics of the region.

\subsection{Overview of This Work}

This work focuses on short-term, low-latitude electrodynamic variability. Electric fields at these latitudes control the composition and distribution of the ionospheric plasma and strongly affect the generation of plasma waves and density structures over a large range of scale sizes. The resultant ionosphere strongly affects a large range of spacebased industrial applications including navigation and communication.

Equatorial vertical plasma drifts are driven by these electric fields and are the primary drivers in several low-latitude ionospheric effects, including the equatorial 
fountain, and the development of equatorial spread F (a plasma instability). Several authors have determined the monthly average behavior of these drifts; however, the shortterm variability is not yet quantified. To address this problem, our team is undertaking a multiyear study of the short-term variability of these drifts with the goal of producing a long-term empirical model of the drifts by a perturbative method. In this work, we review the climatology of the plasma drifts and their short-term variability and then focus on an important source of this variability, lunar tidal effects.

In Chapter 2, we first briefly review the basic ionospheric quiet-time electrodynamic processes including the $\mathrm{E}$ and $\mathrm{F}$ region dynamos. Then, we review the climatological geomagnetic quiet equatorial plasma drifts dependence on local time, season, solar flux, and longitude as derived from radar and satellite measurements. We conclude this chapter by briefly mentioning some of the sources of the short-term variability of the equatorial drifts.

In Chapter 3, we present a detailed study of the lunar tidal effects on the electrodynamic, low-latitude vertical plasma drifts over Jicamarca, Peru. This Chapter largely extends the study of lunar tidal effects on equatorial ionospheric electrodynamics published by Fejer and Tracy [2013], including the first detailed study of lunar diurnal tidal effects. In Chapter 4, we summarize our results and offer suggestions for future work on studies of equatorial ionospheric electrodynamics. 


\section{CHAPTER 2}

\section{LOW-LATITUDE IONOSPHERIC PLASMA DRIFTS}

\subsection{Introduction}

Electric fields and plasma drifts play fundamental roles in the dynamics of the upper atmosphere. Low-latitude electric fields drive the equatorial electrojet and ionospheric electrodynamic ( $\mathbf{E x B})$ plasma drifts. These processes control the composition and distribution of the ionospheric plasma and strongly affect the generation of plasma waves and density structures over a large range of scale sizes (tens of $\mathrm{cm}$ to hundreds of kilometers). At low latitudes, the accurate specification of the temporal and spatial variations of the ionospheric plasma drifts constitutes the main challenge for improved forecasting of ionospheric weather, which can strongly affect the performance of the rapidly increasing number of space-based navigation systems, as pointed out by several authors [e.g., Fejer, 2011].

The morphology of equatorial plasma drifts have been extensively studied over the last 40 years using incoherent and coherent scatter radar measurements [e.g., Woodman, 1970; Chau and Woodman, 2004], daytime equatorial magnetic field [e.g., Anderson et al., 2002], and nighttime ionosonde observations [e.g., Abdu et al., 2007]. These studies determined the average seasonal, solar cycle, and magnetic effects on the low-latitude plasma drifts, and their control over the F-region plasma density distribution [e.g., Fejer, 1997]. In the last two decades, measurements on board the Atmospheric Explorer-E (AE-E), San Marco, Republic of China Satellite (ROCSAT-1), Dynamics Explorer-B (DE-2), Defense Meteorological Space Probe (DMSP), CHAMP and 
$\mathrm{C} / \mathrm{NOFS}$ satellites provided detailed information on the longitude-dependent, low-latitude plasma drifts, equatorial electrojet, total electron content (TEC), and spread F. These studies were recently reviewed by Fejer [2011].

The basic electric field and plasma drift generation mechanisms have been determined by complementary experimental and theoretical numerical modeling studies [e.g., Richmond, 1995b]. Numerical models include global upper atmosphere threedimensional, time-dependent National Center for Atmospheric Research (NCAR) models (TIEGCM, TIME-GCM, MTIEGCM) [e.g., Fesen et al., 2000; Hagan and Forbes, 2002, 2003; Richmond et al., 2003; Vichare and Richmond, 2005], the Coupled ThermosphereIonosphere-Plasmasphere model (CTIP) [e.g., Millward et al., 2001], and the Sami2 is Another Model of the Ionosphere (SAMI2) model [e.g., Huba et al., 2000]. A model incorporating global experimental ionospheric data through a Gauss-Markov Kalman filter and a physics-based model is the Global Assimilation of Ionospheric Measurements (GAIM) [Schunk et al., 2002; Scherliess et al., 2004, 2006]. Storm-time ionospheric effects were studied using the coupled global ionospheric and convection models [e.g., Huba et al., 2005; Maruyama et al., 2007].

In the following sections we will review the present understanding of the fundamental plasma ionospheric quiet-time drift generating mechanisms, including the Eand F-region dynamos, and then discuss their season, solar cycle and longitudedependent climatologies. Finally, we will briefly discuss their short-term variability.

\subsection{E- and F-region Dynamo and Polarization Fields}

Low-latitude, quiet-time plasma drifts are primarily driven by E- and F-region 
neutral winds of tidal origin, but are also affected by F-region polarization fields, gravity and plasma pressure driven currents, conductivity changes, and lower atmosphere gravity and planetary waves [e.g., Richmond, 1995a, 1995b]. During geomagnetic storms, solar wind-magnetosphere dynamo and ionospheric-disturbance dynamo can significantly alter the plasma drifts [e.g., Fejer, 1997]. In this section we briefly describe the E- and Fregion dynamos, which are the primary drivers of the plasma drift during geomagnetic quiet times.

The solar diurnal tide, caused by solar heating of the atmosphere, drives the lowlatitude E-region neutral wind system [Richmond, 1995a]. This heating occurs primarily in the stratosphere and troposphere, and these tidal oscillations propagate upward to ionospheric heights. Above about $30^{\circ}$ latitude as the semidiurnal tide becomes dominant, the diurnal tide cannot propagate upwards and is trapped in the stratosphere. The lunar semidiurnal tide (period of 12.4 hours) creates the next strongest neutral wind system, but its strength is one order of magnitude smaller than those of the solar tides [Schunk and Nagy, 2009].

The solar quiet $(\mathrm{Sq})$ current system is the result of the solar-generated neutral wind field's interaction with the E-region plasma. The Sq current system's strength follows the Pedersen conductivity, maximizing at $150 \mathrm{~km}$ around noon when the Pedersen conductivity maximizes, and very small at night due to low plasma densities. The Sq currents maximize at about $30^{\circ}$ latitude and decrease at higher and lower latitudes.

The E-region dynamo are mapped along magnetic field lines to F-region heights. 
In the nighttime mid- and low-latitude ionosphere, the dynamo effects of F-region thermospheric neutral winds also generate electric fields and currents. During the day, the high E-region conductivity shorts out these polarization electric fields; therefore, daytime E- and F-region plasma drifts are primarily driven by E-region electric fields. At night, the local F-region dynamo is the dominant plasma drift generation mechanism.

At the equatorial dusk terminator, the F-region dynamo is no longer completely shorted out by the E-region due to low E-region conductivity. This results in negative charges piling up and generating an Eastward polarization electric field. This eastward electric field is then mapped back up to the F-region where it drives large upward ExB plasma drift velocities on the dayside of the terminator and downward drifts on the nightside. This large evening upward drift is commonly known as the prereversal velocity enhancement. These electric fields are the major drivers of electrodynamic plasma drifts $\left(\mathbf{V}=\mathbf{E x B} / \mathbf{B}^{2}\right)$. These low-latitude ionospheric drifts are the subject of our study.

\subsection{Quiet-Time Plasma Drifts}

Most of the data about plasma drifts at equatorial latitudes comes from incoherent scatter radar (ISR) measurements at the Jicamarca Radio Observatory near Lima, Peru $\left(11.95^{\circ} \mathrm{S}, 76.87^{\circ} \mathrm{W}\right.$, magnetic $\left.\operatorname{dip} 2^{\circ} \mathrm{N}\right)$. This ISR operates at $50 \mathrm{MHz}$ and is capable of measuring the plasma temperature, density, composition, and ion drift velocity as functions of altitude and time from the backscatter due to thermal fluctuations in the

plasma. Jicamarca F-region plasma drifts are measured typically between 200-800 km with a height resolution of $15-25 \mathrm{~km}$ and a time resolution of 1-5 min. These data are 
most accurate near the F peak (generally between 300-600 km), where the signal-to-noise ratio is highest, and the drifts generally do not change much with altitude. Most of the past studies of Jicamarca drifts have used height-averaged values with an integration time of $5 \mathrm{~min}$. In this case, the accuracy of the vertical and zonal drift is about $1 \mathrm{~m} / \mathrm{s}$ and 10 $\mathrm{m} / \mathrm{s}$, respectively, during the day with larger values at night. Over Jicamarca, an F-region upward (eastward) plasma drift velocity of $40 \mathrm{~m} / \mathrm{s}$ corresponds to an eastward (downward) electric field of $1 \mathrm{mV} / \mathrm{m}$.

The characteristics of the quiet-time vertical and zonal F-region plasma drifts were described in several publications [e.g., Fejer, 1997, 2011; Scherliess and Fejer, 1999]. Figure 2-1 shows the local time and season-dependent Jicamarca average vertical plasma drifts and the corresponding results from the Scherliess-Fejer empirical model for low, moderate and high solar flux magnetic quiet conditions. These drifts have large dayto-day variability at all local times. They are upward during the day and downward at night with typical values of $25 \mathrm{~m} / \mathrm{s}$ except near sunrise and sunset where they can vary considerably with solar flux. The prereversal enhancement is season and solar flux dependent with the largest effects seen in December solstice and Equinox. Figure 2-2 shows the solar-flux dependence of the evening prereversal enhancement in more detail. These drift velocities increase linearly during Equinox from $10 \mathrm{~m} / \mathrm{s}$ during solar minimum to well above $50 \mathrm{~m} / \mathrm{s}$ for solar flux over 200 units. Peak prereversal enhancement velocities during June solstice are best fit by a quadratic for low values of solar flux and a constant peak drift of $20 \mathrm{~m} / \mathrm{s}$ for high flux values. December solstice peak prereversal enhancement velocities can be fit equally well by a linear or quadratic fit 

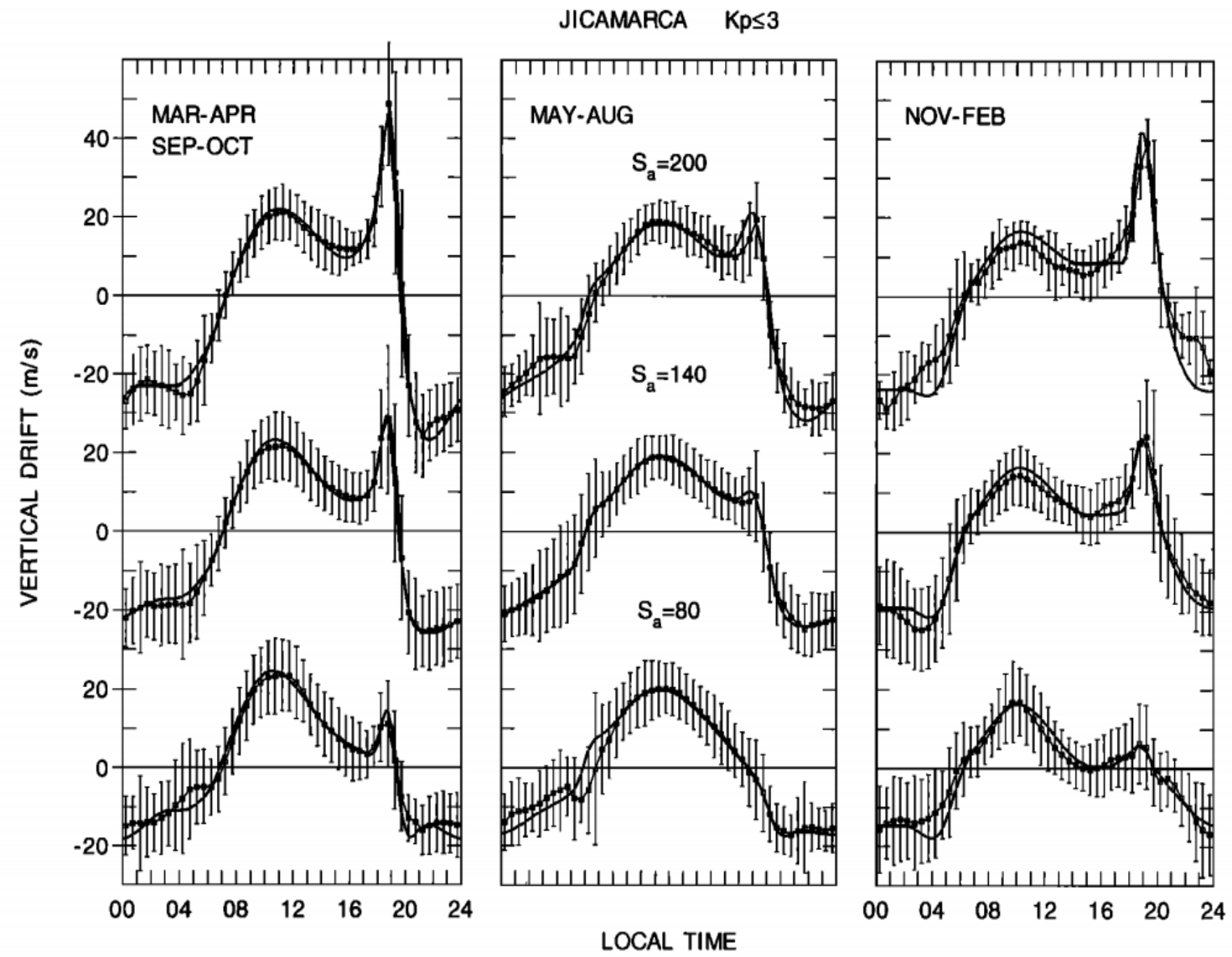

Figure 2-1. Jicamarca F-region average season and solar-flux-dependent vertical (positive upward) plasma drifts. The scatter bars represent the standard deviation and the solid lines show results from an empirical model [after Scherliess and Fejer, 1999].

and have a minimum around $10 \mathrm{~m} / \mathrm{s}$ and a maximum around $50 \mathrm{~m} / \mathrm{s}$ for solar flux above 200 units.

Over the last decade, daytime (between about 0800 and 1600 LT) equatorial vertical and zonal plasma drifts over Jicamarca have also been derived from Doppler measurements of coherent radar echoes at altitudes near $150 \mathrm{~km}$ using the Jicamarca Unattended Long-term Ionosphere and Atmosphere (JULIA) radar system [e.g., Kudeki and Fawcett, 1993; Chau and Woodman, 2004]. JULIA uses the large antenna array and low transmitted power allowing for longer and more frequent runs than the more 


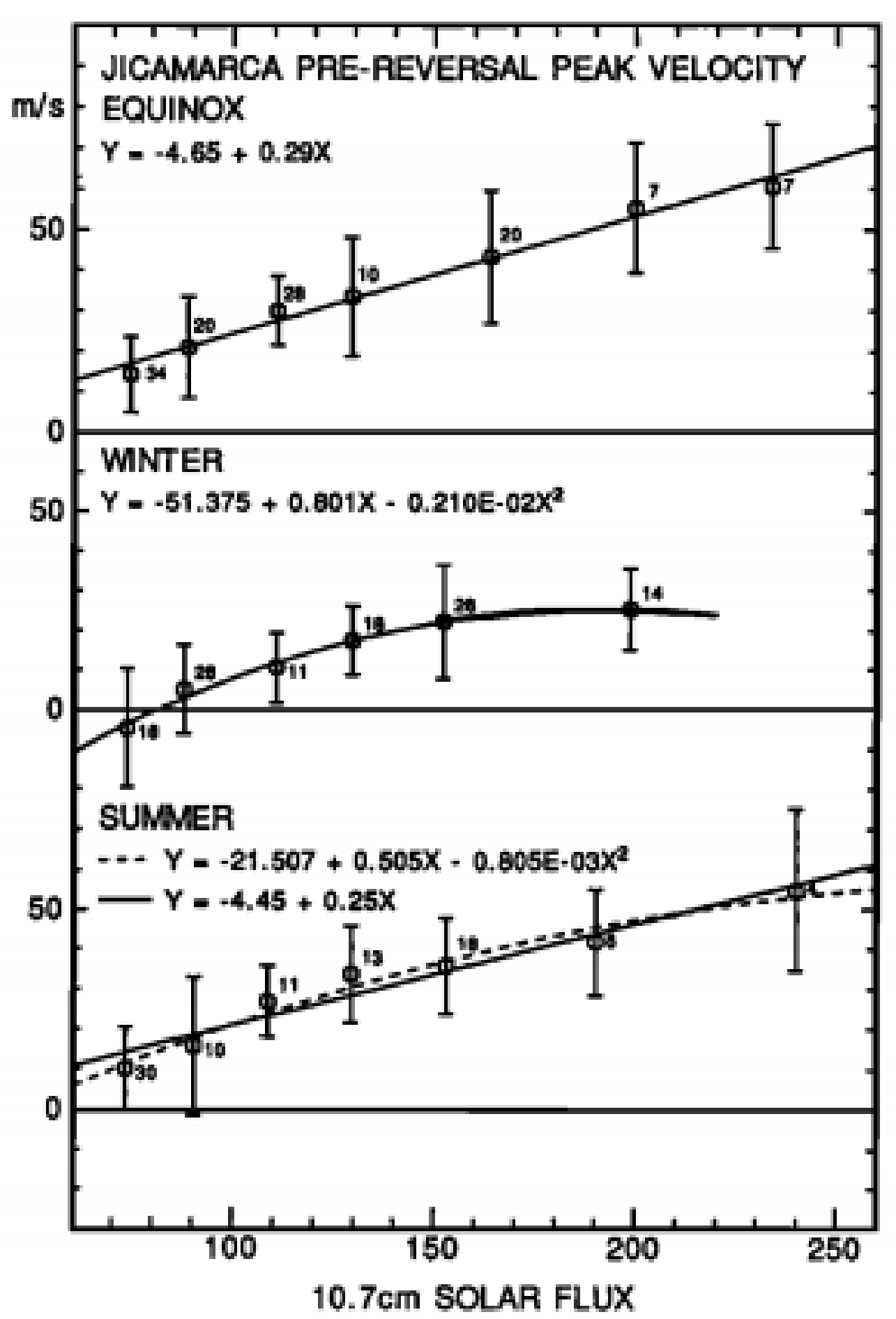

Figure 2-2. Jicamarca prereversal peak velocity for three seasons as a function of solar flux. The error bars represent the standard deviation of the average. The numbers of data points is also shown [from Fejer et al., 1991]. 
expensive ISR system. Typically these drifts have a time resolution of 5 minutes. Under these conditions these drift measurements have typical accuracies of $1 / 2 \mathrm{~m} / \mathrm{s}$ and $5 \mathrm{~m} / \mathrm{s}$ in the vertical and zonal directions, respectively. Numerous studies have shown the vertical drifts measured by this method are indicative of the vertical drifts at F-region heights, but the zonal drifts have poor to fair agreement with the F-region zonal drifts [e.g., Chau and Woodman, 2004 and references therein]. The climatology and the day-to-day variability of the JULIA drifts was recently modeled by Alken [2009]. Figure 2-3 shows the climatology of the ISR and JULIA drifts as a function of season and LT. The difference between them is indicative of the gradient in the drifts as a function of altitude. The ISR drifts have larger values in the morning for all seasons and typically smaller values in the afternoon. June solstice, the ISR, and JULIA drifts are almost identical with the only difference being the morning peak is slightly larger in the ISR data.

Equatorial daytime vertical plasma drifts are also now routinely derived from the difference in magnetic fields from a pair of stations, one over the equator and the other a few degrees off equator at about the same longitude. Vertical drifts derived from data obtained at Jicamarca and Piura $\left(5.2^{\circ} \mathrm{S}, 80.6^{\circ} \mathrm{W} ; 6.8^{\circ}\right.$ magnetic $)$ are generally in good agreement with $150 \mathrm{~km}$ and F-region drifts measured at Jicamarca; however, their accuracy can be affected by magnetic field changes produced by variable low-latitude Eregion winds [e.g., Fang et al., 2008]. Since 1992 ionosonde-derived drifts have also routinely been obtained at Jicamarca. These drifts generally agree with the ISR-measured drifts from about sunset to sunrise and during periods of high magnetic activity [e.g., Bertoni et al., 2006]. 


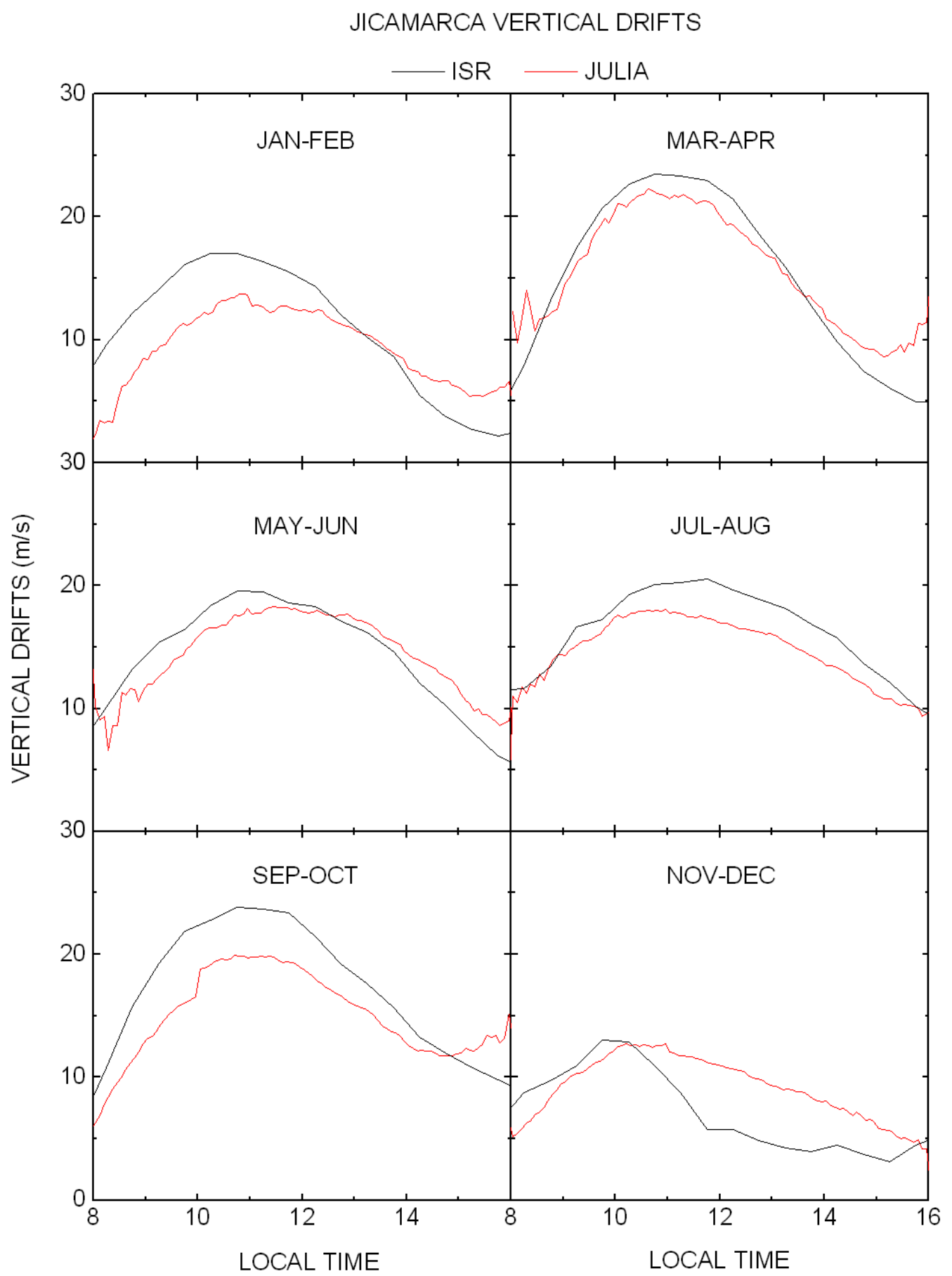

Figure 2-3. Jicamarca average quiet-time vertical plasma drifts as a function of season for moderate solar flux conditions as derived from ISR F-region and JULIA $150 \mathrm{~km}$ measurements. 
Equatorial F-region zonal plasma drifts have been routinely made at Jicamarca since 1970 [e.g., Woodman, 1972]; however, less frequently than the corresponding vertical drifts. These drifts are derived from the difference of line-of-sight measurements from two beams perpendicular to the geomagnetic field, one from a beam pointed $2.5^{\circ}$ to the east and the other from a beam pointed $4.3^{\circ}$ to the west of vertical. These morphology of the Jicamarca zonal drifts has been reviewed in several papers [e.g., Fejer et al., 2005; Fejer, 2011]. Figure 2-4 shows the season and local time-dependent Jicamarca average zonal drifts and the corresponding results from the Fejer et al. [2005] empirical model for low, moderate and high solar flux magnetic quiet conditions. These drifts are westward
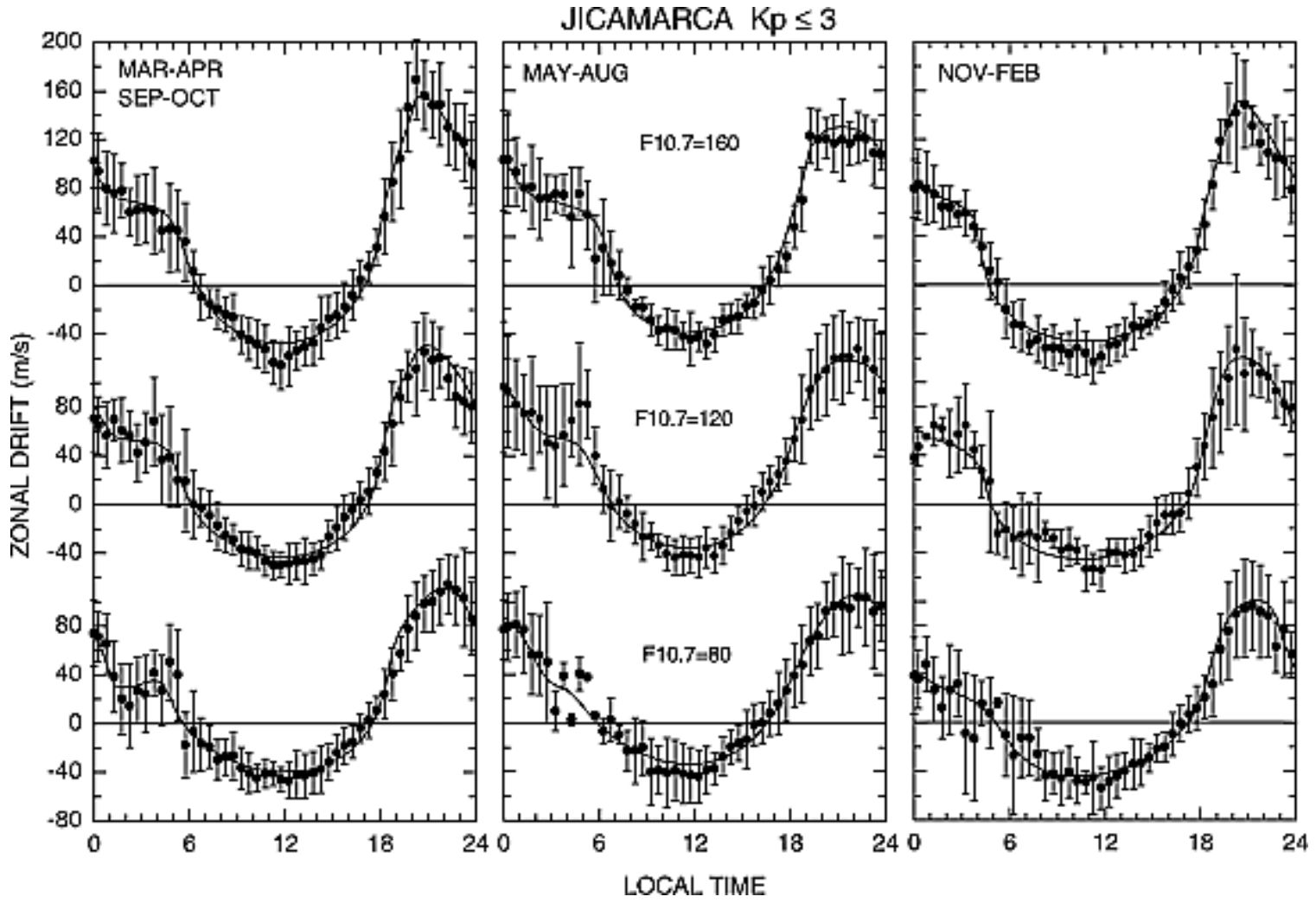

Figure 2-4. Jicamarca average season and solar-flux-dependent zonal (positive eastward) plasma drifts. The error bars represent the standard deviation and the solid lines result from an empirical model [from Fejer et al., 2005]. 
during the day with typical values of about $40 \mathrm{~m} / \mathrm{s}$ and eastward at night with much larger magnitudes. The daytime drifts and morning and afternoon times of reversal vary little with solar flux. The time of the evening peak occurs earlier for all seasons with increasing solar flux. The evening peak's dependence on solar flux is shown in more detail in Figure 2-5. The December solstice and equinox evening peaks are almost identical and increase roughly linearly with solar flux from $100 \mathrm{~m} / \mathrm{s}$ at solar minimum to $180 \mathrm{~m} / \mathrm{s}$ at solar maximum. The June solstice evening peaks vary less with solar flux. It increases from $100 \mathrm{~m} / \mathrm{s}$ at solar minimum to $150 \mathrm{~m} / \mathrm{s}$ at solar maximum with the increase tapering off for higher solar fluxes.

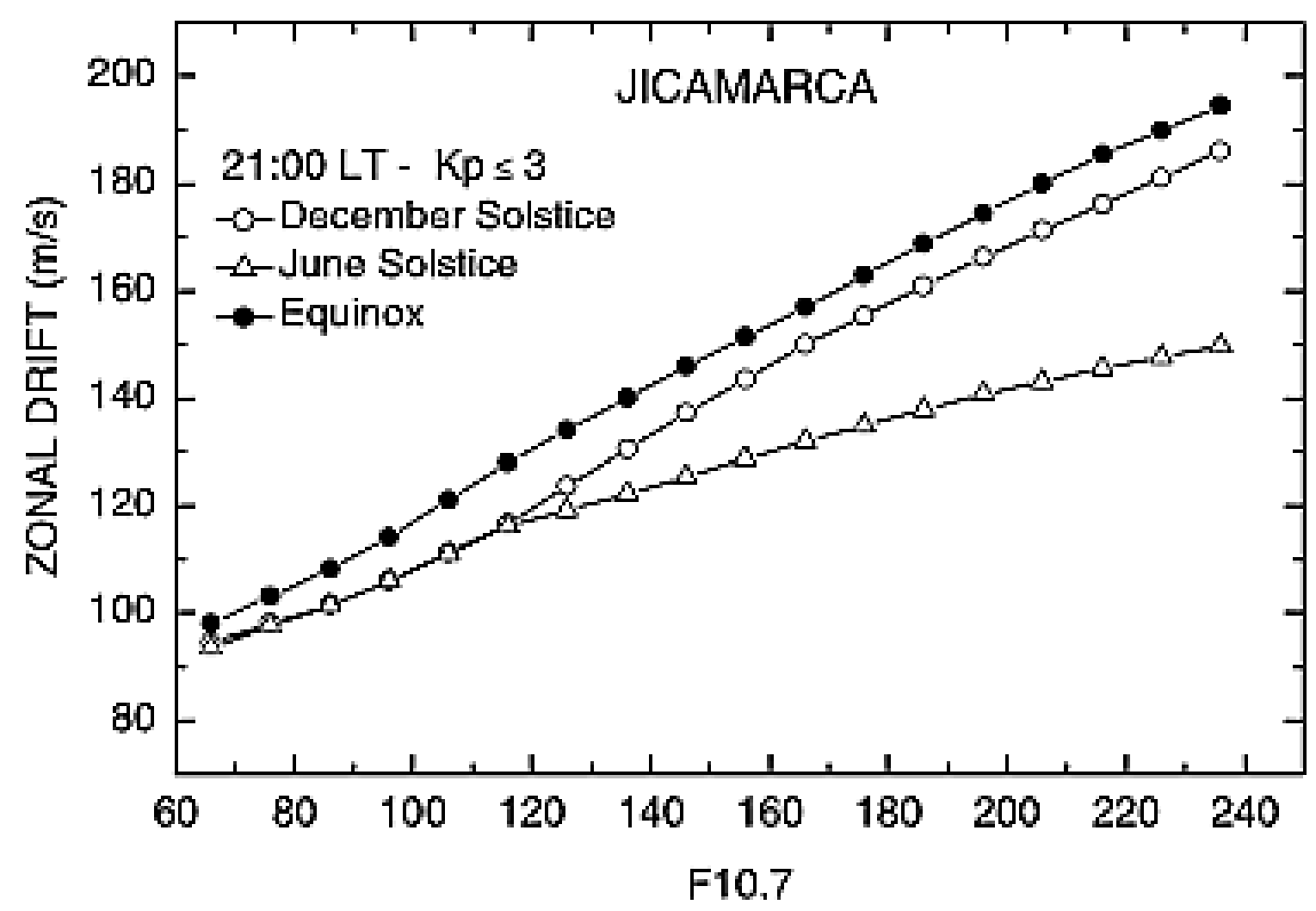

Figure 2-5. Solar flux dependence of the nighttime F-region eastward peak velocity [from Fejer et al., 2005]. 


\subsection{Longitude Dependence of the Vertical and Zonal Plasma Drift}

Coley et al. [1990] presented the initial results of equatorial vertical plasma drifts measured by the low-inclination (19.6 $)$ AE-E satellite during 1977-1979. They showed the local time dependence of the longitudinally averaged low-latitude AE-E satellite ion drift meter data is consistent with the Jicamarca ISR drifts. Fejer et al. [1995], using the same data set, determined the average dependence of these drifts on solar flux and season for four longitude sectors. Scherliess and Fejer [1999] incorporated the AE-E drift data and 1968-1999 ISR data from Jicamarca into the first detailed season and solar-cycledependent global empirical model of the equatorial vertical plasma drifts. This drifts model, derived using cubic-b splines, has been used extensively in the validation of theoretical models. Regional empirical models have been presented by Batista et al. [1996] and Sastri [1996].

Fejer et al. [2008] used five years (1999-2004) of ion drift measurements at an altitude of $600 \mathrm{~km}$ on board the ROCSAT-1 satellite to study and empirically model the local time, longitudinal, seasonal, and solar cycle dependence of the equatorial F-region vertical plasma drifts. These model drifts are in good agreement with the Jicamarca drifts presented by Scherliess and Fejer [1999] as shown in Figure 2-6. The longitude dependence of the ROCSAT-1 model drifts is significantly more accurate than that of the Scherliess and Fejer [1999] model due to the much larger number of ROCSAT measurements. The ROCSAT-1 model also shows much larger prereversal velocity enhancements during December Solstice and equinox.

Figure 2-7 shows the local time, seasonal and longitudinal dependence of quiet- 


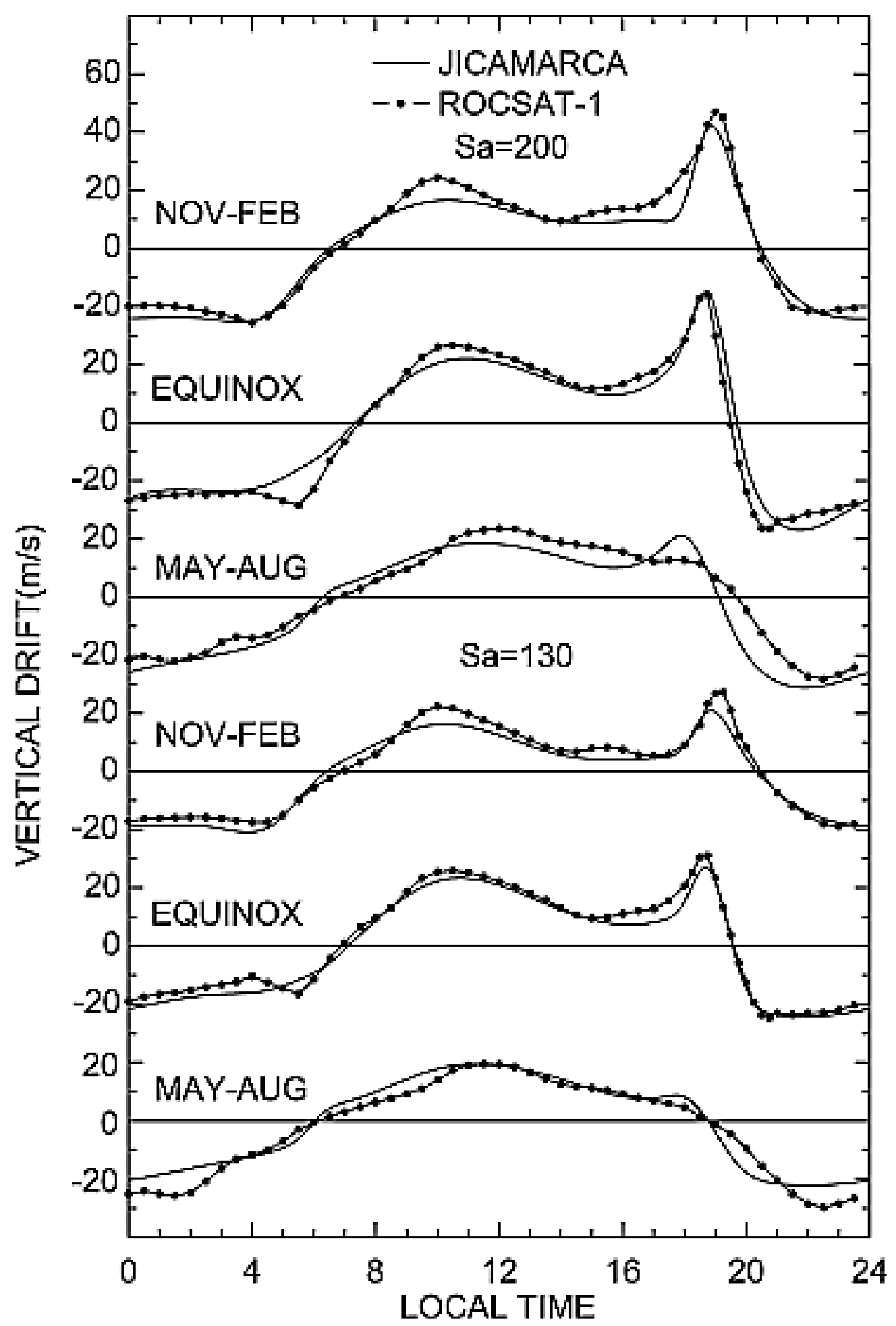

Figure 2-6. Average vertical plasma drifts as a function of season and local time from the ROCSAT Fejer et al. [2008] and Jicamarca ISR/ AE-E from Scherliess and Fejer [1999] empirical models [from Fejer et al., 2008]. 
time equatorial vertical plasma drifts for moderate solar flux conditions derived from ROCSAT-1 data. These drifts are upward during the day with typical values of $20-40 \mathrm{~m} / \mathrm{s}$ and downward at night with typical values of $20 \mathrm{~m} / \mathrm{s}$. These drifts have large longitudinal variations in all seasons and local times, especially in the morning and dusk sectors.

Figure 2-8 shows the ROCSAT-1 model drifts in more detail highlighting their solar flux dependence. The equinox and December solstice morning drifts do not change much with solar flux, but the afternoon and evening upward drifts and the nighttime downward drifts increase with solar flux. Figure 2-8 also shows the increase of the evening prereversal enhancements with solar flux is noticeably longitude dependent during December and June solstice. The evening reversal times do not change with solar flux, except in the American sector during June solstice. The morning reversal times generally occur earlier with decreasing solar flux.

Figures 2-7 and 2-8 both show strong wavenumber-4 longitudinal modulation on the upward drifts during equinox and June solstice. Figure 2-9, which displays the longitude and season-dependent average vertical drifts for 0900-1200 LT and 1300-1600 LT, shows this pattern in more detail. The equinox, June solstice and December eastern hemisphere morning and afternoon peaks are at nearly identical longitudes. The December solstice western hemisphere morning and afternoon drifts have considerably different longitude dependence leading to not as clear wavenumber-4 signature as in the other seasons. This pattern has also been found in many different in-situ and remote sensing measurements [e.g., Sagawa et al., 2005; Immel et al., 2006; Hartman and Heelis, 2007; Kil et al., 2008; Scherliess et al., 2008; Fang et al., 2009, Huang et al., 

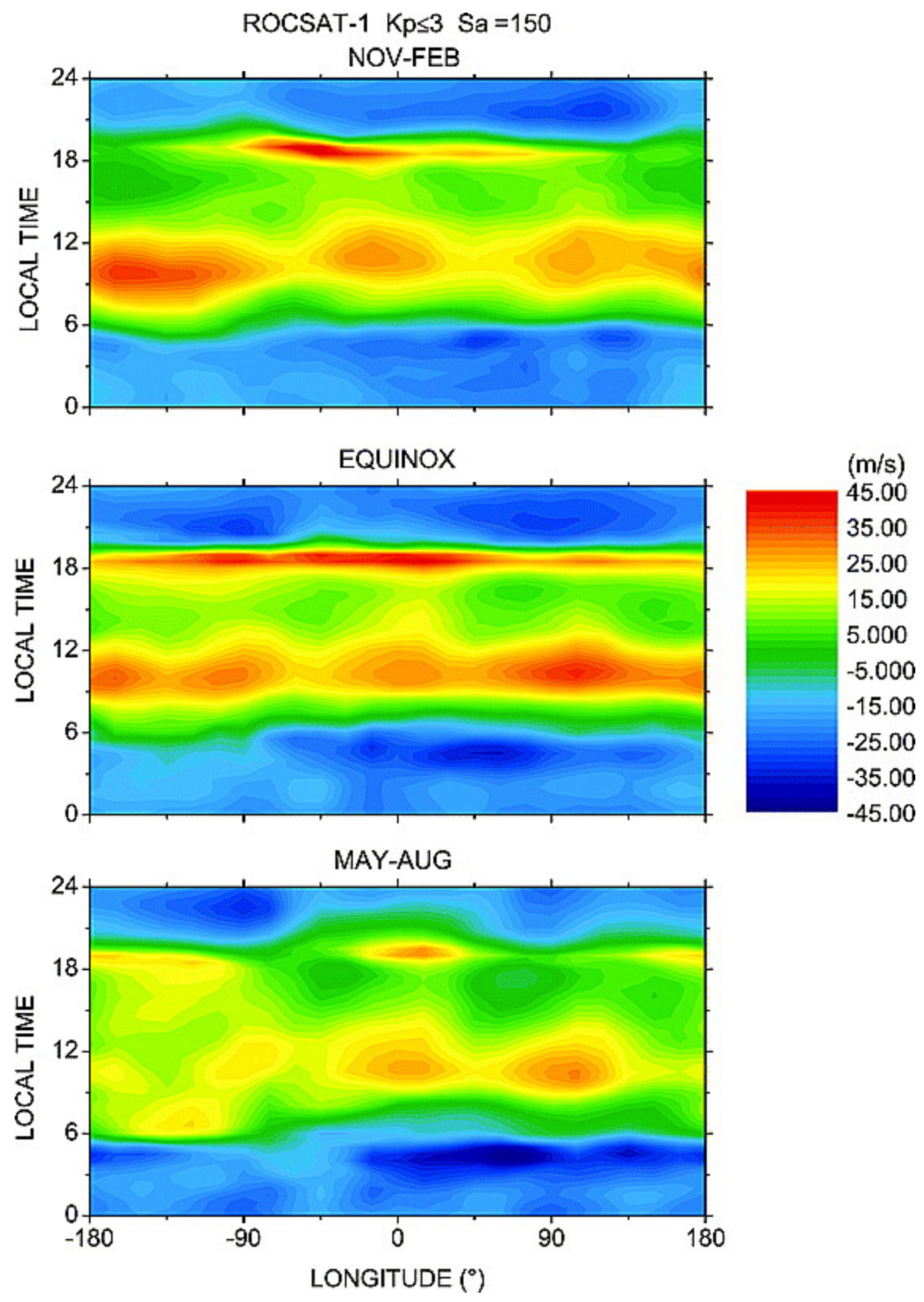

Figure 2-7. Local time, season and longitude-dependent vertical plasma drifts (positive upward) as derived from ROCSAT-1 satellite measurements [from Fejer et al., 2008]. 

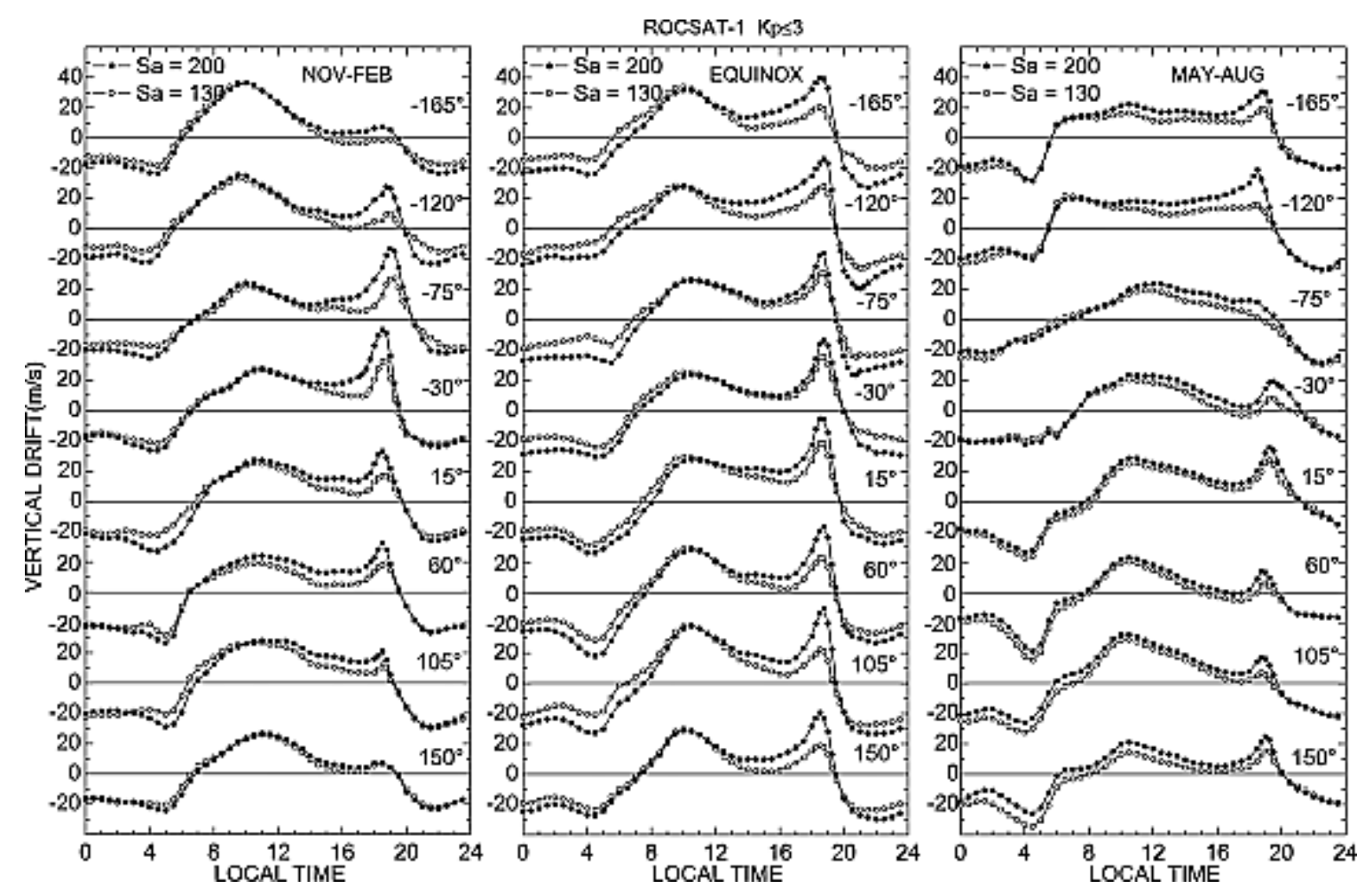

Figure 2-8. Local time, longitude and solar flux variation of the quiet-time vertical plasma drift for eight longitude sectors and three seasons as derived from ROCSAT-1 data [from Fejer et al., 2008].

2010].

Numerous studies suggest the wavenumber-4 structure appears to be predominantly due to the modulation of the zonal electric field by the eastward propagating diurnal tide with zonal wavenumber s=-3, often called DE3 [Hagan et al., 2007]. This vertically propagating tide is thought to be generated by the longitudedependent latent heating resulting from deep tropical tropospheric convection [e.g., Hagan and Forbes, 2002; Oberheide et al., 2006]. Numerical simulation using the TIMEGCM indicate the wavenumber-4 evening structure in the equatorial ionization anomaly observed by the IMAGE satellite can be explained by the electrodynamic effects of the 


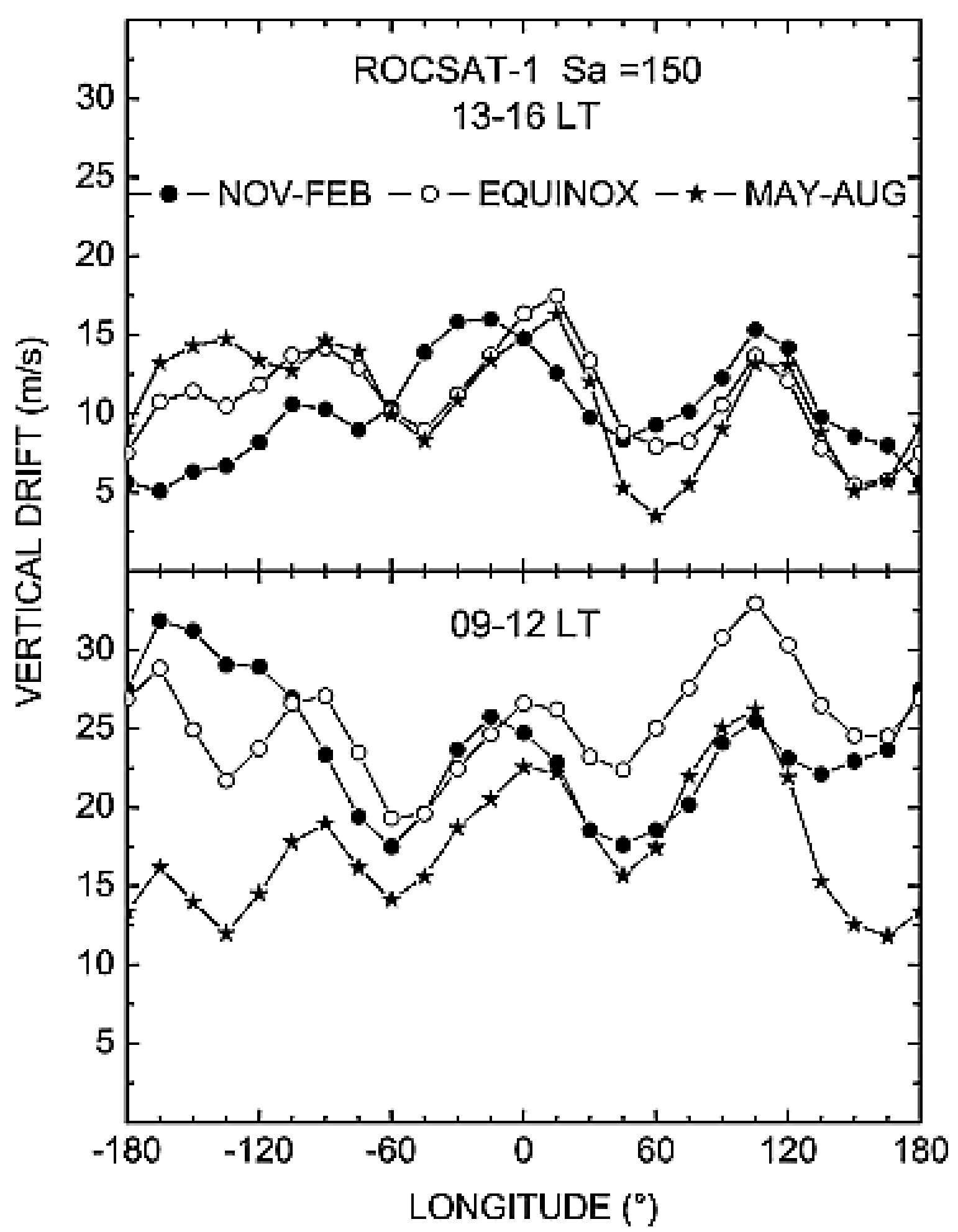

Figure 2-9. Longitude dependence of the vertical plasma drift for three seasons and two local time sectors as derived from ROCSAT-1 data [from Fejer et al., 2008]. 
DE3 tide [Hagan et al., 2007].

Figures 2-7 and 2-8 showed the prereversal enhancement of the vertical drifts is strongly longitude, solar flux, and season dependent. This is shown in greater detail for moderately large flux conditions in Figure 2-10. The equinoctial peaks vary between 25 $\mathrm{m} / \mathrm{s}$ over Asia to $45 \mathrm{~m} / \mathrm{s}$ over the Americas. The December solstice peak values are smallest, approximately $5 \mathrm{~m} / \mathrm{s}$, near $180^{\circ} \mathrm{E}$ and largest over the Americas, with values between $30-50 \mathrm{~m} / \mathrm{s}$. The June solstice peak values vary between about $5 \mathrm{~m} / \mathrm{s}$ and $25 \mathrm{~m} / \mathrm{s}$

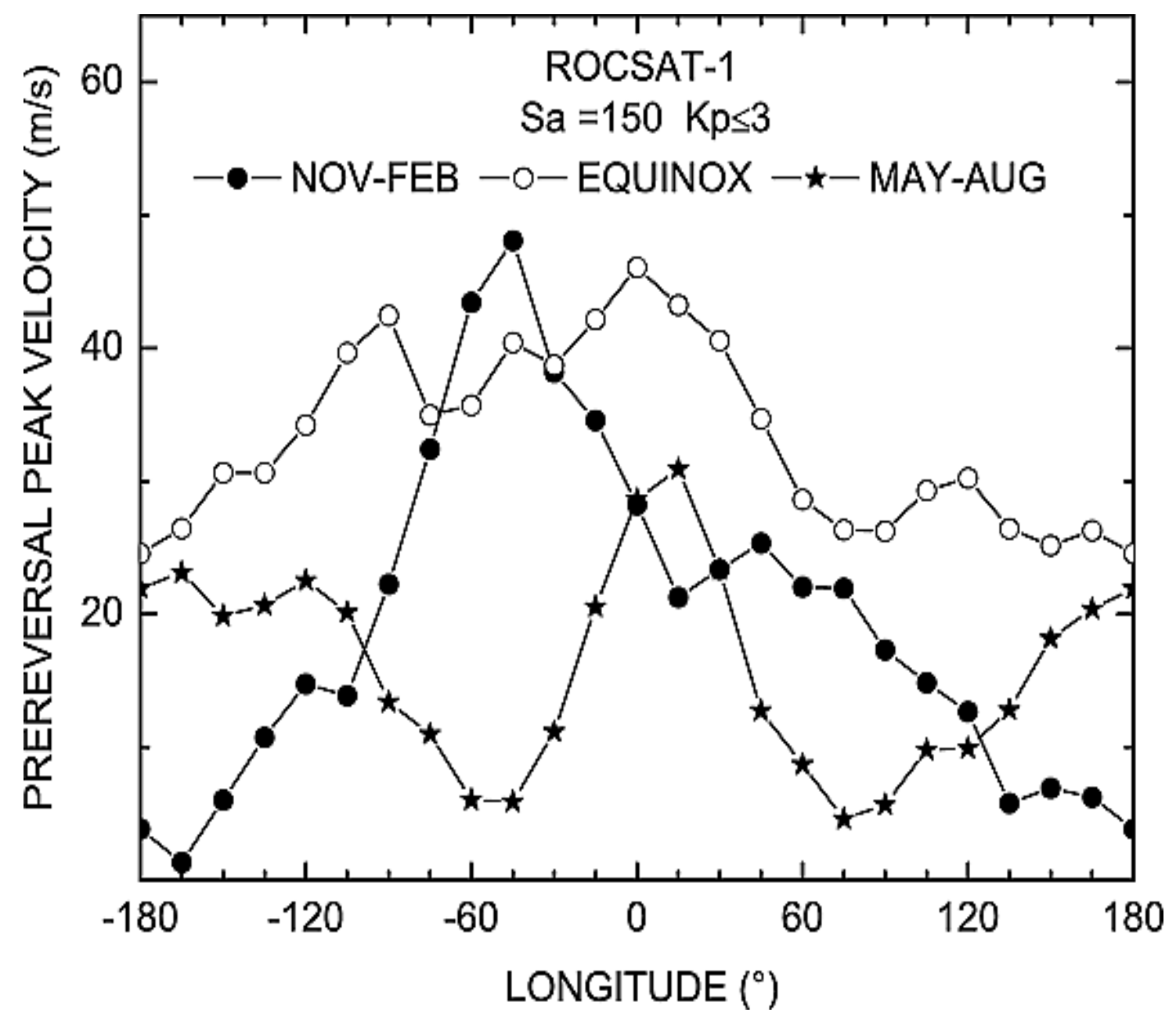

Figure 2-10. Longitude dependence of the prereversal enhancement for three seasons as derived from ROCSAT-1 data [from Fejer et al., 2008]. 
with the maxima located around $15^{\circ} \mathrm{E}$ and from $180^{\circ} \mathrm{E}$ to $120^{\circ} \mathrm{W}$. The December and June solstice peak values are largely anti-correlated, suggesting their control by the magnetic field, line-integrated conductivities.

While the local time, seasonal, and solar flux dependence of the zonal drifts for a given region has been studied extensively [e.g., Coley and Heelis, 1989; Fejer et al., 1991, 2005; Maynard et al., 1995], the longitudinal dependence of zonal drifts has not been studied in detail until recently. Jensen and Fejer [2007] presented the initial study of the longitudinal dependence of the zonal drifts measured between August 1981 and February 1983 onboard the Dynamics Explorer-2 (DE-2), but only in large local time bins and selected seasons, as local time and season were locked together in these measurements. Huang et al. [2010] presented the ion density and drift velocities from the Defense Meteorological Satellites Program (DMSP) F13 and F17 satellites as a function of season and longitude for two local times. They found wavenumber 4, 3, and 2 structures during equinox, June solstice, and December solstice, respectively. Huang et al. [2012] used data from several instruments onboard the Communication/Navigation Outage Forecasting System (C/NOFS) and Gravity Recovery and Climate Experiment (GRACE) satellites to show broad plasma depletions generally occur in specific longitudes and their location appears to be related to the longitudinal dependence of the zonal drifts.

Recently Fejer et al. [2013] presented the first detailed longitudinal, seasonal, and local time-dependent climatology of equatorial zonal drifts using three years (May 2008February 2011) of Vector Electric Field Investigation (VEFI) data from onboard the 
C/NOFS satellite. The C/NOFS satellite is in a low-Earth orbit $\left(13^{\circ}\right)$, covering geographic latitudes $-12^{\circ}$ to $12^{\circ}$ and having a perigee of $400 \mathrm{~km}$ and an apogee of 850 $\mathrm{km}$. These satellite data agree well with the incoherent scatter radar data, as shown in Figure 2-11. The radar and satellite data presented are the average quiet time F-region zonal plasma drifts and correspond to altitudes of about $400 \mathrm{~km}$ for the radar and $650 \mathrm{~km}$ for the satellite. The standard deviations of these data are about $15 \mathrm{~m} / \mathrm{s}$ during the day and $40 \mathrm{~m} / \mathrm{s}$ at night for the radar measurements and $20 \mathrm{~m} / \mathrm{s}$ during the day and $45 \mathrm{~m} / \mathrm{s}$ at night for the satellite data. These large standard deviations are due, in part, to the large day-today variability of the drifts, as evidenced by the very small $2-3 \mathrm{~m} / \mathrm{s}$ standard error of the mean for the satellite drifts for all local times. The drifts measured by the two instruments follow the same pattern as a function of local time for each season; however, the drifts measured by C/NOFS have smaller eastward drifts and larger westward drifts. This difference may be due to a difference in the altitudes of the measurements. The afternoon drift reversal time is the same, but the morning drift reversal time is generally earlier for the satellite data.

Figure 2-12 shows the local time- and longitude-dependent average quiet time equatorial zonal plasma drifts derived from C/NOFS VEFI data for three seasons, December solstice (November-February), equinox (March-April and SeptemberOctober), and June solstice (May-August). These drifts are westward during the day and eastward at night with large longitudinal variations. The equinocial data and solstice data show four and three clear bulges with strong wavenumber 4 and 3 patterns, respectively. The equinocial data also show a strong, short-lived westward peak just before sunrise for 


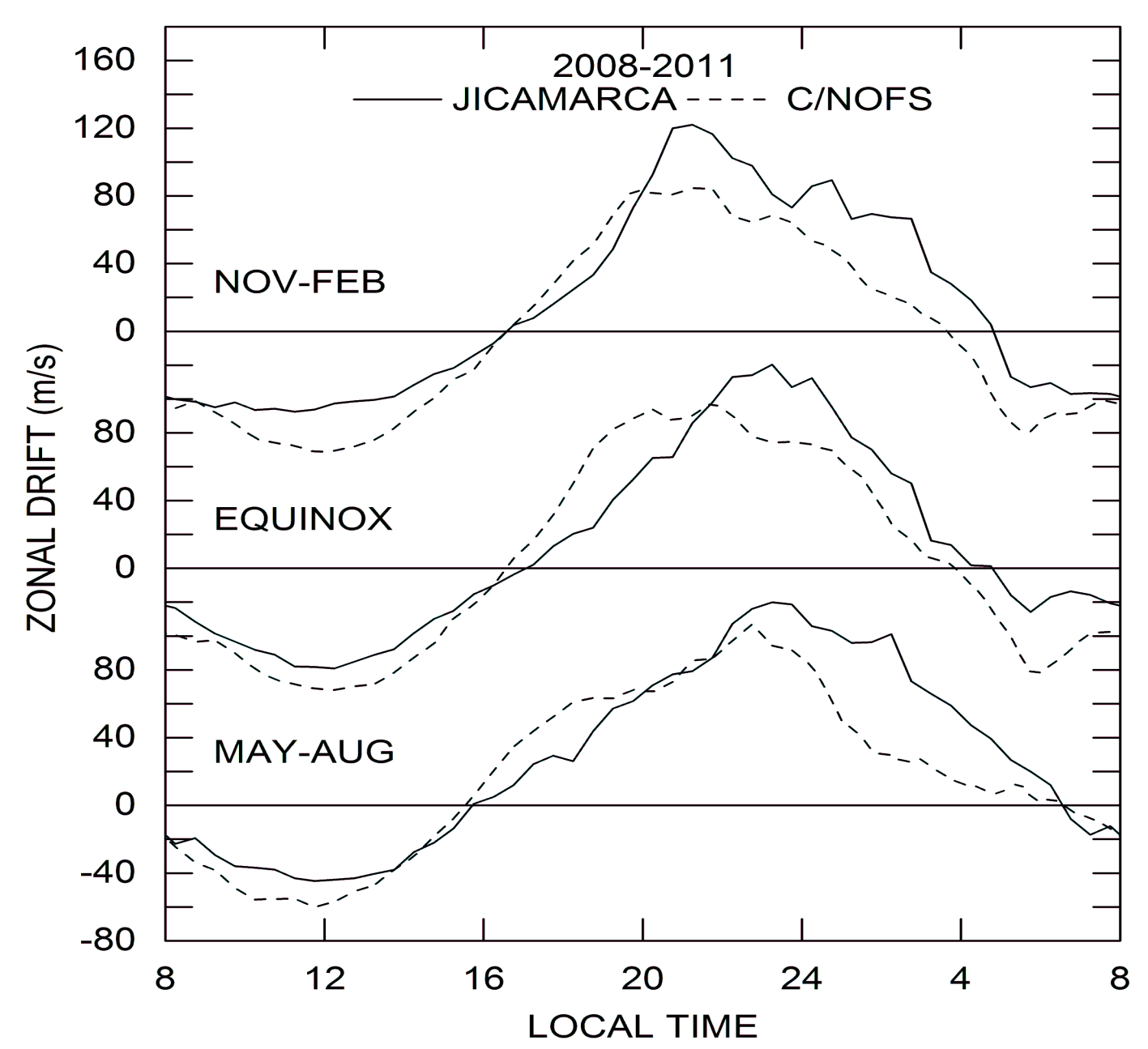

Figure 2-11. Average F-region quiet-time zonal (positive eastward) plasma drift as a function of local time and season from C/NOFS VEFI measurements over the Peruvian equatorial region and from the Jicamarca radar [from Fejer et al., 2013].

most longitudes.

Figure 2-13 shows the C/NOFS zonal drifts data in more detail for eight selected longitude sectors. The standard deviations are about $20 \mathrm{~m} / \mathrm{s}$ during the day and $40 \mathrm{~m} / \mathrm{s}$ at night for all longitudes. The corresponding standard error of the means are about 2 and 3 $\mathrm{m} / \mathrm{s}$, respectively. The early morning drifts are strongly westward for short amounts of 


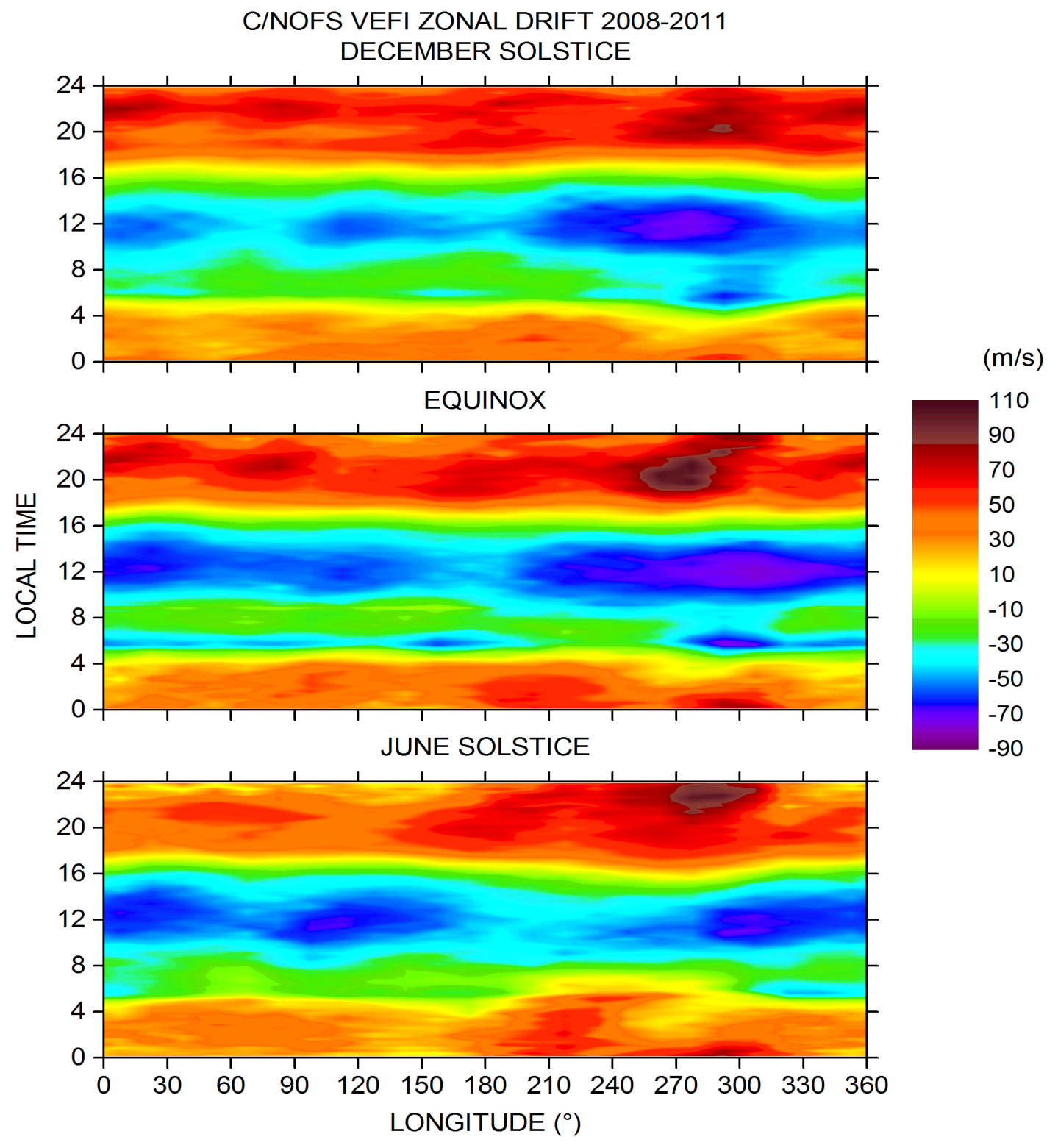

Figure 2-12. Local time, season, and longitude-dependent average zonal plasma drifts from VEFI measurements onboard the C/NOFS satellite [from Fejer et al., 2013]. 
time, especially during equinox where they can reach values of $60 \mathrm{~m} / \mathrm{s}$. The daytime drifts vary between $40-70 \mathrm{~m} / \mathrm{s}$ depending on longitude, with peak values occurring about $120^{\circ}$ and $300^{\circ}$. There is about an hour difference in the evening reversal time between the eastern and western hemisphere during the solstices (16.5 $\pm 0.5 \mathrm{LT})$, while the evening reversal time (17LT) is almost longitude independent during equinox. The nighttime eastward values are highest in the premidnight sector with peak values of about $110 \mathrm{~m} / \mathrm{s}$ in the $240^{\circ}-300^{\circ}$ sector. The post-midnight drifts remain eastward until about $5 \mathrm{LT}$ where
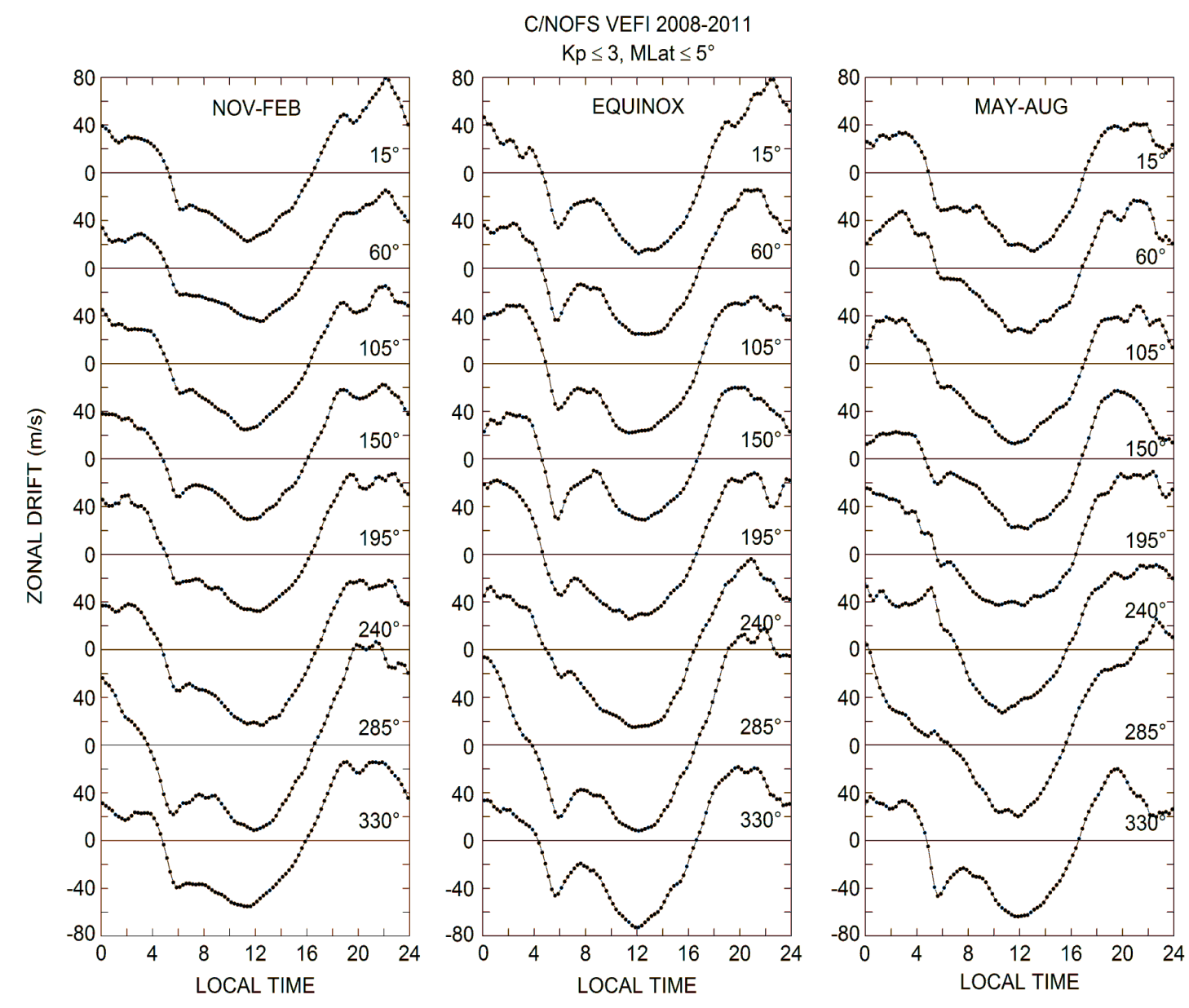

Figure 2-13. Local time and longitude variation of the average low-solar-flux quiet-time zonal plasma drift for eight longitude sectors and three seasons from VEFI measurements onboard the C/NOFS satellite [from Fejer et al., 2013]. 
they reverse to westward once more. The time of this reversal shows greatest seasonal variability at about $240^{\circ}$.

Figure 2-14 shows the longitude and seasonal variation of the zonal drifts for 1000- 1400 LT and 1400- 1800 LT. The midday drifts have magnitudes of 40- $70 \mathrm{~m} / \mathrm{s}$ with the largest values occurring near $120^{\circ}$ and $300^{\circ}$. The afternoon drifts have values between $-30 \mathrm{~m} / \mathrm{s}$ and $20 \mathrm{~m} / \mathrm{s}$ with June solstice having the largest value near $270^{\circ}$. The longitude dependence of the drifts is almost uniform for all the seasons in the eastern hemisphere. In the western hemisphere, however, the solstice drifts are anticorrelated. In the eastern hemisphere, the equinox drifts have nearly the same magnitude as the drifts from June solstice, whereas in the western hemisphere the equinox drifts follow the December solstice drifts in the $180^{\circ}-300^{\circ}$ sector and those of the June solstice drifts in the $300^{\circ}-360^{\circ}$ sector. Wavenumber-4 pattern is clearly seen in the afternoon drifts.

Figure 2-15 shows the longitude and seasonal variation of the zonal drifts for 1800- 2100 LT and 2100- 2400 LT. Near dusk, the drifts increase in magnitude from the eastern to the western hemisphere and have similar longitude structures for all seasons with a clear wavenumber-4 pattern. In the 2100- 2400 LT sector, the drifts peak around $280^{\circ}$ for all seasons. June solstice average drifts for $2100-2400$ LT increases from $30 \mathrm{~m} / \mathrm{s}$ in the eastern hemisphere to $90 \mathrm{~m} / \mathrm{s}$ in the western hemisphere. Due to the late peak times of June solstice near $280^{\circ}$, the drifts are largest for this season. Equinox drifts have a wavenumber-4 pattern that mostly controls the longitudinal dependence of the drifts during 2100- 2400 LT. The exception is the enhancement of one of the peaks of the wavenumber- 4 pattern to unusually high values near $280^{\circ}$. December solstice is nearly 


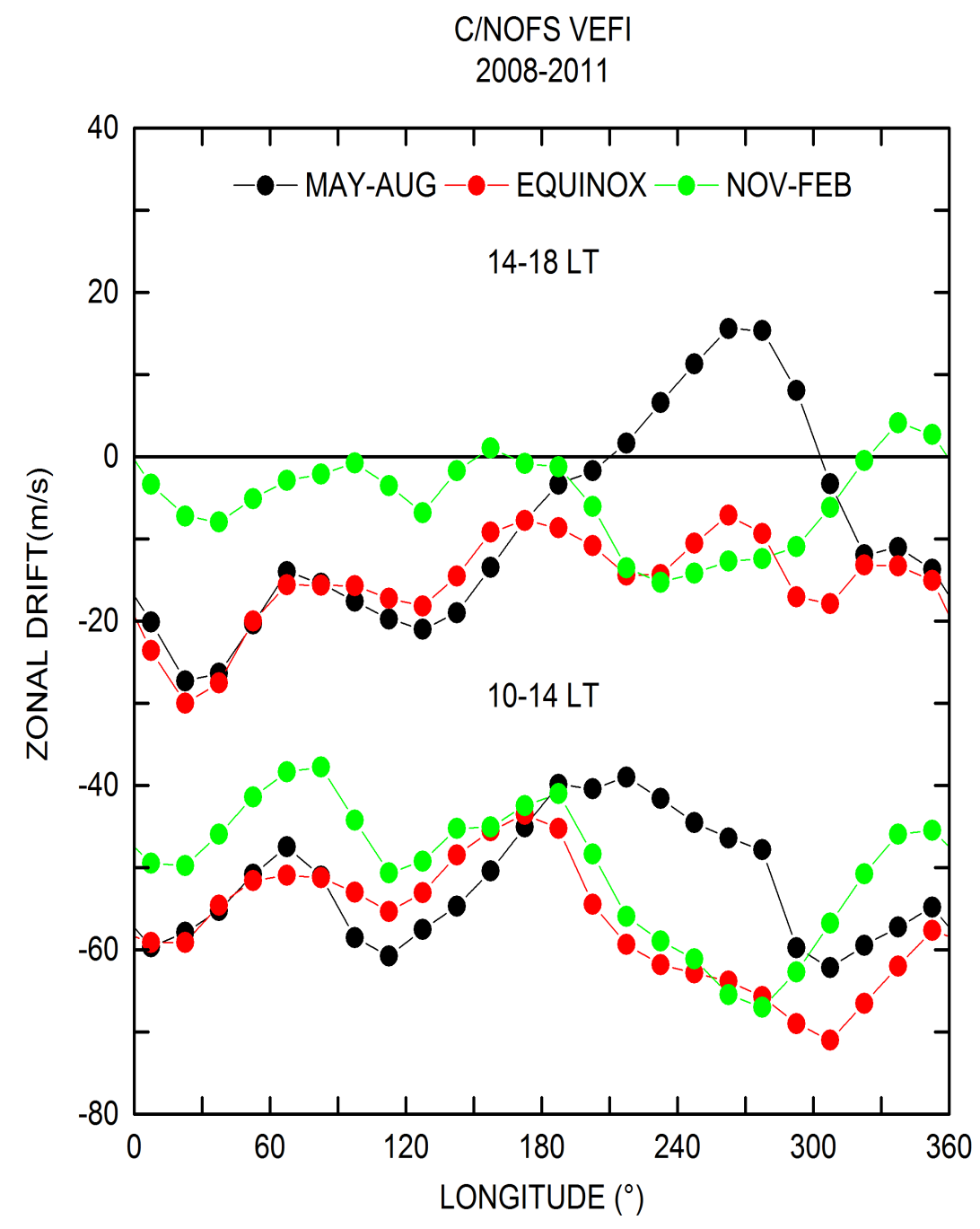

Figure 2-14. Longitude and seasonal dependence of the zonal plasma drift for two local time sectors as measured by VEFI onboard the C/NOFS satellite [from Fejer et al., 2013].

longitude independent; however, still having a peak around $280^{\circ}$ and traces of a wavenumber- 4 pattern is noticeable in the December solstice drifts. The post-midnight drifts exhibit only weak longitudinal dependence up to about 03 LT and have typical values of about $30 \mathrm{~m} / \mathrm{s}$ [Fejer et al., 2013]. 


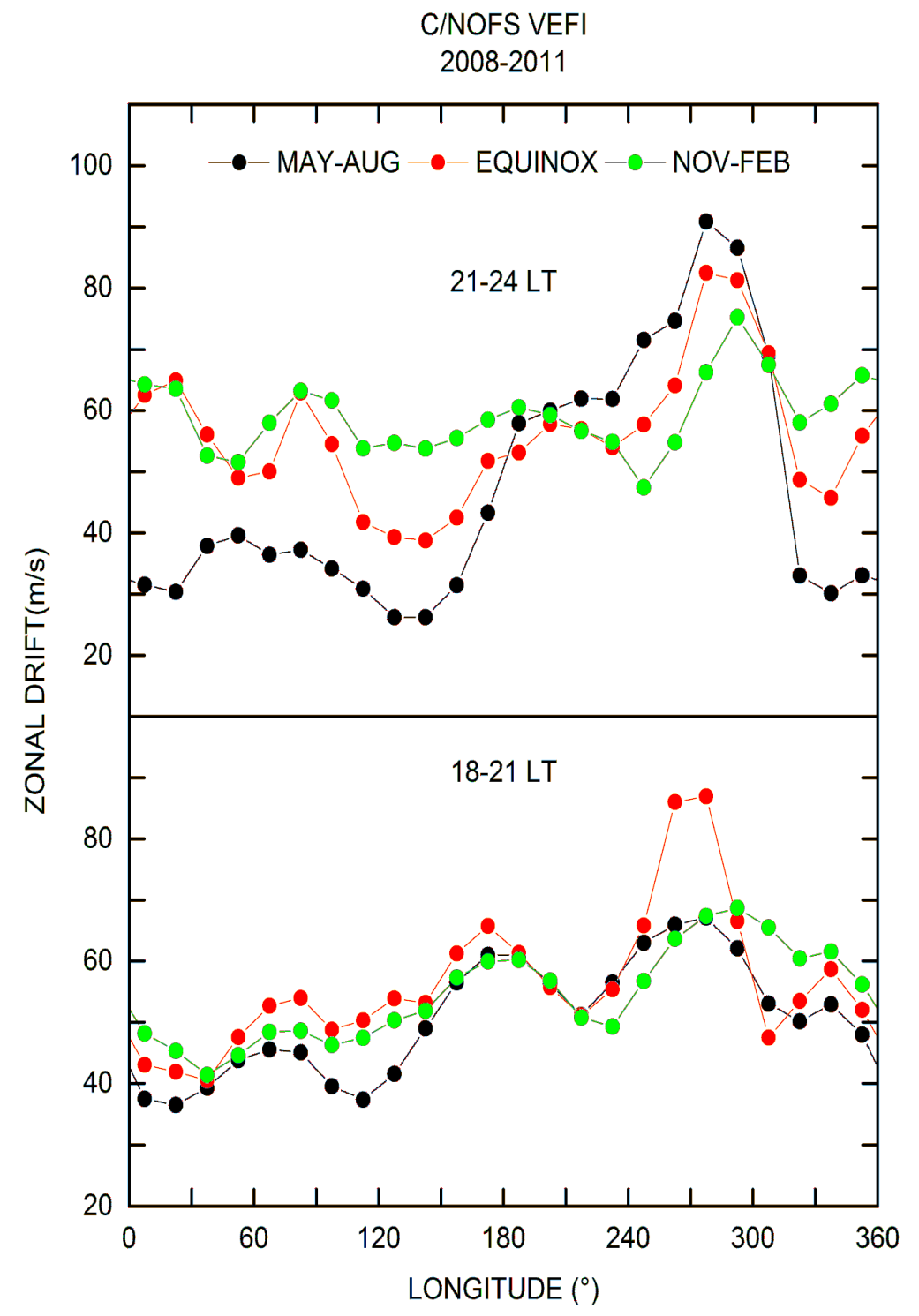

Figure 2-15. Longitude and seasonal dependence of the zonal plasma drift for two local time sectors, including prereversal enhancement, as measured by VEFI on board the C/NOFS satellite [from Fejer et al., 2013].

\subsection{Ionospheric Weather}

Ionospheric variability is larger during storm events than during solar quiet days. This is especially true during the super fountain effect and prompt penetration electric 
fields. In this section, we consider only quiet-time ionospheric drift variability. Information on storm-time variability are available in Fejer [2011] and references therein.

The quiet-time variability is largely due to lower atmospheric processes. Shortterm (few hours) variability in the electrodynamics is believed to be related with gravity wave effects. Longer period variability (up to about a month) is probably related to the effects of complex changes in tidal forcing of global winds, and effects of planetary waves and irregular winds in the dynamo region. Lunar semidiurnal tidal modulations of equatorial vertical drifts over Jicamarca have amplitudes of up to $6 \mathrm{~m} / \mathrm{s}$ in the Northern winter [Stening and Fejer, 2001]. Large oscillations with two-day and longer periods (5-, 10-, 16-day) were identified in the intensity of the equatorial electrojet and ionization anomaly. These oscillations occur simultaneously with planetary wave activity. There is strong evidence these ionospheric electrodynamic perturbations result from the nonlinear interaction of planetary waves and diurnal and semidiurnal tides [e.g., Parish et al., 1994]. Jicamarca F-region vertical drifts suggest largest variability occurs during dawnnoon sector and during March equinox solar minimum conditions [Fejer and Scherliess, 2001]. 


\section{CHAPTER 3}

\section{LUNAR TIDAL EFFECTS ON THE EQUATORIAL PLASMA DRIFTS}

\subsection{Introduction}

In this chapter, we present and discuss some recent results on the study of quiet time variability in electrodynamics of the low-latitude ionosphere due to lunar tidal effects. Tidal effects are known to create variations in the oceans, atmospheric pressure, geomagnetic fields, ionospheric currents and electric fields, and electron densities [e.g., Chapman and Bartels, 1940; Matsushita, 1967, and references therein; Chapman and Lindzen, 1970; Schwiderksi, 1979]. The lunar tide has attracted considerable attention despite the relatively small size because, in principal, the forcing mechanism is exactly known, which creates the ideal situation for comparison between models and data. Further the lunar tide is of interest because, depending on the sampling perspective, it can be responsible for considerable day-to-day variability; quantification of the lunar tide within the ionosphere can thus lead to improved prediction of ionospheric parameters. In this chapter, we focus on lunar tidal effects on the equatorial vertical plasma drifts, their enhancements during Sudden Stratospheric Warming (SSW) events, and effects on the occurrence of equatorial spread $\mathrm{F}$. This chapter includes significantly more detailed studies of the topics covered in Fejer and Tracy [2013].

Periodic oscillations that occur at lunar periods are referred to as the lunar daily variation or, more commonly, the lunar tide. These tides are driven by the centripetal force and gradients in the gravitational field and can be greatly amplified due to local topology. In the ionosphere, lunar tidal currents arise due to modulation of the dynamo 
generated electric fields [Matsushita, 1967]. Vial and Forbes [1994] showed the tidal wind field associated with the semidiurnal lunar tide propagates vertically and is capable of penetrating into the ionospheric E region. The tidal winds, in turn, modulate the solardriven wind fields and influence the dynamo-generated ionospheric currents and electric fields. This process generates the lunar current system, which is superimposed upon the larger solar quiet current system.

The general characteristics of the lunar tides in the lower atmosphere and in Earth's geomagnetic fields have been discussed in detail by Chapman and Bartels [1940] and Chapman and Lindzen [1970], respectively, and the following information is summarized from these sources. The moon revolves around the Earth in 27 days, 7 hours, and 43 minutes, (the sidereal period), so the mean lunar day, or average interval between two successive passages of the moon across any terrestrial meridian, is 24 hrs, 50.47 minutes. The moon revolves around the Earth relative to the line through the center of the sun in 29.5306 days. This period is called a lunation, lunar cycle, or the synodic or lunar month. Lunar age, $v$, measures what part of the lunar month the Earth, moon, sun system is in. Lunar age is calculated based on the angle, $v$, between the meridian half-planes through the sun and moon (positive values are associated with the moon being east of the sun), see Figure 3-1. New moon corresponds to $v=0$, and the values of $v$ at one-eighth phase, first quarter (half moon), full moon, and so on, are $\pi / 4, \pi / 2, \pi$, and so on. The local apparent lunar (solar) time is measured from the east longitude $\tau(\mathrm{t})$ of any station $\mathrm{P}$ relative to the meridian opposite to that containing the moon (sun). Figure 3-1 shows how, if angular measure is used for these three parameters, the phase law 


\section{LOCAL TIME MEASUREMENTS ON EARTH}

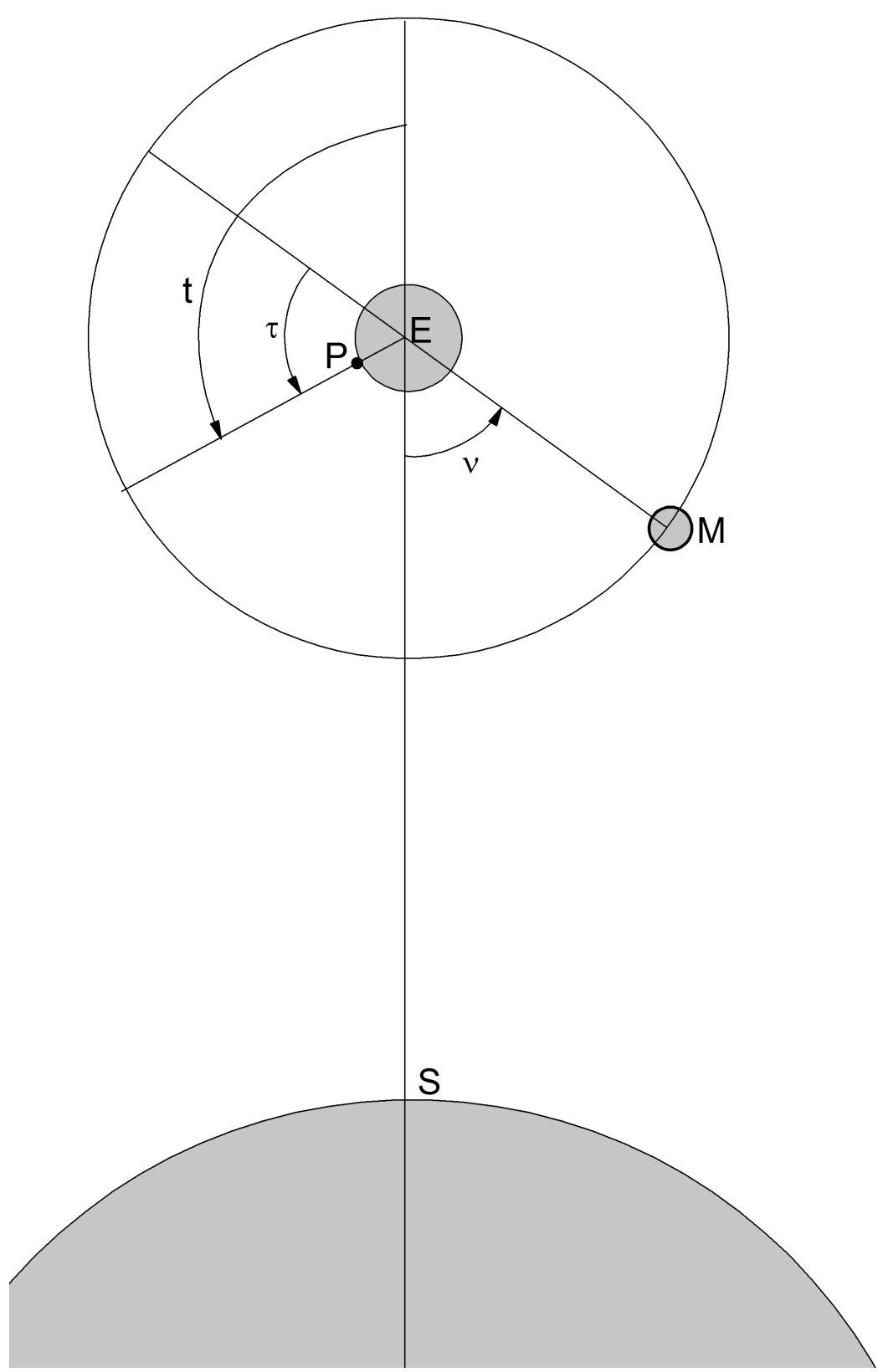

Figure 3-1. Local solar time, t, local lunar time, $\tau$, lunar age, $v$, and the relationship between them is shown for a point, $\mathrm{P}$, on the Earth, E. The sun is represented by the shaded semicircle at the bottom of the figure labeled $\mathrm{S}$ and the moon is represented by the small shaded circle labeled $\mathrm{M}$. 


$$
\mathrm{t}=\tau+v
$$

is clearly valid.

A lunar semidiurnal tide is one that repeats twice with respect to a lunar day in the form

$$
\operatorname{asin}(2 \tau)+b \cos (2 \tau)
$$

where $\mathrm{a}$ and $\mathrm{b}$ are amplitudes. A lunar diurnal tide is one that repeats once in a lunar day in the form

$$
\operatorname{csin}(\tau)+\mathrm{d} \cos (\tau)
$$

Using the phase law found above, $\mathrm{t}=\tau+v$, these can be rewritten as functions of $\mathrm{t}$ and $v$ yielding,

$$
\begin{gathered}
\operatorname{asin}[2(t-v)]+b \cos [2(t-v)], \text { and } \\
\operatorname{csin}(t-v)+d \cos (t-v) .
\end{gathered}
$$

Thus a lunar semidiurnal (diurnal) tide repeats twice (once) in solar local time for any given lunar age and similarly the semidiurnal (diurnal) lunar tide repeats twice (once) in lunar age for any given local time.

The intensity of the plasma drifts is dependent upon not only the driving winds, but also on the electrical conductivity of the ionosphere. The ionospheric conductivity is basically, a function of the the electron density, and thus largely depends on solar local time. A daily variation of the lunar tidal effects on the vertical plasma drifts in a solar time frame is called the luni-solar tide. Equations 4 and 5, when modified to include solar time-dependent amplitudes, represent the luni-solar tidal effects as

$$
a(t) \sin [2(t-v)]+b(t) \cos [2(t-v)] \text {, and }
$$




$$
c(t) \sin (t-v)+d(t) \cos (t-v)
$$

Simplifying these yields

$$
\begin{gathered}
a^{\prime}(t) \sin (2 v)+b^{\prime}(t) \cos (2 v), \text { and } \\
c^{\prime}(t) \sin (v)+d^{\prime}(t) \cos (v) .
\end{gathered}
$$

A harmonic analysis of data using equations 8 and 9 would yield the luni-solar tidal effects; however, these could also be termed as lunar semimonthly and lunar monthly variations due to the periodic variations with respect to a lunar month. This is similar to the procedure followed by Yamazaki et al. [2012a].

Until recently studies of lunar tidal effects have focused primarily on the semidiurnal component in magnetic variations due to ionospheric currents and in ionosonde observations. The lunar tidal modulation of the intensity of the equatorial electrojet has been known for several decades [e.g., Bartels and Johnson, 1940; Rastogi and Trivedi, 1970; Rastogi, 1974]. The initial study on lunar tidal effects on equatorial electrojet horizontal plasma drifts was by Tarpley and Balsley [1972] using Jicamarca radar measurements. The electrojet horizontal drifts are proportional to the F-region vertical plasma drifts and zonal electric field [e.g., Kelley, 2009]. The lunar semidiurnal tidal effects on the vertical drifts over Jicamarca were studied by Stening and Fejer [2001]. They found the effects were season dependent being strongest in December solstice and the effects were independent of solar flux. Lunar tidal modulations in the equatorial ionosphere were also studied using ionospheric maps of global positioning system (GPS) total electron content (TEC) [Pedatella and Forbes, 2010], low-latitude ionospheric sensor network data [Eccles et al., 2011], and CHAMP [Lühr et al., 2012] 
satellite measurements. Pedatella et al. [2012a] examined, in detail, the semidiurnal lunar tide climatology in surface pressure, and zonal and meridional winds in the mesosphere and thermosphere using the Whole Atmosphere Community Climate Model (WACCM).

\subsection{Data and Methodology}

As mentioned in Chapter 2, the Jicamarca incoherent scatter radar measures Fregion plasma drifts typically between about 200 and $800 \mathrm{~km}$ [e.g., Woodman, 1970]. However, most past studies have used drifts averaged over about $250-600 \mathrm{~km}$, where they do not change much with altitude. In this case, the accuracy of the vertical drifts is about 1-2 $\mathrm{m} / \mathrm{s}$ for an integration time of $5 \mathrm{~min}$. Since 2001, daytime (between about 0800 and 1600 LT) plasma drifts have been derived from Doppler observations of coherent echoes at altitudes of about $150 \mathrm{~km}$ using the low-power Jicamarca Unattended Long-term Ionosphere and Atmosphere (JULIA) radar system [e.g., Chau and Woodman, 2004]. Over Peru, an ionospheric upward (eastward) plasma drift velocity of $40 \mathrm{~m} / \mathrm{s}$ corresponds to an eastward (downward) electric field of about $1 \mathrm{mV} / \mathrm{m}$.

We used 1660 days from 2001 - 2013 of JULIA and 862 days from 1968 - 2010 of ISR vertical drift data from Jicamarca Radio Observatory $\left(11.95^{\circ} \mathrm{S}, 76.8^{\circ} \mathrm{W}\right)$. As mentioned earlier, the JULIA measurements are restricted to daytime. In our analysis, we restricted our data to quiet times ( $\mathrm{Kp} \leq 3$ and considered data during SSWs separately). The distribution of our data over the lunar cycle is shown in Figure 3-2. ISR data displays a strong bias towards the new moon, which handicaps our study of the luni-solar monthly tidal effects (period of 29.5306 solar days). The JULIA data does not display this limitation and allowed a more detailed study of these effects. 
Lunar tidal effects were derived by first placing the drift data in 5- or 30-minute local time and day after the new moon bins. We then averaged the data in each bin and found the mean perturbation drift with respect to the lunar month averaged value. Fejer and Tracy [2013] followed the same procedure up to this point; however, they then used a Fast Fourier Transform to find the amplitudes and phases of the lunar tidal effects. In contrast, we applied the expectation maximization (EM) algorithm [Dempster et al., 1977; Wu, 1983; Moon and Stirling, 2000] to these perturbations in each local time bin to find the maximum likelihood amplitudes and phases. The EM algorithm provides estimates of the amplitudes and phases for sections of the data (local time and day after new moon bins) that are empty. This was especially beneficial for the ISR data set as we were able to study the luni-solar monthly tidal effects despite the bias in the data. The EM algorithm consists of two primary steps: an expectation step, followed by a maximization step. The expectation is obtained with respect to the unknown underlying variables, using the current estimate of the parameters and conditioned upon the observations. The maximization step then provides a new estimate of the parameters. These two steps are iterated until convergence, which is guaranteed to a local maximum [e.g., $W u, 1983]$. In our study the model to maximize was of the form

$$
\mathrm{A} \sin (2 \pi \mathrm{x} / \mathrm{t})+\mathrm{B} \cos (2 \pi \mathrm{x} / \mathrm{t})
$$

where $\mathrm{A}$ and $\mathrm{B}$ are the parameters to maximize, $\mathrm{x}$ is the days after the new moon, and $\mathrm{t}$ is the period. The expectation step then finds the expected value of the missing data (local time and day after the new moon bins without data) and this process is repeated until convergence. As the missing values were assumed to be random and to have a Gaussian 


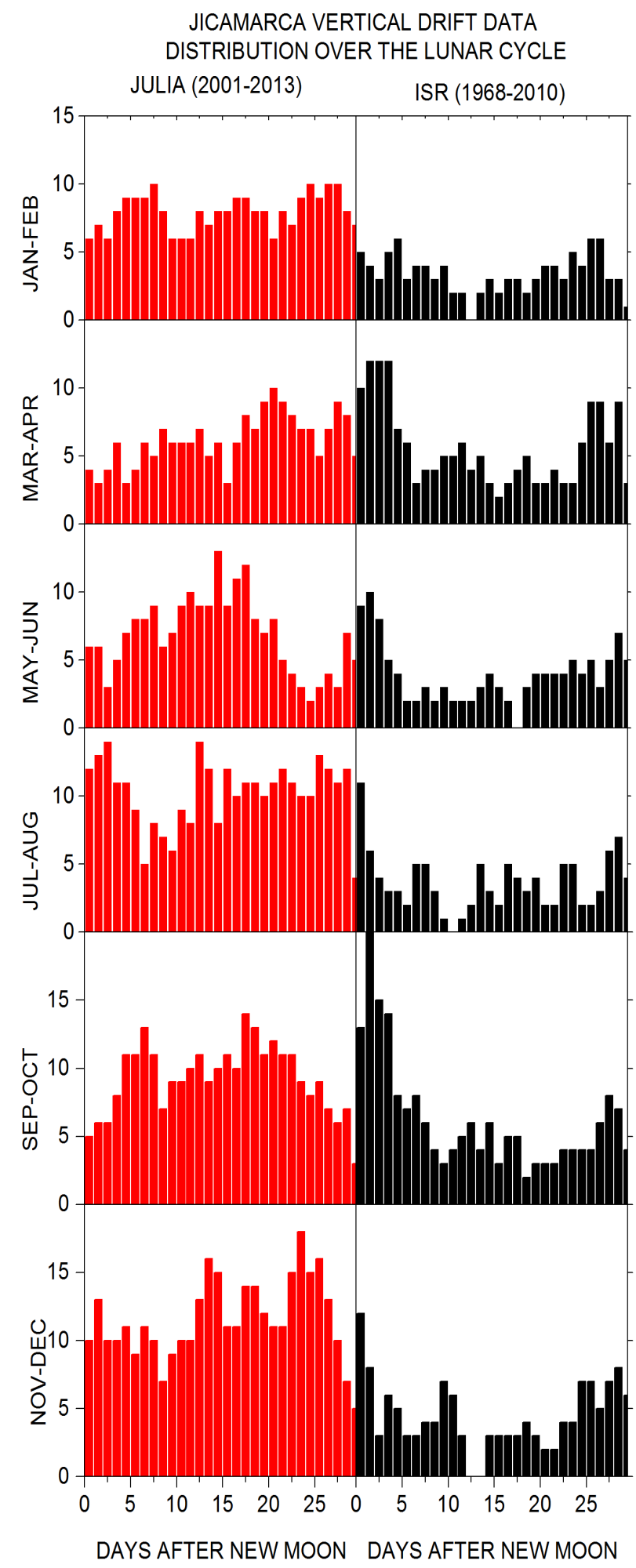

Figure 3-2. Days of data during each day of the lunar cycle from the ISR and JULIA radar systems at Jicamarca, Peru. 
distribution in our application of the algorithm, this process is identical to a least squares analysis. These maximum likelihood estimates are then converted into an amplitude and phase of the form

$$
A \sin (2 \pi x / t)+B \cos (2 \pi x / t)=C \sin (2 \pi x / t+\varphi)
$$

The phase is finally converted into the day after new moon of maximum lunar amplification the lunar day of max by

$$
\mathrm{L}_{\mathrm{MAX}}=(\pi / 2-\varphi) \mathrm{t} / 2 \pi+\mathrm{nt}
$$

where $\mathrm{n}$ is any integer.

\subsection{Lunar Tidal Effects}

Figure 3-3 shows the average vertical drift perturbations as a function of local time and day after new moon for December solstice, which was obtained using all available Jicamarca ISR quiet time $(\mathrm{Kp} \leq 3)$ drifts from April 1968 to April 2010 when the average F10.7 solar flux index was about 120. This data base consists of 275 days of measurements. In this case, we first placed the residual drifts in 30-min local time and day after new moon bins and averaged the data in each bin. Our database is much larger during the day than at night when we have between zero and ten data per bin. Then, for each local time bin, we determined the mean perturbation drift and their variation relative to the lunar month averaged value. Finally, we performed three-point running averages on the resulting data. Figure 3-3 shows the lunar daytime semimonthly lunar tidal effects have 5-6 m/s amplitudes, which is similar to the value reported by Stening and Fejer [2001] for the semidiurnal lunar tidal effects. The nighttime lunar semimonthly effects also appear to be comparable to the daytime values, and thus larger than the $2-3 \mathrm{~m} / \mathrm{s}$ 


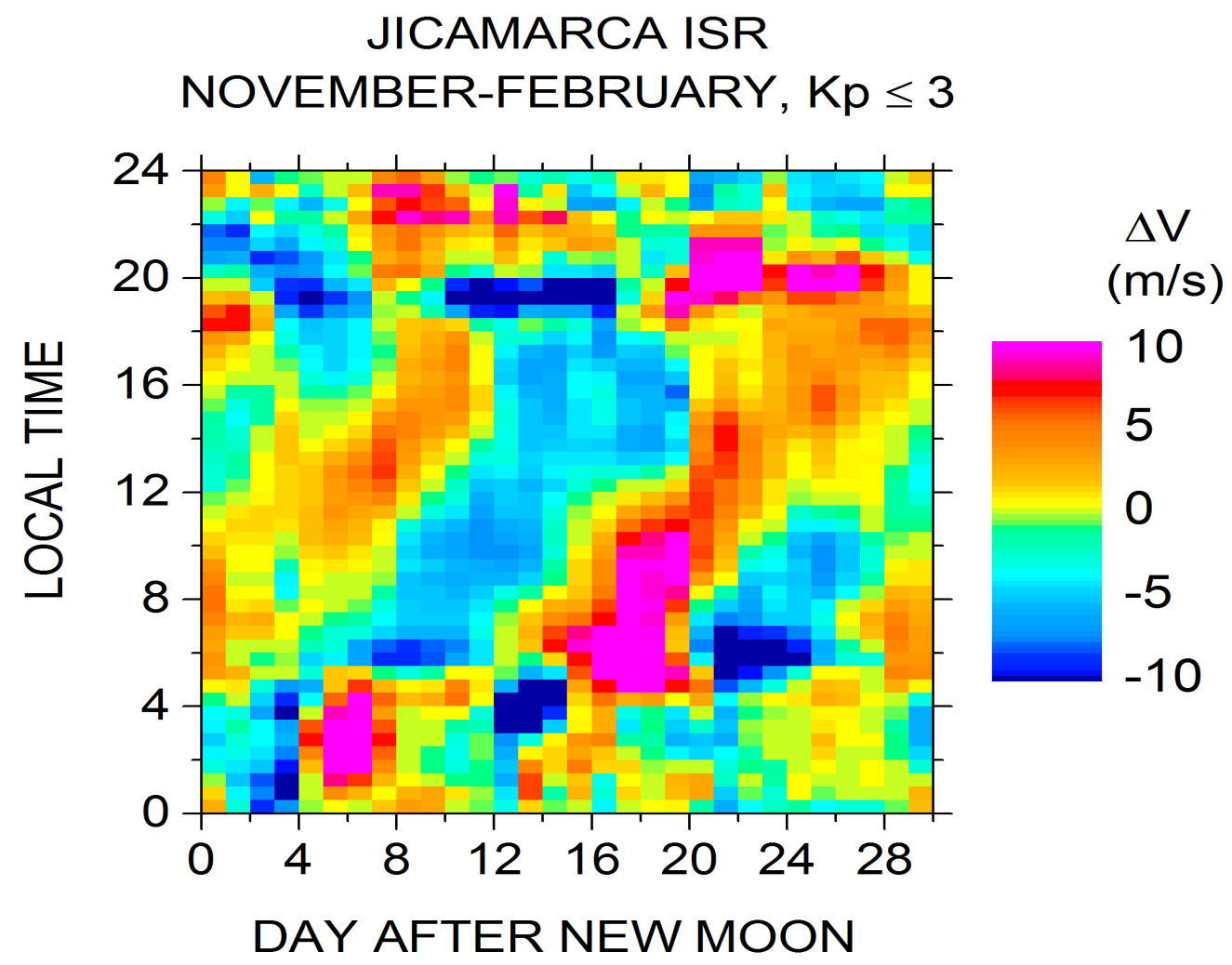

Figure 3-3. Equatorial vertical plasma drift perturbations (positive upward) as a function of local time and day after the new moon derived from Jicamarca incoherent scatter radar measurements during December solstice.

values derived by Stening and Fejer [2001]. Lunar monthly effects are also noticeable in Figure 3-3. It is important to note, however, the Jicamarca incoherent scatter radar database has significantly more measurements close to new moon than to full moon as a result of the standard scheduling of the so-called World Days with complementary optical observations, which certainly biased the results shown in Figure 3-3. From October through March the extraction of nighttime lunar tidal effects from Jicamarca incoherent scatter drift data is further complicated by the frequent occurrence of equatorial spread $\mathrm{F}$, which precludes these measurements. This task is most difficult during December solstice 
when, over Jicamarca, spread F is strongest and longest lasting [Fejer et al., 1999].

Daytime lunar tidal effects on the Jicamarca drifts can be studied more easily using the more extensive, and evenly distributed in lunar age, JULIA database (more than 1600 days from August 2001 to April 2013). Figure 3-4 shows the local time variation of daytime (between about 0800 and $1600 \mathrm{LT}$ ) vertical drift perturbations as a function of days after new moon for November-February in the top panel, and bihourly averaged perturbation drifts in the bottom panel. In this case, we have excluded data during SSW events, which will be discussed later. The average solar decimetric flux index during these measurements was about 100 . These results were derived using the same procedure described above, except we used 5-min data. In Figure 3-4, semimonthly lunar perturbation drifts are again the dominant feature having amplitudes of about $5 \mathrm{~m} / \mathrm{s}$. Lunar monthly modulations are also noticeable. During this season, the amplitude of the lunar monthly perturbation is of the order of $2 \mathrm{~m} / \mathrm{s}$. Since for December solstice moderate solar flux conditions, the daytime average upward drift velocities vary between about 15 $\mathrm{m} / \mathrm{s}$ in the morning to about $4 \mathrm{~m} / \mathrm{s}$ during midafternoon. Lunar tidal effects significantly modulate these drift velocities. We note in Figure 3-3 the largest drifts between 0800 and 1000 LT occur at about 16-18 days after the new moon whereas in Figure 3-4 (based on a much larger and better suited database) they appear near 0-3 days after the new moon. This difference results from the sampling bias in the incoherent scatter radar database.

\subsubsection{Luni-Solar Semimonthly Tidal Effects}

Figures 3-3 and 3-4 have showed the average perturbation drifts. Figures 3-5 and 36 , in contrast, show just the maximum likelihood lunar semimonthly drifts derived from 

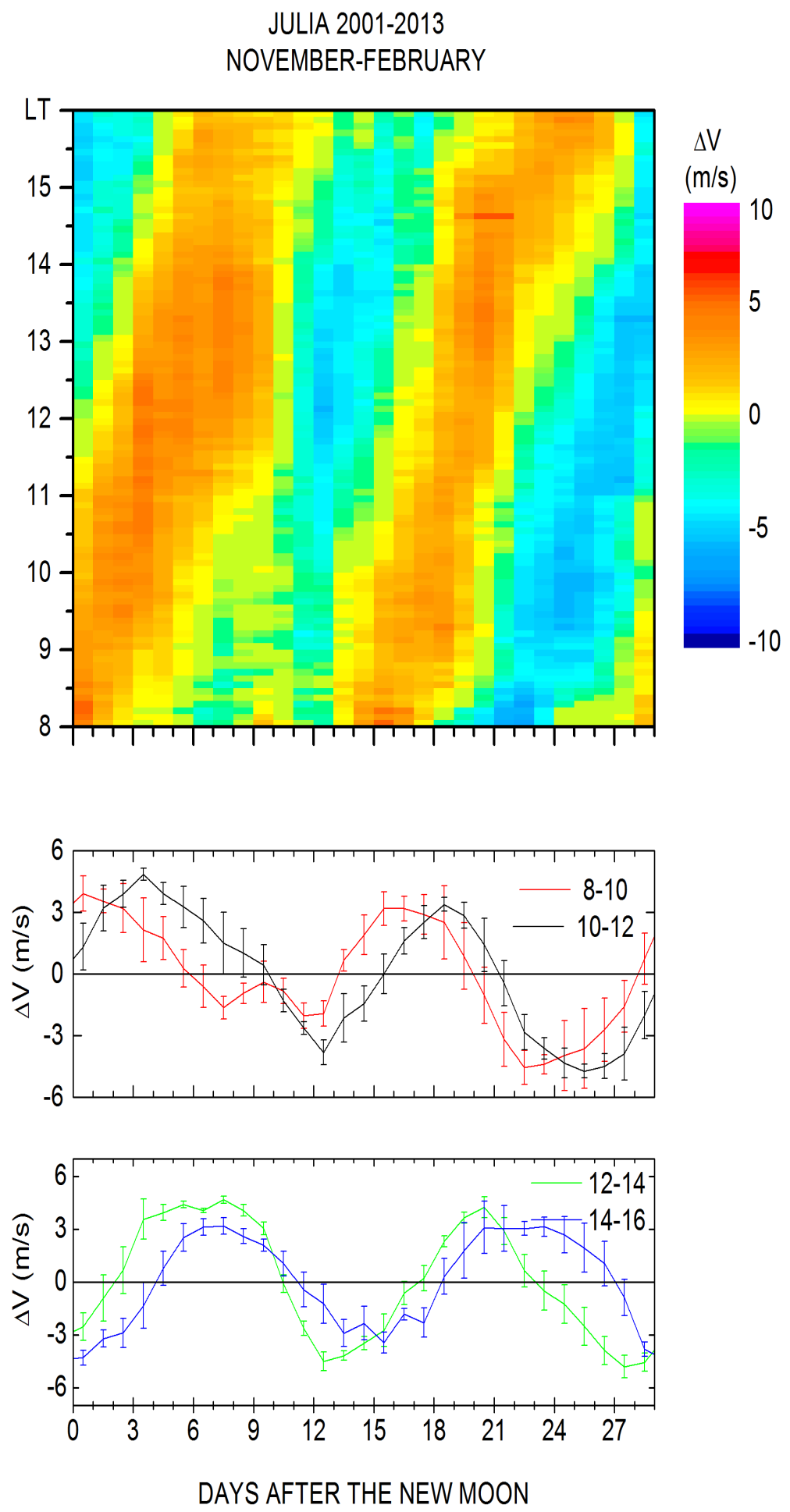

Figure 3-4. Daytime vertical plasma drift perturbations as function of local time and day after new moon for November-February derived from JULIA data (top panel) and bihourly average of the daytime perturbation vertical drifts (center and bottom panels). 
the JULIA data using the EM algorithm for 3 four-month seasons and 6 bimonthly periods, respectively. The amplitudes are strongest during December solstice and weakest during June solstice. The phase progression is also seasonal dependent having the steepest slopes during June solstice. Figure 3-7 shows the three-point smoothed 9-15 LT bimonthly average amplitudes and phases of the lunar semimonthly drifts. In these data, the standard deviations were less than $1 \mathrm{~m} / \mathrm{s}$ and 0.5 days, respectively. Figure 3-7 shows largest drifts near December solstice and smallest around June solstice, which is in good agreement with the Stening-Fejer data, except for the larger amplitudes of the JULIA drifts during the autumnal equinox, and also with the seasonal variation derived from Peruvian equatorial electrojet magnetic field data (Stening, 2011). WACCM simulations of the atmospheric lunar semidiurnal tide climatology in the mesosphere-lower atmosphere showed a primarily semiannual variation in the zonal and meridional winds with maxima near December and June solstice [Pedatella et al., 2012b].

The JULIA data indicate the daytime lunar semimonthly perturbation drifts do not have significant solar flux dependence, as reported previously by Stening and Fejer [2001]. Fejer and Tracy [2013] showed during January-February, when the lunar semimonthly effects are the strongest, the daytime drifts decrease by about $2 \mathrm{~m} / \mathrm{s}$ from early morning to late afternoon. Figure 3-8 similarly shows during July-August, when lunar tidal effects are weakest, the amplitudes of the bihourly averaged lunar semimonthly daytime drifts decrease by about $4 \mathrm{~m} / \mathrm{s}$ from early morning to late afternoon, although this result should be used with caution due to the large standard deviations in the morning data. Stening [1989] suggested the variation of the amplitude of 

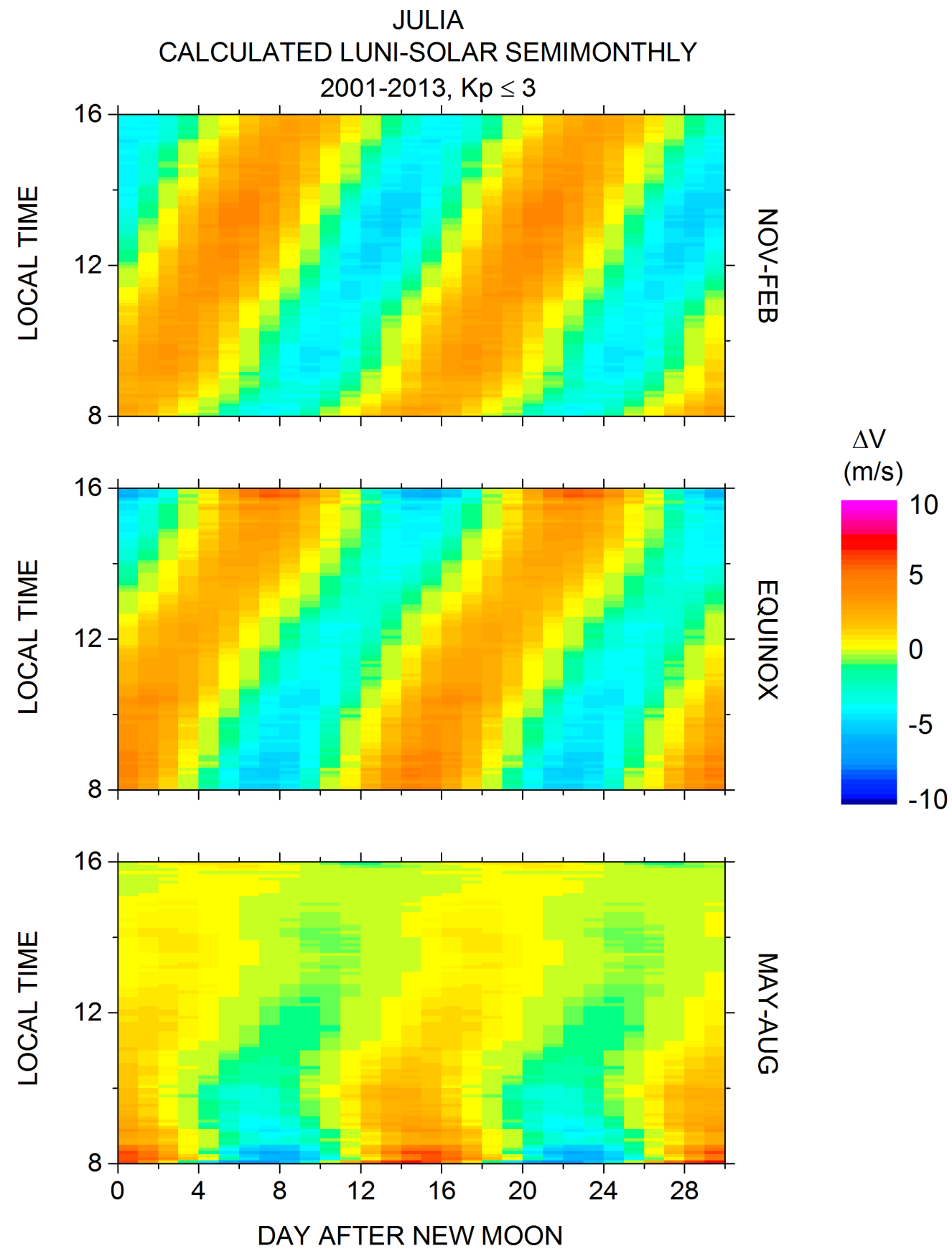

Figure 3-5. Daytime maximum likelihood luni-solar semimonthly lunar drifts as derived from JULIA data for three seasons. 
JULIA

CALCULATED LUNI-SOLAR SEMIMONTHLY

$2001-2013, \mathrm{Kp} \leq 3$
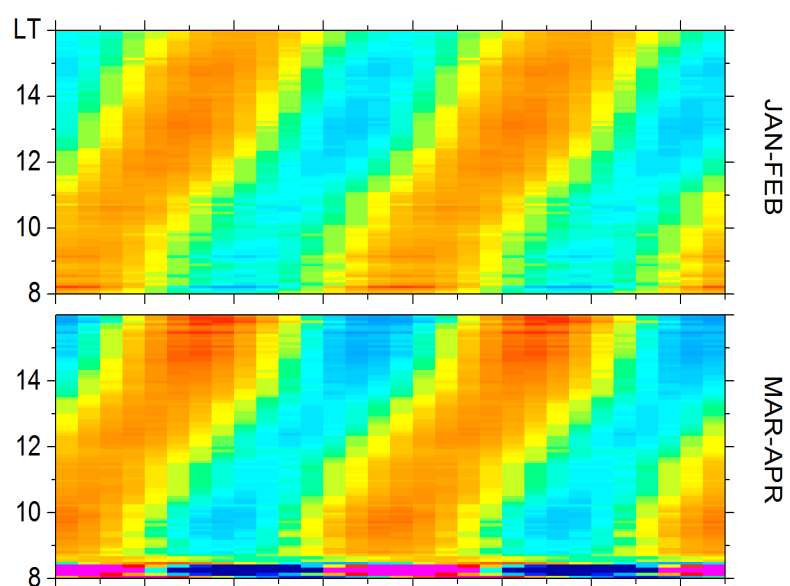

\section{3
$D$
0
$⿱ 亠 乂$
0
0}
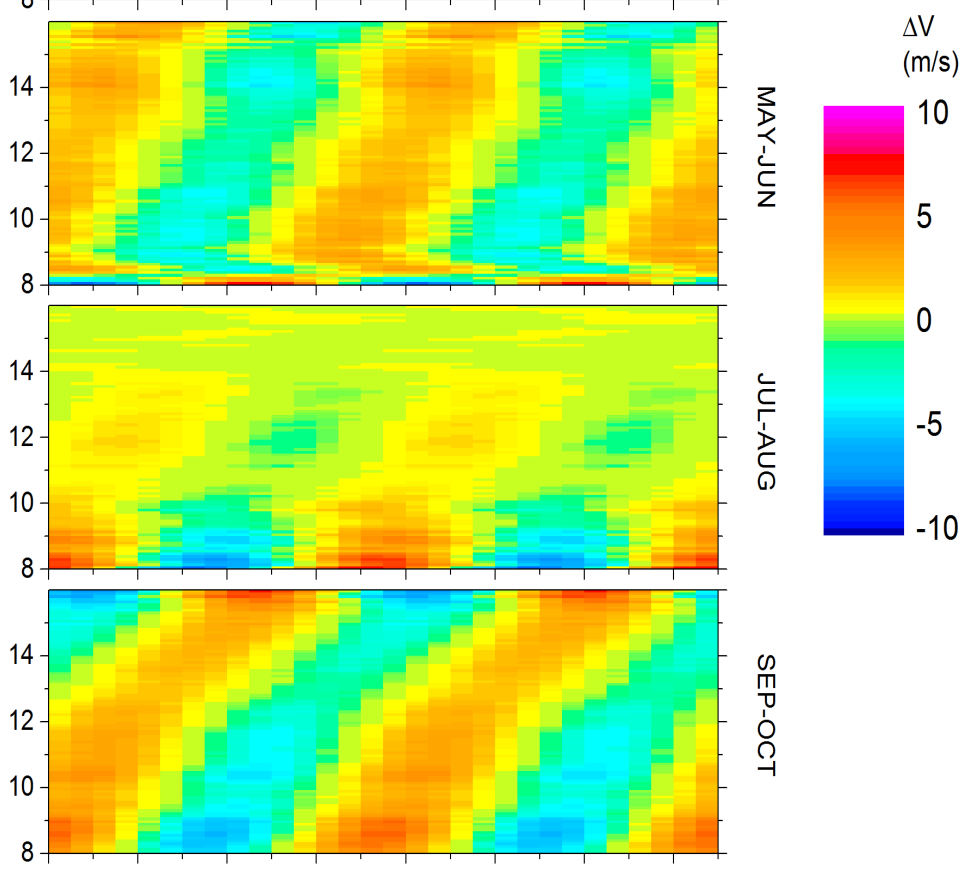

0
0
0
0
0
-1

8

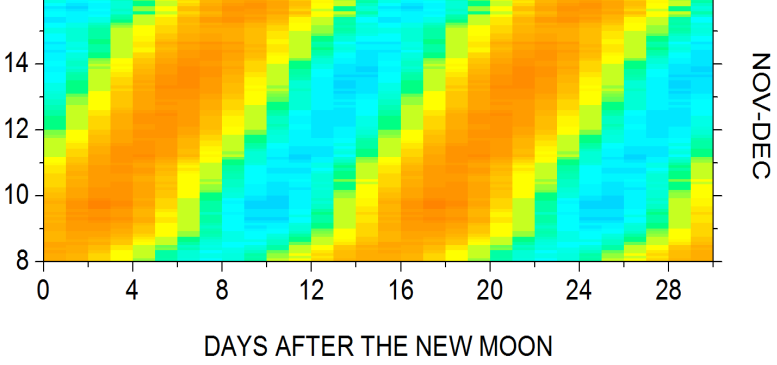

Figure 3-6. Daytime maximum likelihood luni-solar semimonthly lunar drifts as derived from JULIA data for six bimonthly periods. 


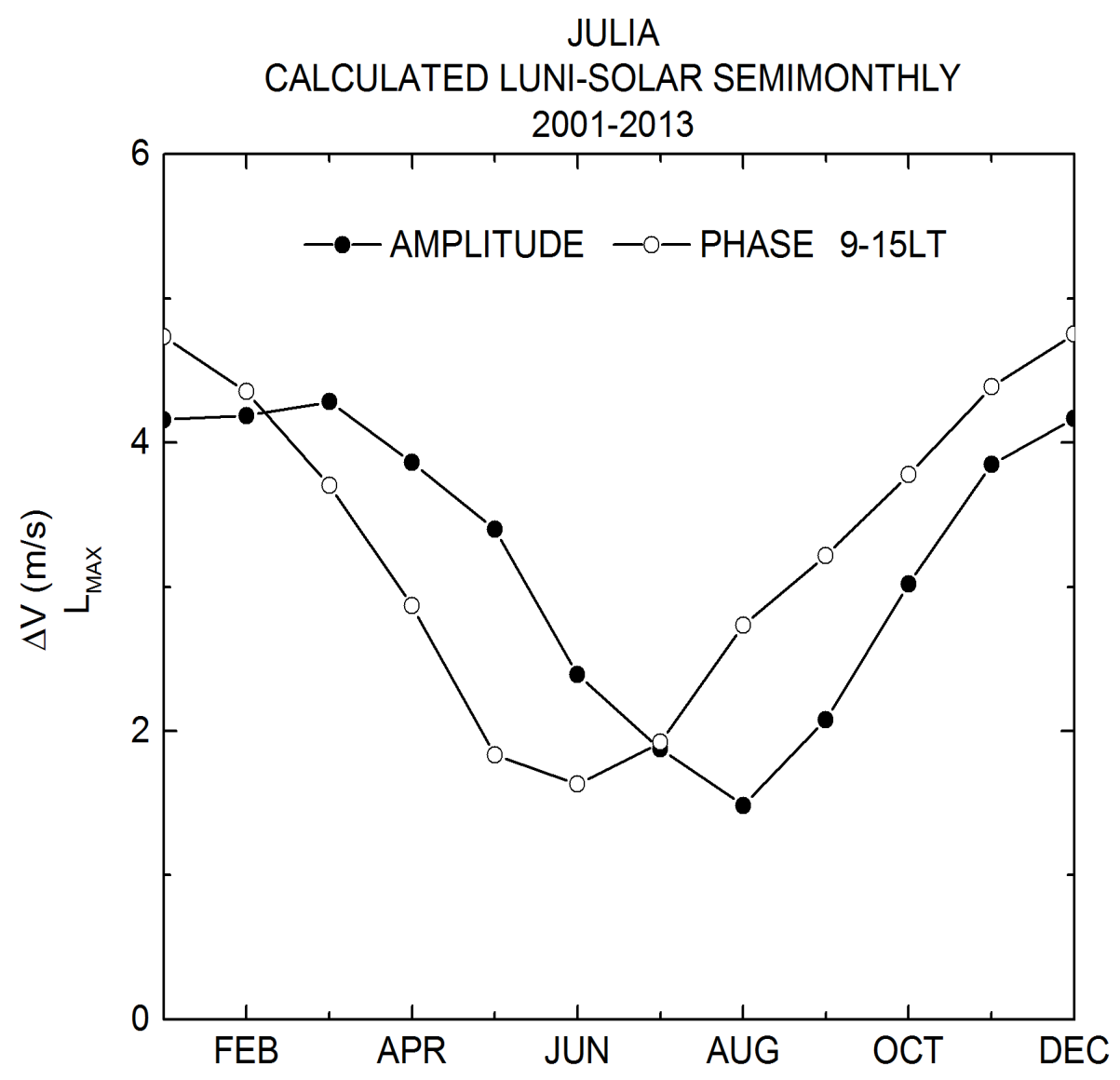

Figure 3-7. Bimonthly variation of the amplitudes and phases of daytime (9-15 LT) maximum likelihood luni-solar semimonthly vertical perturbation drifts as derived from JULIA data.

the semidiurnal lunar tide as a function of local time could be due to interactions with the diurnal and semidiurnal solar tides as they rise through the atmosphere.

Figure 3-9 shows the day and nighttime maximum likelihood lunar semimonthly drifts derived from ISR data for 3 four-month seasons. Figures 3-10 and 3-11 show these data for bimonthly periods during the day (8-16 LT) and at night (18-06LT), respectively. The daytime amplitudes are strongest during December solstice and weakest during June 
solstice. The nighttime amplitudes are similar across the seasons with a particularly large increase in amplitude near dusk. There is a phase shift around dusk, which is seasonally dependent.

As partially explained above, the phase progression of the lunar semidiurnal tide comes from the difference in the time it takes for the sun (24hrs) and moon (24.8hrs) to be over the same spot on the Earth. This would lead to the time of maximum increase

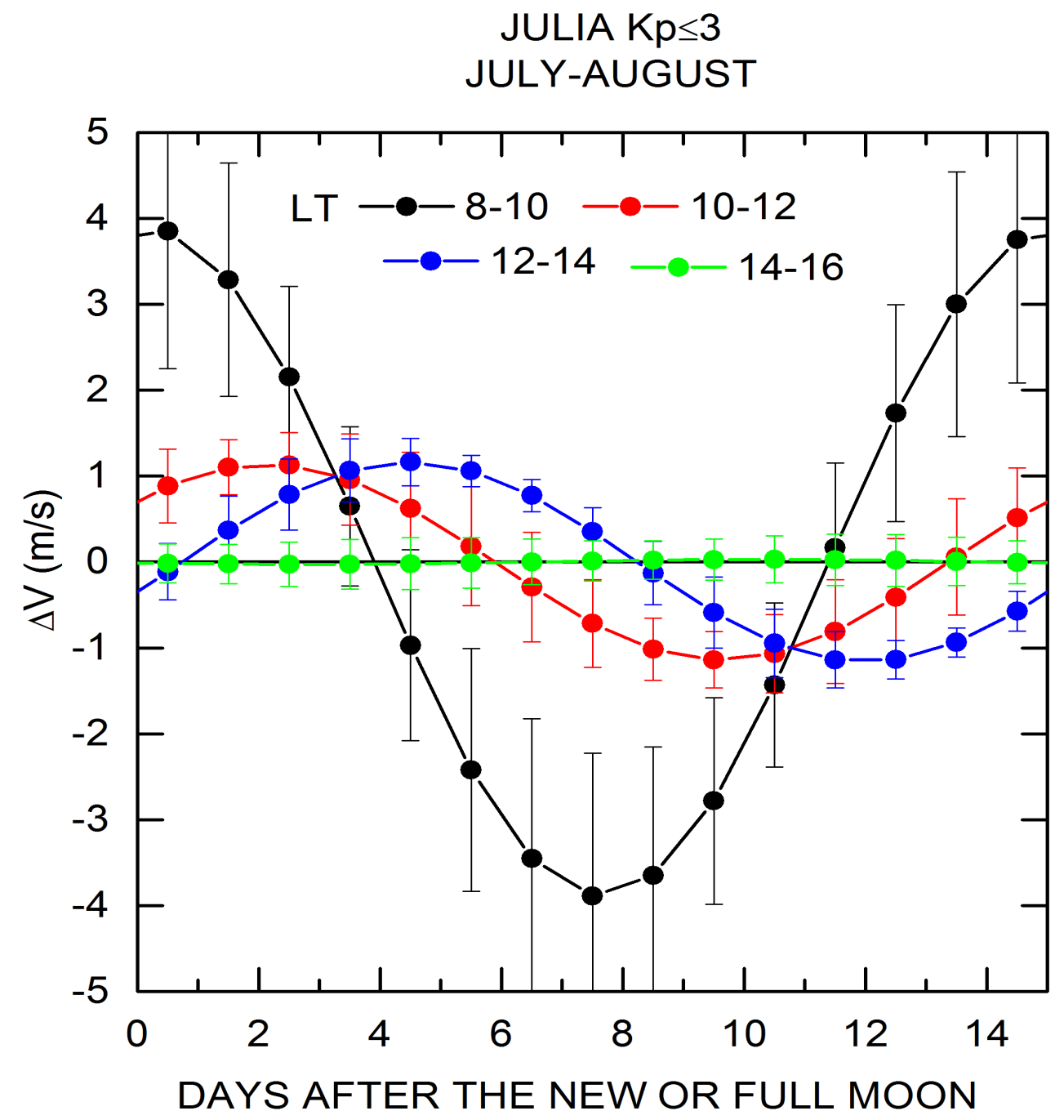

Figure 3-8. Local time variation of the amplitudes and phases of maximum likelihood luni-solar semimonthly daytime drifts during July-August from JULIA data. 

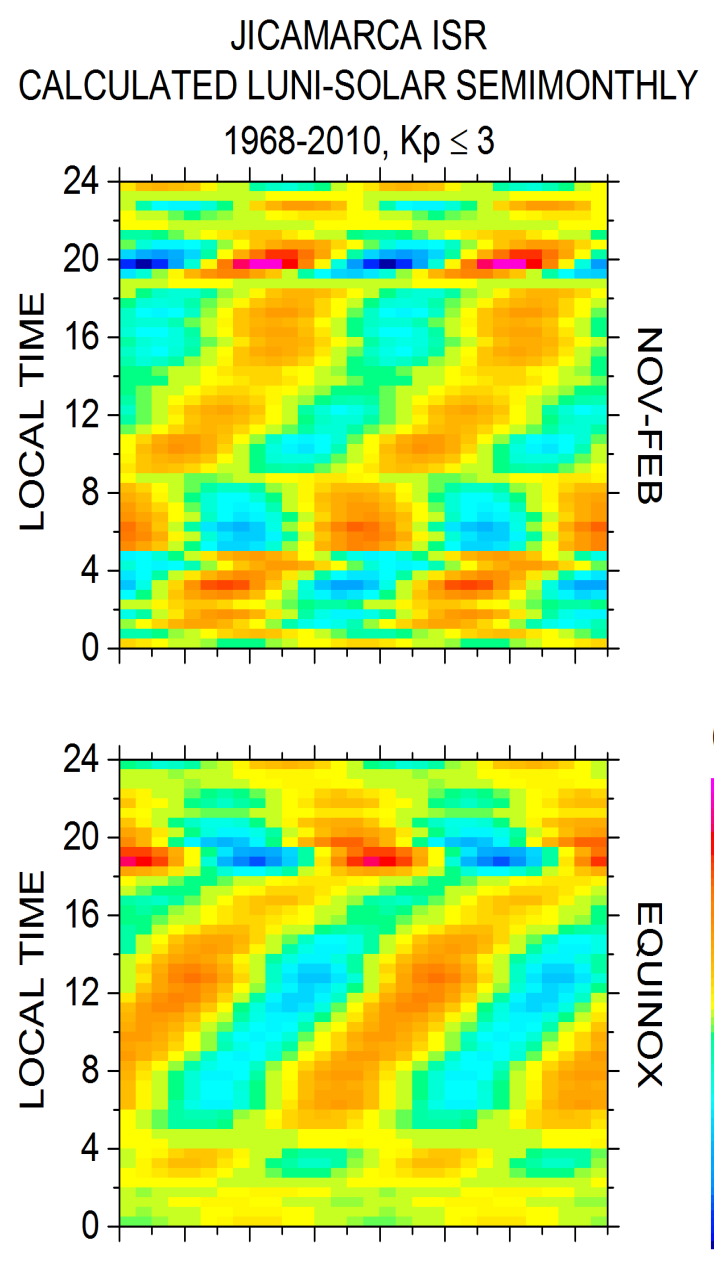

$(\mathrm{m} / \mathrm{s})$
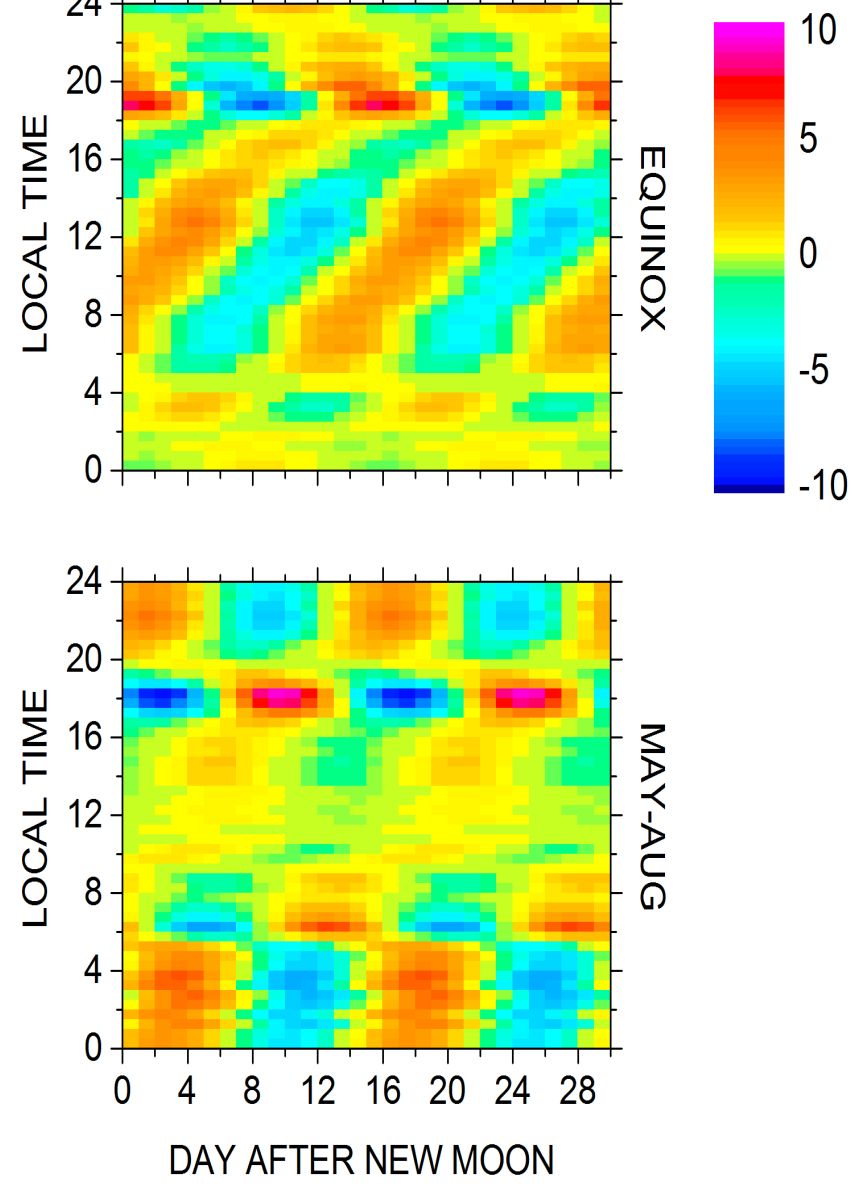

Figure 3-9. Day and nighttime maximum likelihood luni-solar semimonthly perturbation drifts as derived from ISR data for three seasons. 


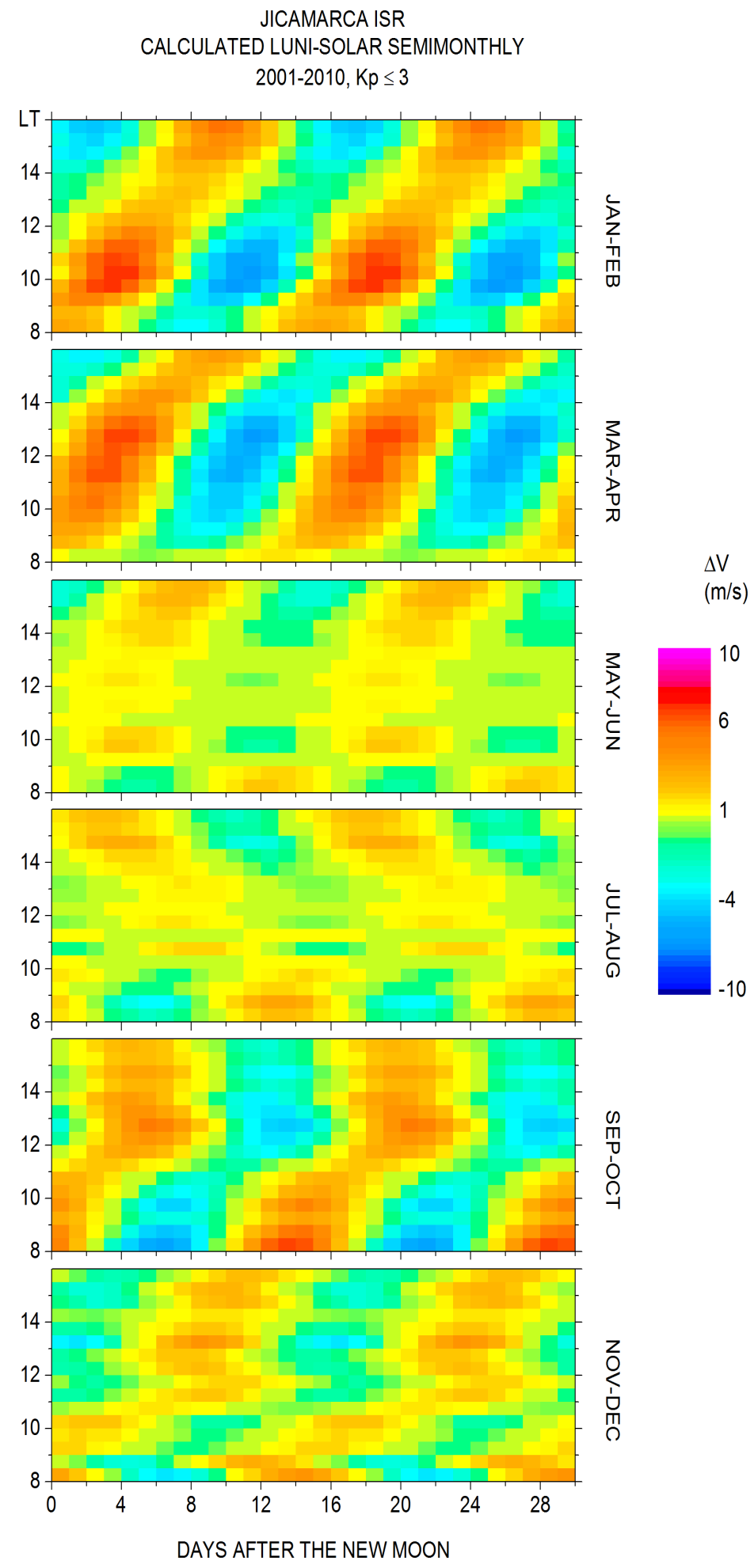

Figure 3-10. Daytime maximum likelihood luni-solar semimonthly perturbation drifts as derived from ISR data for six bimonthly periods. 


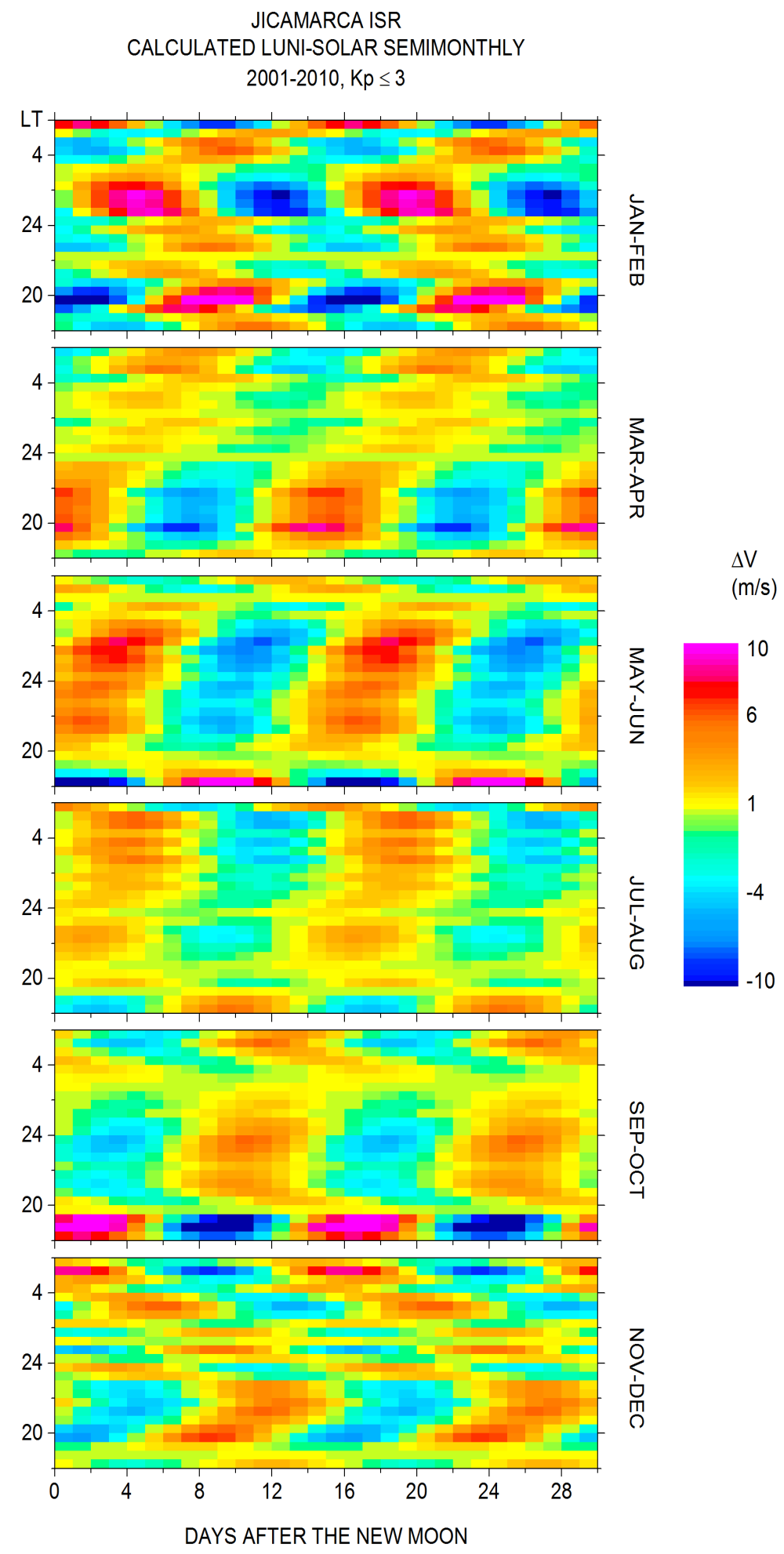

Figure 3-11. Nighttime maximum likelihood luni-solar semimonthly perturbation drifts as derived from ISR data for six bimonthly periods. 
being about one hour later each day. This phase progression is displayed in Figure 3-12 (which shows the January-February data from Figures 3-10 and 3-11 for two solar local time and lunar cycles, and the calculated and theoretical phase progressions). In our work, we will define a phase that increases in $\mathrm{L}_{\mathrm{MAX}}$ with an increase in local time as positive (think about finding the slope of the lines in Figure 3-12). As the calculated lunisolar semimonthly tidal effects generally follows the expected phase progression for the lunar semidiurnal tidal effects, we conclude the lunar semidiurnal tide is the primary driver of luni-solar semimonthly effects, as expected. The variations from the expected value give an idea as to the lunar tidal coupling with other atmospheric tides. The large change in phase at night could be explained, if there is a phase shift in the lunar tidal winds with altitude, by the switch in the primary drivers of the drifts from E-region dynamo to F-region dynamo. Further, if there is a phase shift with altitude, then as the height of the dynamo layer shifts with solar local time, the phase progression, while generally following the expected value, will vary with the phase of the altitude of the dynamo layer.

We found these phase progressions to be seasonally dependent with the steepest slopes during June solstice and generally the best agreement with theory during spring equinox. The general pattern of the phase progression found is shown in Figure 3-12. It is approximately linear until dawn where there is a phase shift, then an s-shaped slope during the day, which on average, follows the expected slope, but is steeper near dusk and dawn, and finally a phase shift at dusk and another linear slope. The negative slope that appears during some bimonthly phase shifts agrees with the expected slope if you make it 


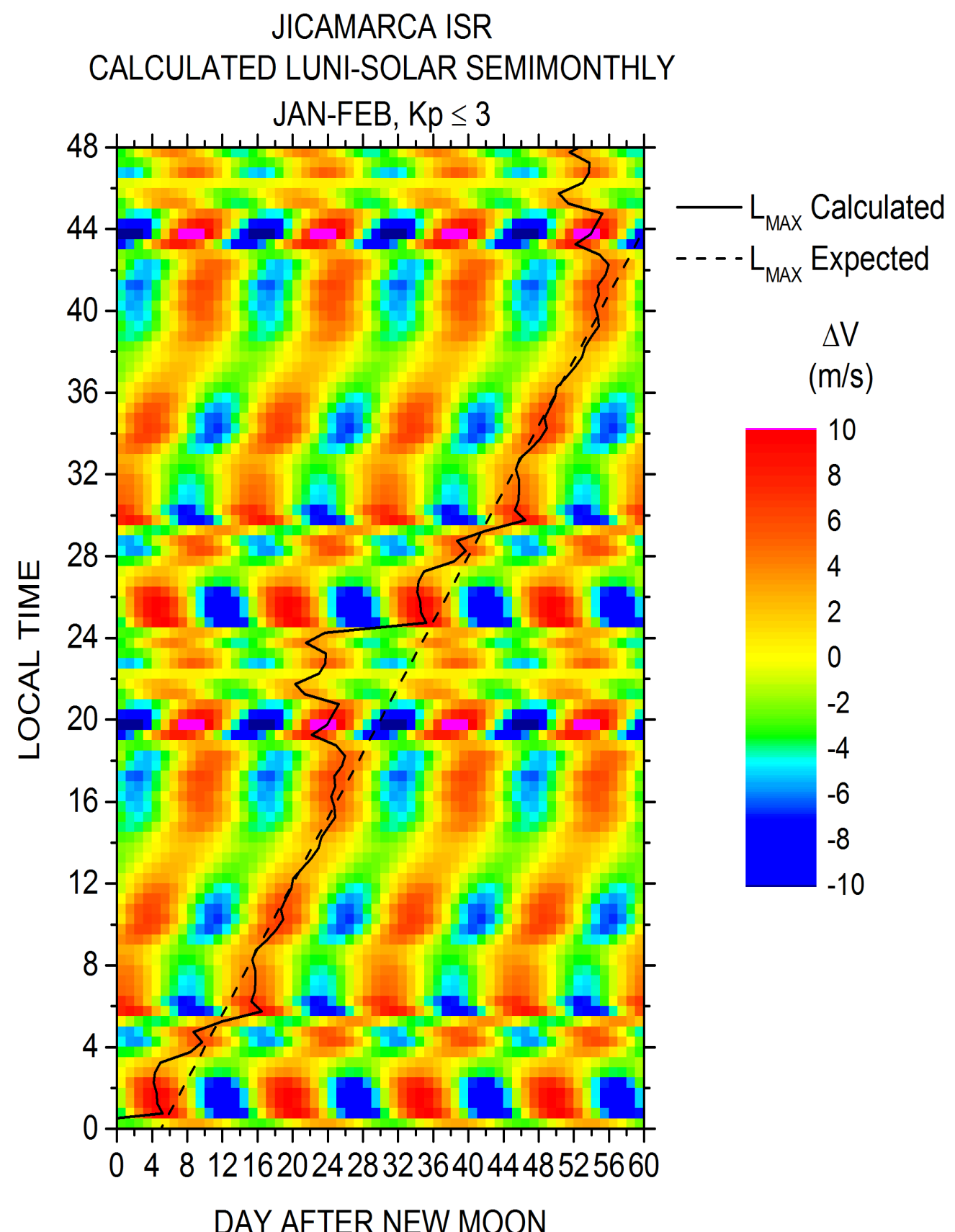

Figure 3-12. Day and nighttime maximum likelihood luni-solar semimonthly perturbation drifts as derived from ISR data for January-February and the calculated and expected phase. 
negative. Note, March-April and September-October both have positive phase progressions with slightly different slopes that results in them having slightly different phases during the day and being largely anticorrelated at night. These differences results in the smaller amplitudes and negative slope at night during the equinoctial calculation. The difference in these bimonthly periods highlights the need to take care in calculating lunar tidal effects for four-month seasons.

The bimonthly variation of the lunar semimonthly drifts is shown in Figure 3-13, which shows the 9-15 LT bimonthly average amplitudes and phases, and Figure 3-14, which shows the 20-06 LT bimonthly average amplitudes and phases. In these data, the standard deviations were less than $1 \mathrm{~m} / \mathrm{s}$ and 0.5 day, respectively. Figure 3-13 shows largest drifts near spring equinox and smallest around June solstice, which is in good agreement with the Stening-Fejer data, except for the larger amplitudes of the ISR drifts during the autumnal equinox. Note, the phase progression we found during the autumnal equinox is different than the rest of the data analyzed here. As Stening and Fejer [2001] fixed the phase progression (slope) and then found the amplitude and phase (intercept), this could explain the smaller amplitudes obtained by them during this time period. Figure 3-14 shows smallest amplitudes during the equinoxes and largest amplitudes during the solstices. As noted above, the values are significantly larger than the values obtained by Stening and Fejer [2001]; however, note they used 18-06 LT for their nighttime values, and as there is typically a large phase shift around 19LT averaging on both sides of the phase shift, which would significantly decrease the calculated amplitudes. Figure 3-15 shows the average of the twelve bimonthly lunar semimonthly 


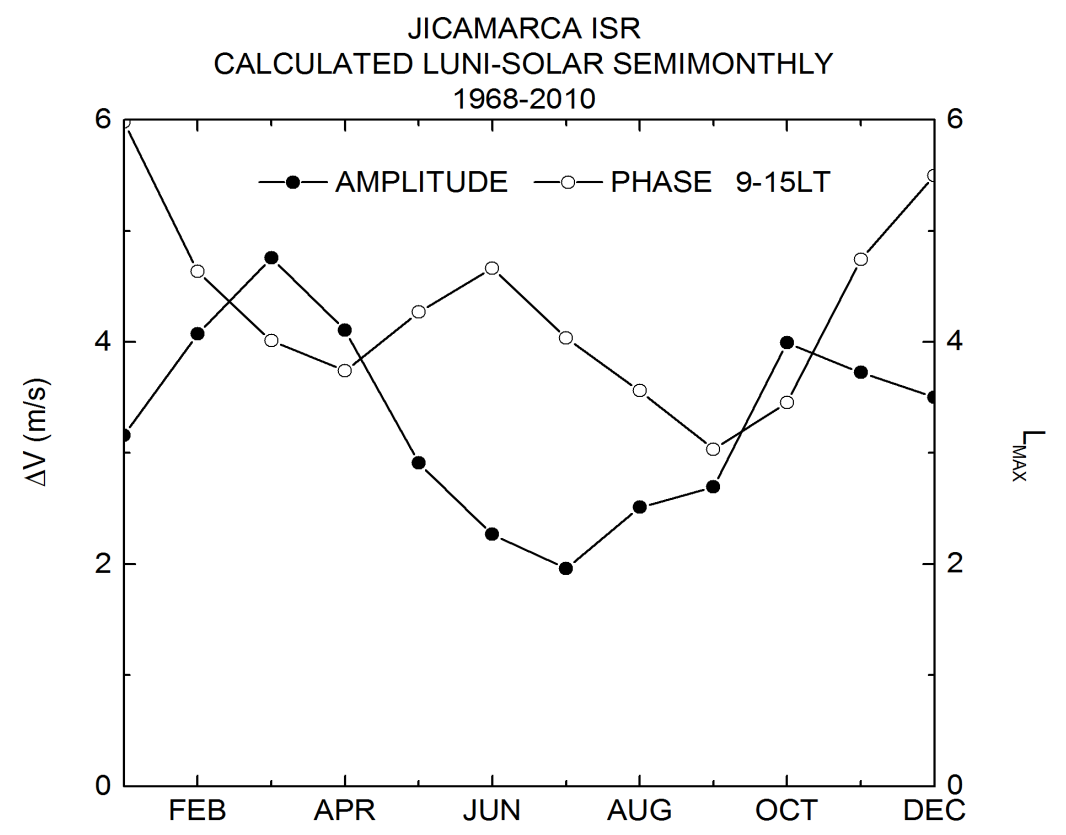

Figure 3-13. Bimonthly variation of the amplitudes and phases of daytime (9-15 LT) maximum likelihood luni-solar semimonthly vertical perturbation drifts as derived from ISR data.

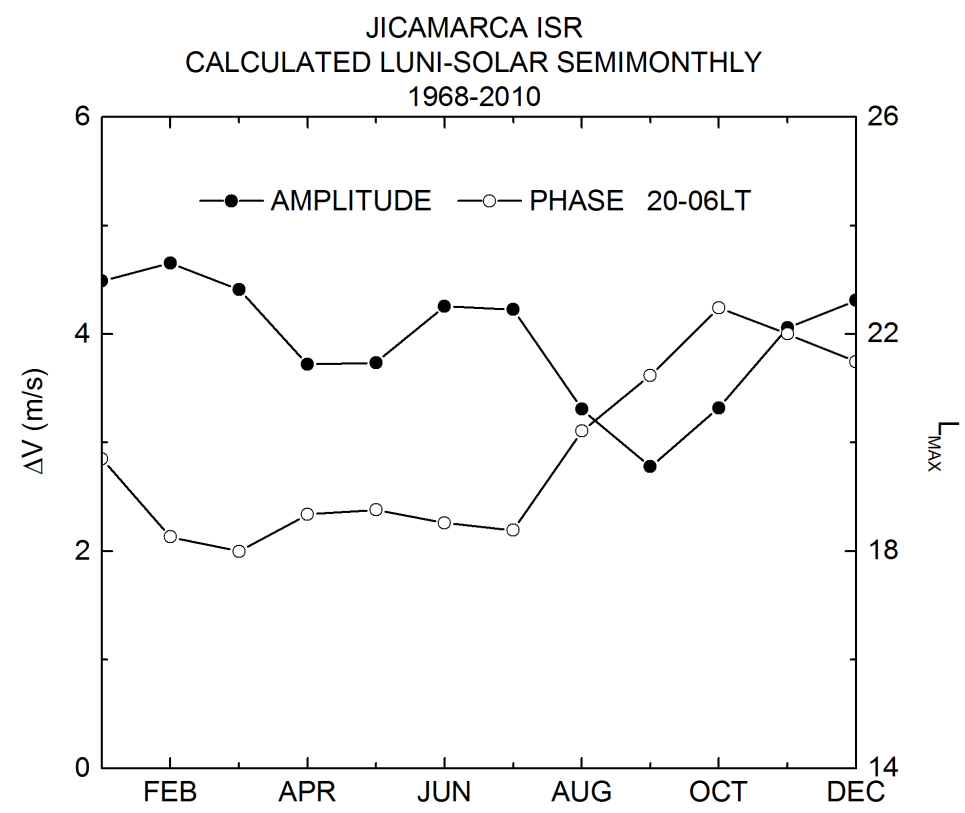

Figure 3-14. Bimonthly variation of the amplitudes and phases of nighttime (20-06 LT) maximum likelihood luni-solar semimonthly vertical perturbation drifts as derived from ISR data. 
amplitudes and phase as a function of local time as derived from the ISR data. Figure 315 shows the semimonthly amplitude is on average $4 \mathrm{~m} / \mathrm{s}$, being slightly larger at night than during the day, and with large increases around dusk and dawn. Figure 3-16 shows the excellent agreement between the bimonthly, semimonthly amplitudes and phases as derived from ISR and JULIA data except the phase during June solstice, when the amplitudes are the smallest.

\subsubsection{Luni-Solar Monthly Tidal Effects}

Several recent studies examined the effects of lunar tides on the low-latitude upper

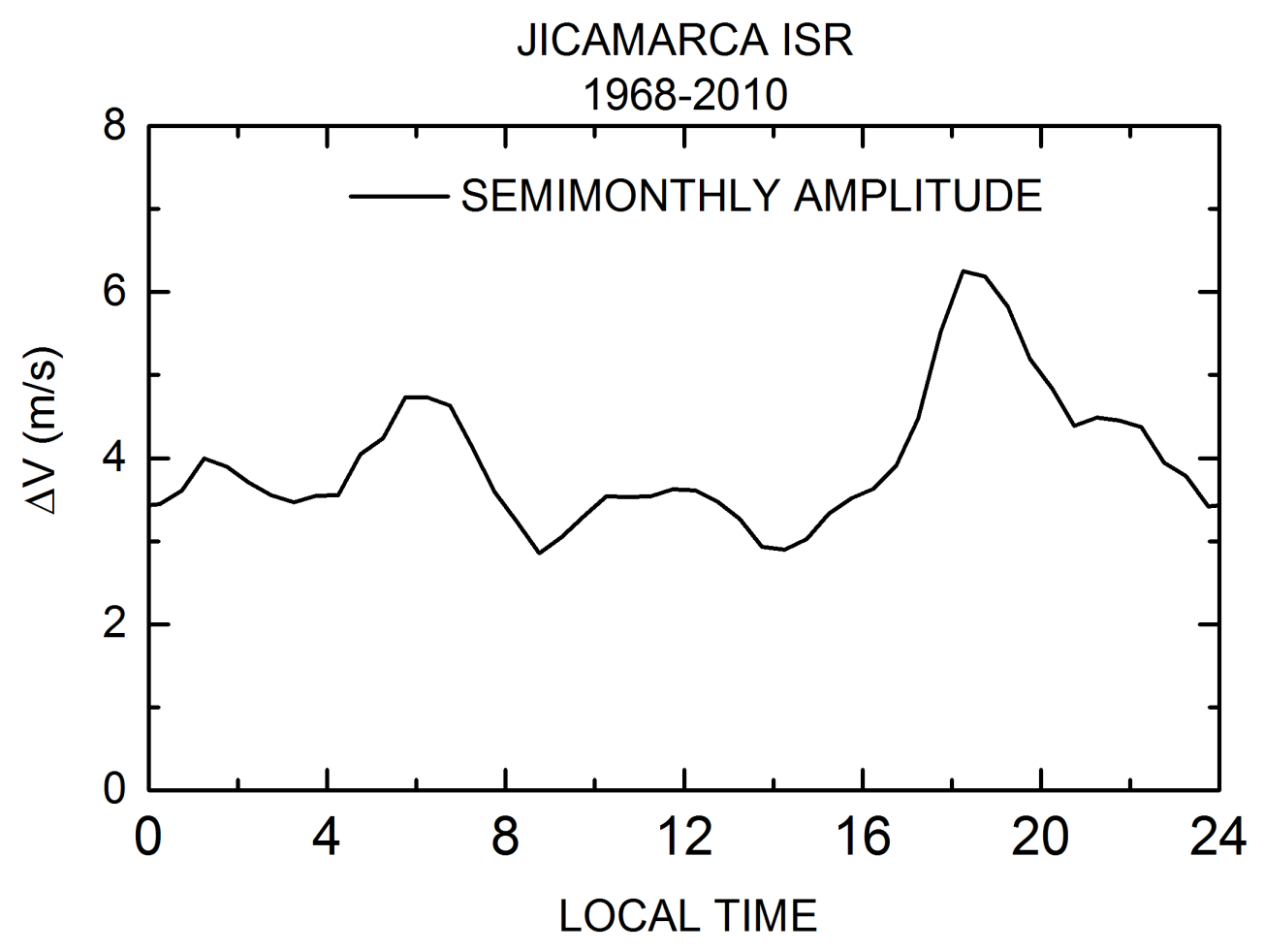

Figure 3-15. Local time variation of the yearly average amplitudes of the luni-solar semimonthly perturbation drifts as derived from the ISR data. This was found by computing the local time variation for each bimonthly period and then averaging the twelve bimonthly periods together. 


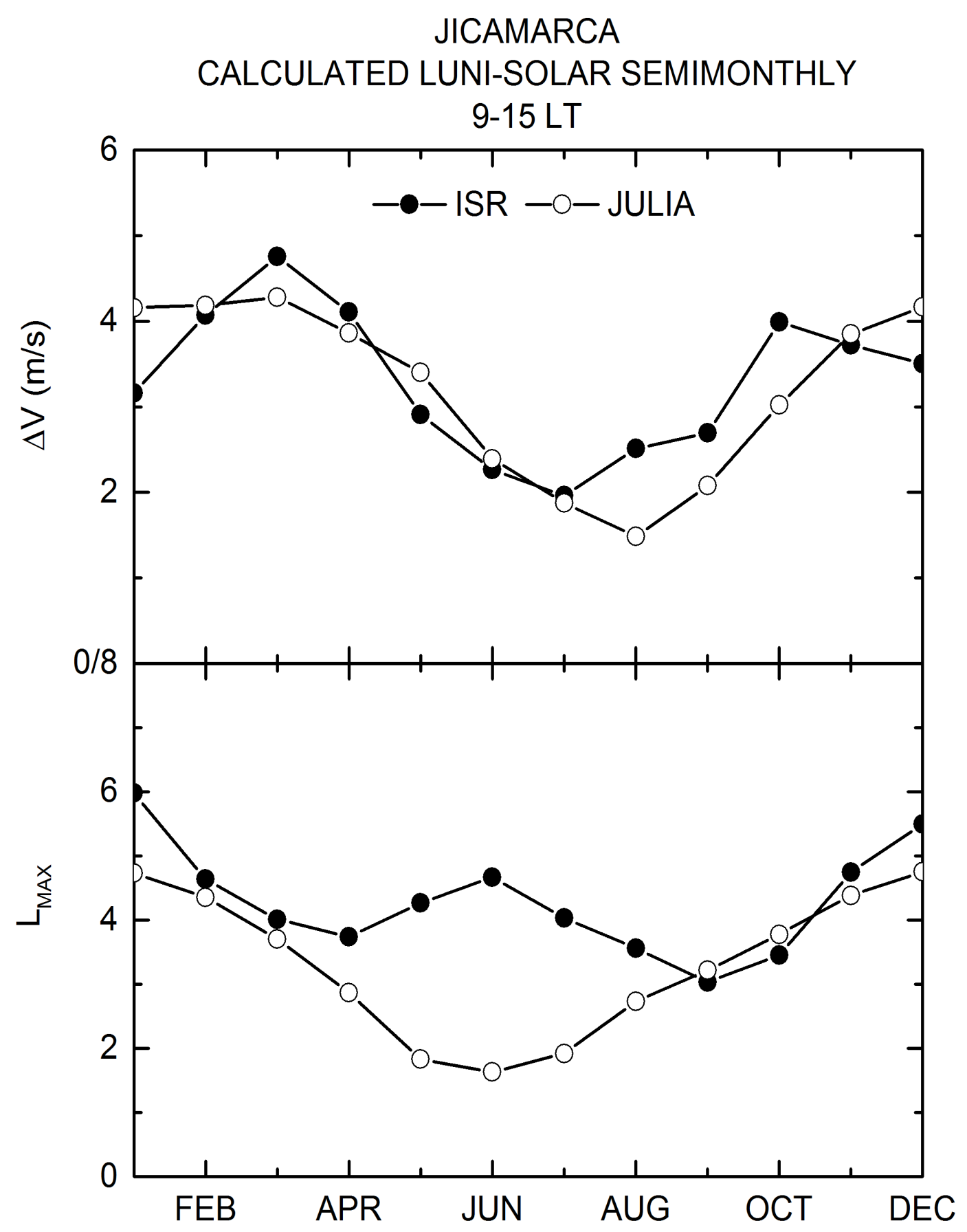

Figure 3-16. Comparison of the bimonthly variation of the amplitudes and phases of daytime (9-15 LT) maximum likelihood luni-solar semimonthly vertical perturbation drifts as derived from JULIA and ISR data. 
atmosphere and ionosphere [Pedatella and Forbes, 2010; Eccles et al., 2011; Stening, 2011; Lühr et al., 2012] and noted the lunar semidiurnal tide does not explain all the variation through the lunar month. Fejer and Tracy [2013] showed JULIA data during December solstice has lunar diurnal drifts with an amplitude about $2 \mathrm{~m} / \mathrm{s}$. Similarly Figure 3-17 illustrates lunar monthly effects on the November-February ISR vertical drifts. This tidal component has an average amplitude of about $2 \mathrm{~m} / \mathrm{s}$ during the day and a

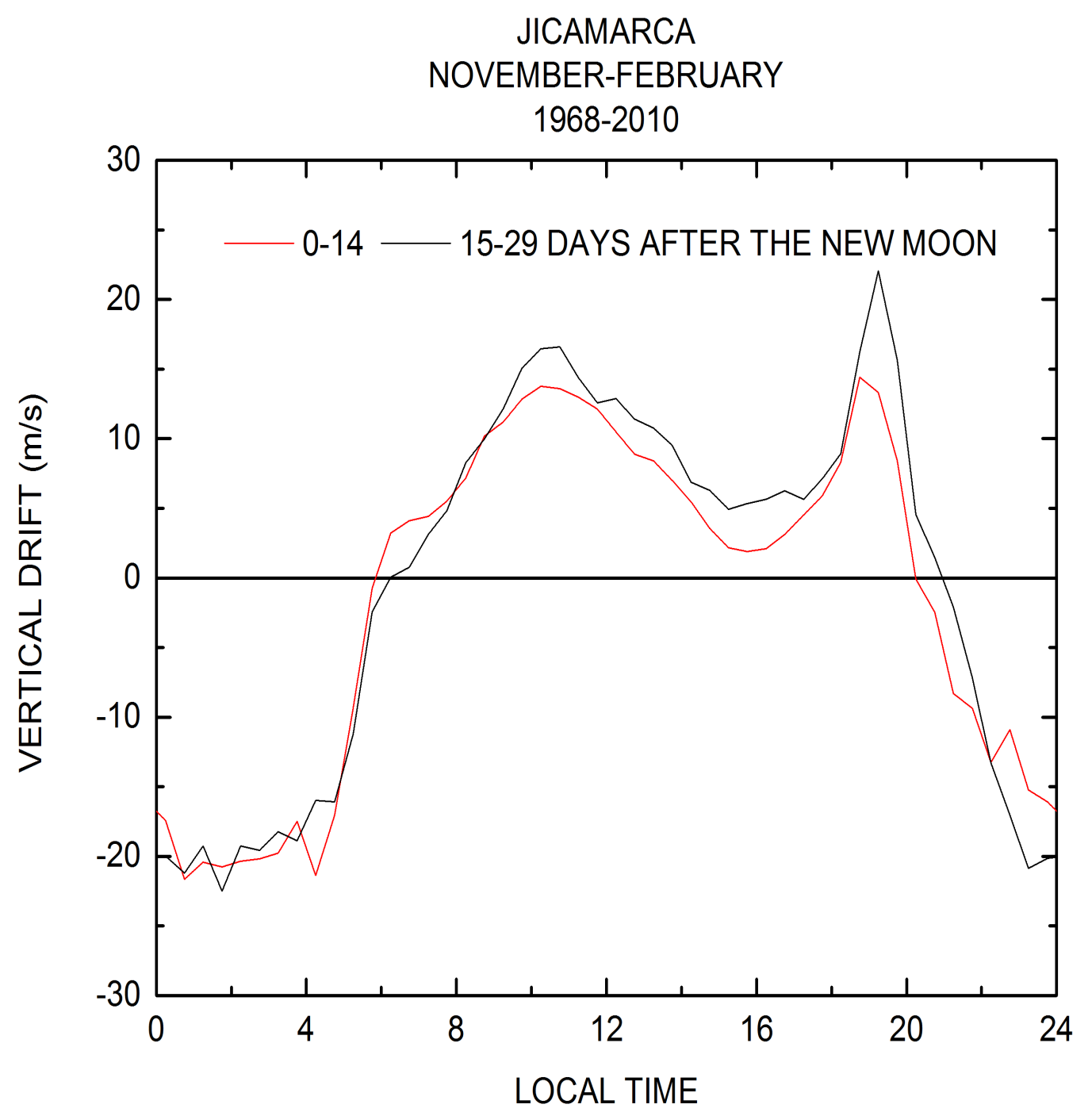

Figure 3-17. Local time variation of average ISR vertical drift velocities for periods starting close to new and full moon. 
much larger value around dusk. The ISR daytime data disagrees with the JULIA data, which because of the large number of days of data and lack of bias, is probably the most correct; however, there is reason to believe the nighttime values are more representative of the actual values. As mentioned later, the large increase of the prereversal velocity enhancement around full moon gives rise to more frequent occurrence of strong equatorial spread F. This was pointed out initially by Aveiro and Hysell [2010]. We will now look at these effects derived first from the JULIA and then the ISR data, and finally compare them.

Figures 3-18 and 3-19 show the maximum likelihood lunar monthly perturbation drifts derived from the JULIA data using the EM algorithm for 3 four-month seasons and six bimonthly periods, respectively. The amplitude is similar across all seasons, while the expected phase progression is most distinct during January-February and MarchApril. Several bimonthly periods show a distinct phase shift around 14 LT. June solstice again has the steepest slopes, with July-August being almost straight up and down. Figure 3-20 shows the three-point smoothed 9-15 LT bimonthly average lunar monthly perturbation amplitudes and phases. In these data, the standard deviations were less than $1 \mathrm{~m} / \mathrm{s}$ and 0.5 days, respectively. The lunar monthly perturbation amplitude is independent of season with an amplitude of about $1.5 \mathrm{~m} / \mathrm{s}$.

Figure 3-21 shows the average of the bimonthly lunar monthly perturbation amplitudes and phase as a function of LT as derived from the JULIA data. Similar to the semimonthly tidal effects, the lunar monthly tidal effect weakens from early morning to late afternoon. 

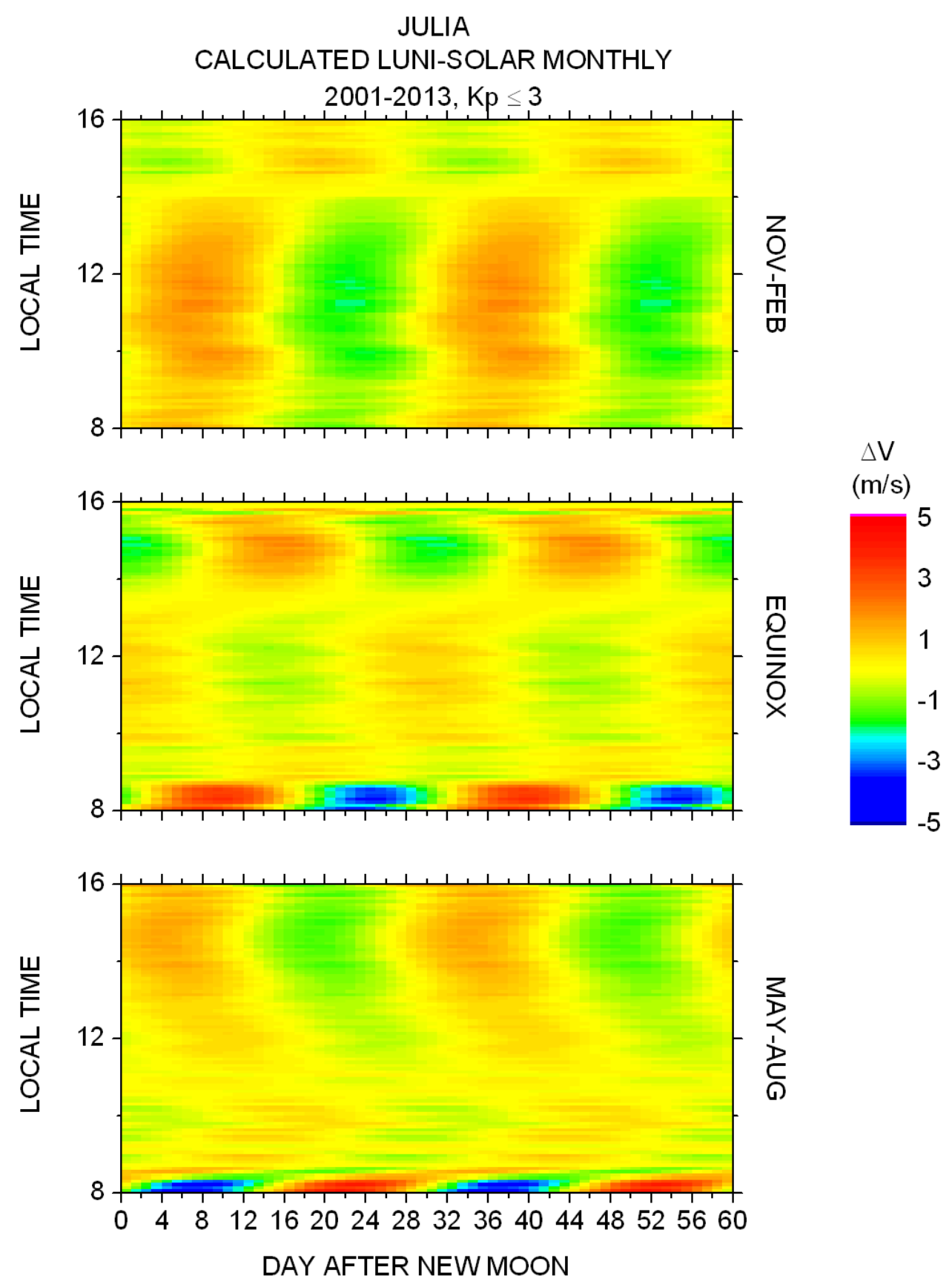

Figure 3-18. Daytime maximum likelihood luni-solar monthly perturbation drifts as derived from JULIA data for three seasons. 
JULIA

CALCULATED LUNI-SOLAR MONTHLY $2001-2013, \mathrm{Kp} \leq 3$

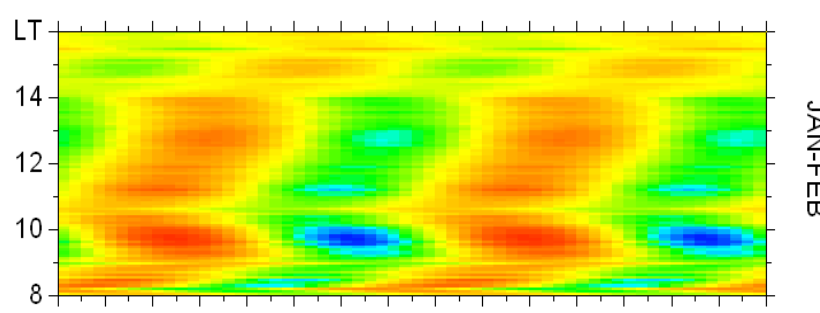

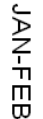

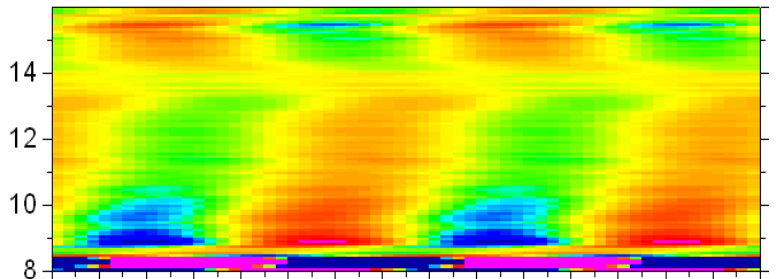

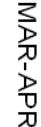

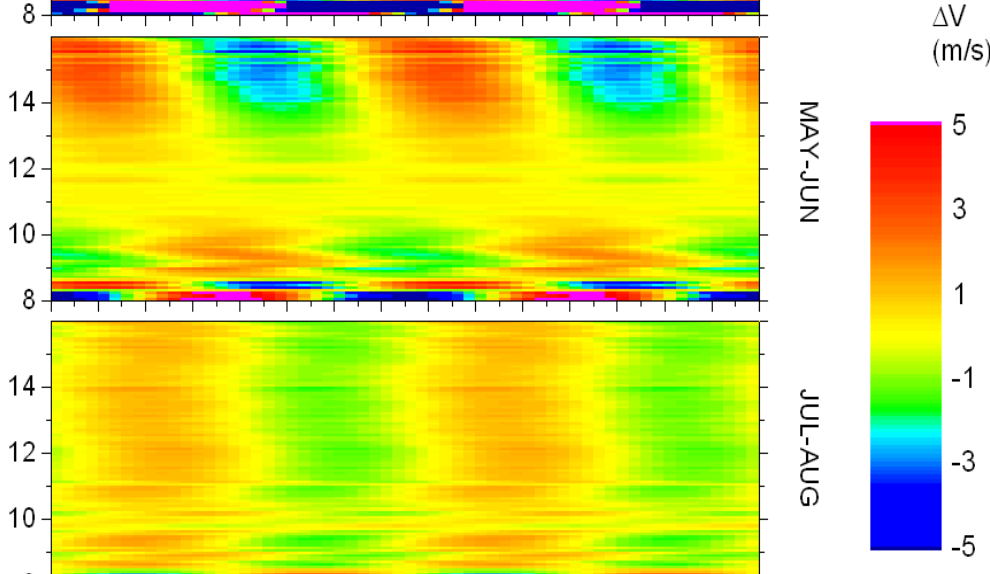

$(\mathrm{m} / \mathrm{s})$
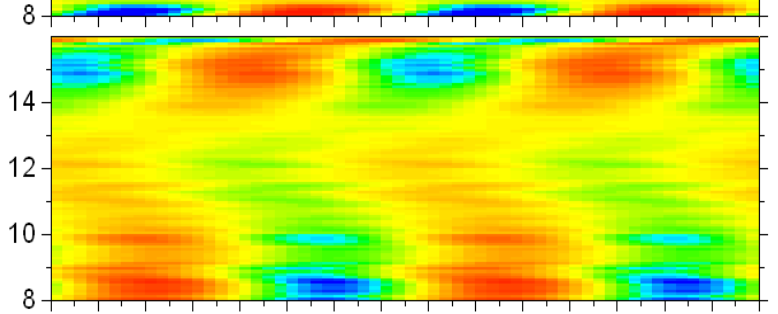

0
m
0
0
0
-1

\section{蕉}

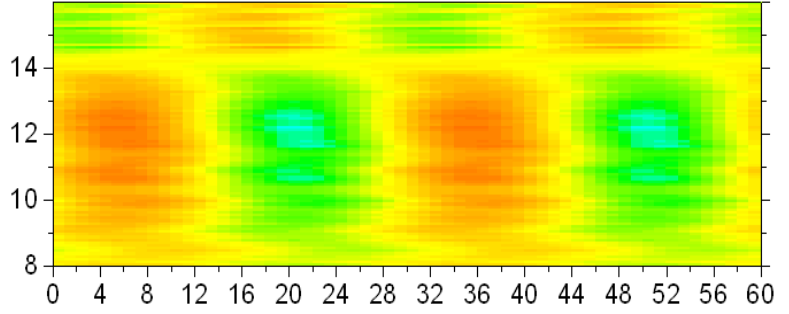

2
0
1
m
m

DAYS AFTER THE NEW MOON

Figure 3-19. Daytime maximum likelihood luni-solar monthly perturbation drifts as derived from JULIA data for six bimonthly periods. 


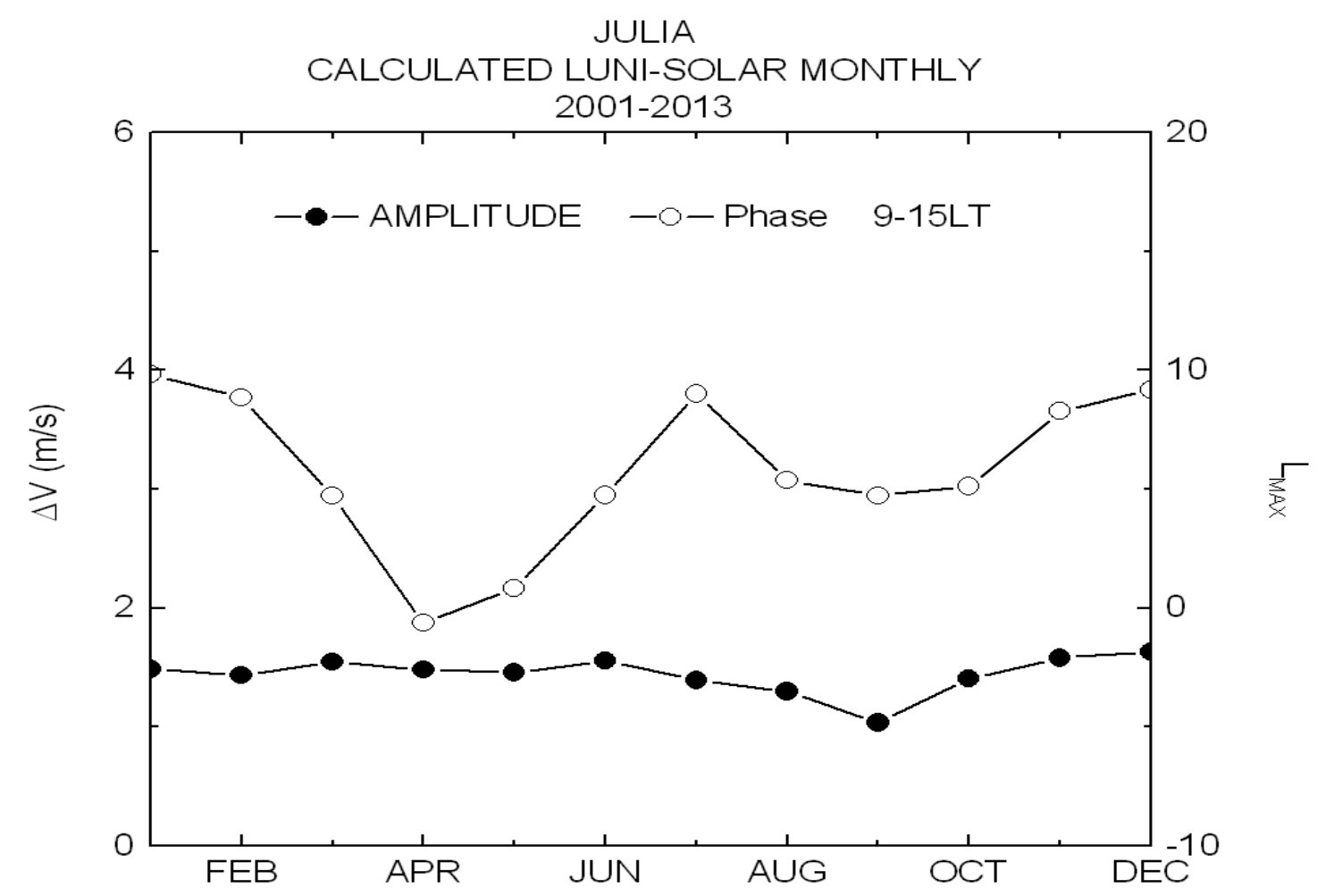

Figure 3-20. Bimonthly variation of the amplitudes and phases of daytime (9-15 LT) maximum likelihood luni-solar monthly vertical perturbation drifts as derived from JULIA data.

Figure 3-22 shows the day and nighttime maximum likelihood lunar monthly perturbation drifts derived from ISR data for 3 four-month seasons. Figures 3-23 and 324 show these data for bimonthly periods during the day (8-16 LT) and at night (1806LT), respectively. The daytime amplitudes are almost season independent and smaller than the nighttime amplitudes during December solstice and equinox. There are large phase shifts near dusk and dawn in all seasons and around 14 LT during some bimonthly periods. There is no current understanding of what drives the lunar monthly tidal effects and its phase progression. Assuming it is caused by dynamo-driven electric fields of lunar diurnal tidal origin (the lunar diurnal tides are also unexplained) and modulated by its 


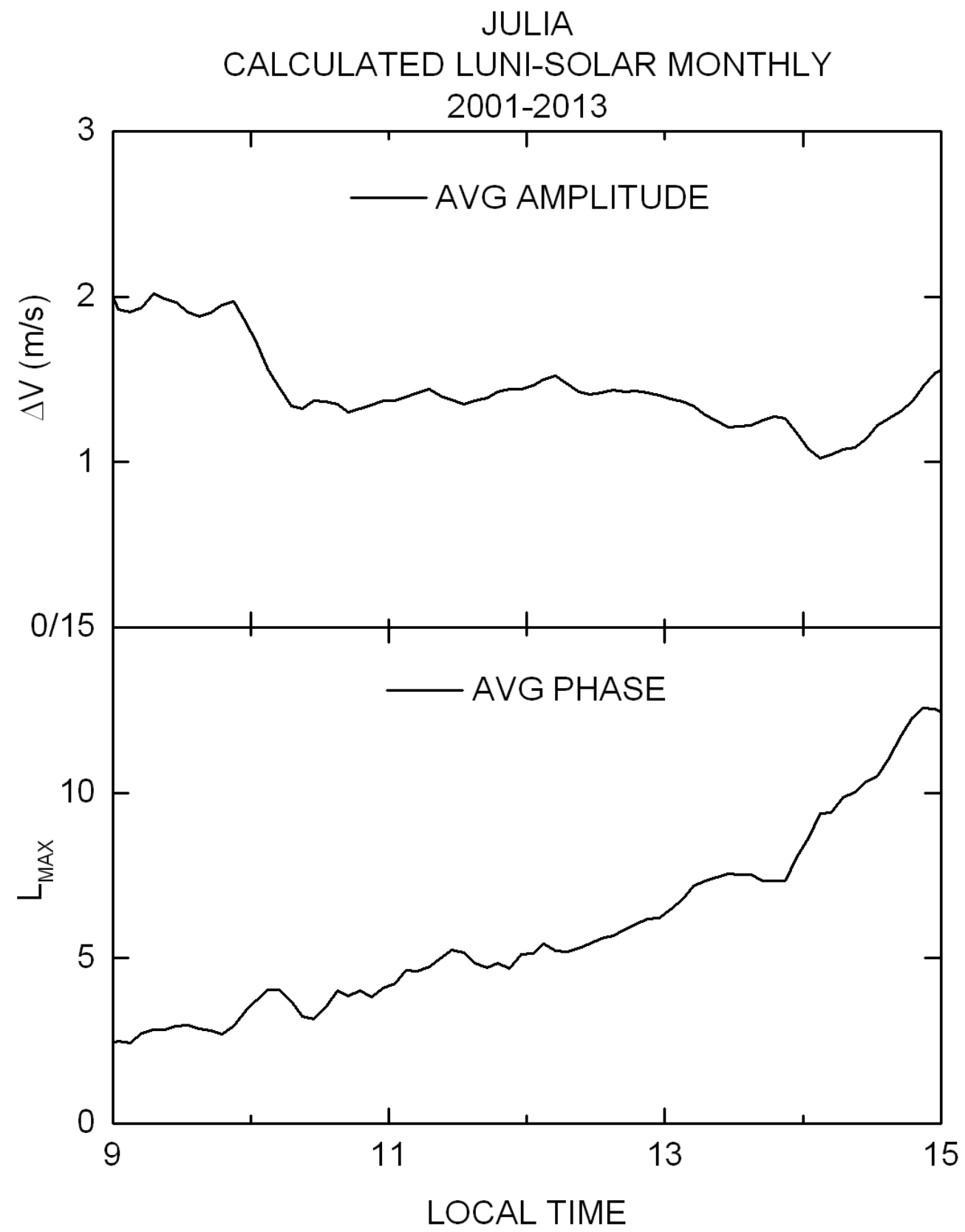

Figure 3-21. Local time variation of the average amplitudes and phases of the luni-solar monthly perturbation drifts as derived from JULIA data. This was found by computing the local time variation for each bimonthly period and then averaging the twelve bimonthly periods together. 

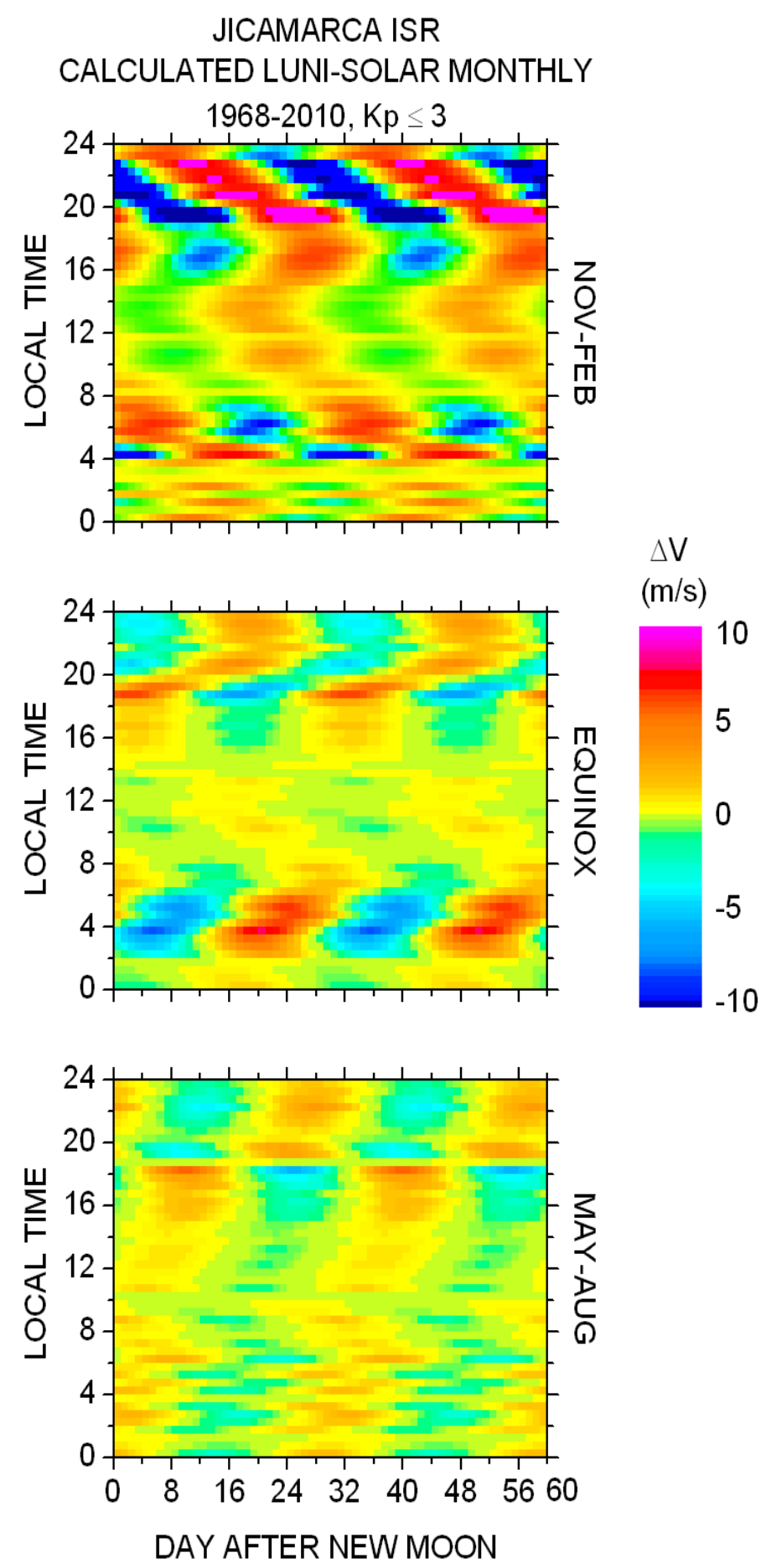

Figure 3-22. Day and nighttime maximum likelihood luni-solar monthly perturbation drifts as derived from ISR data for three seasons. 
CAMARCA ISR

CALCULATED LUNI-SOLAR MONTHLY

$2001-2010, K p \leq 3$

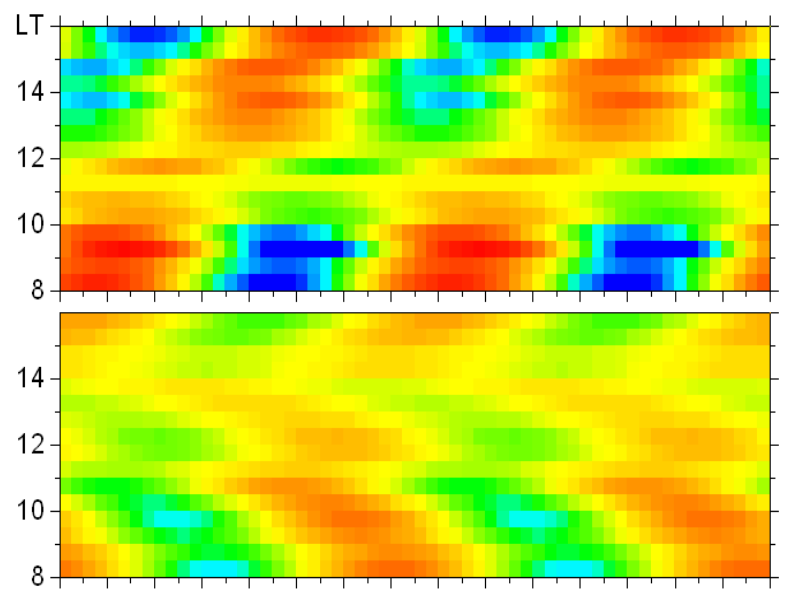

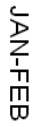
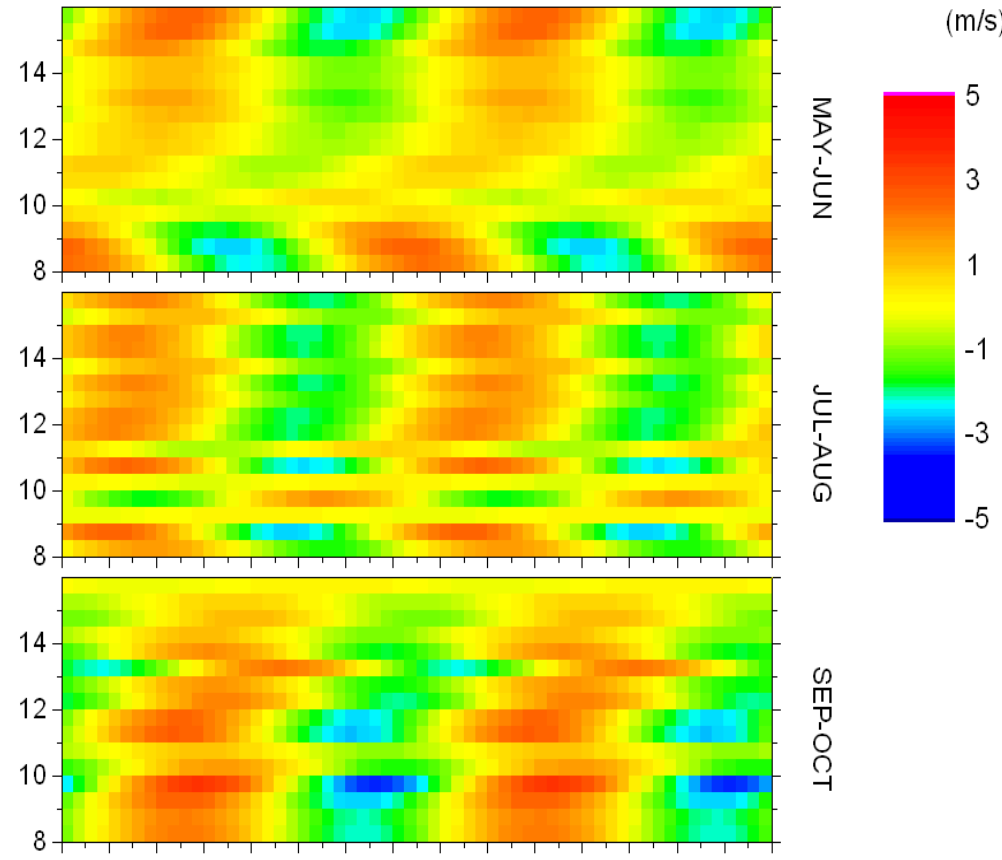

\begin{tabular}{l}
0 \\
0 \\
0 \\
0 \\
\hdashline
\end{tabular}

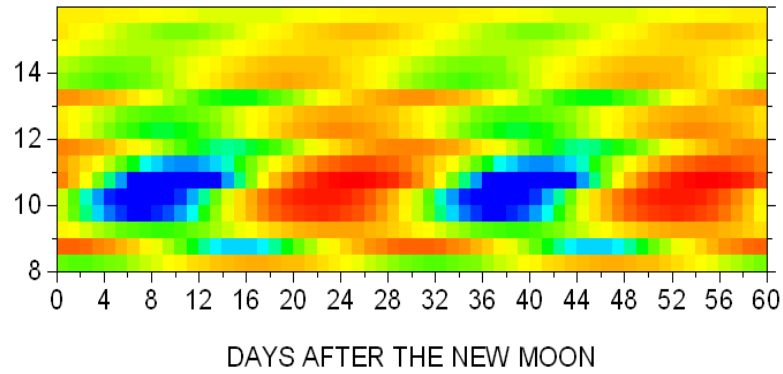

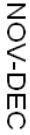

Figure 3-23. Daytime maximum likelihood luni-solar monthly perturbation drifts as derived from ISR data for six bimonthly periods. 


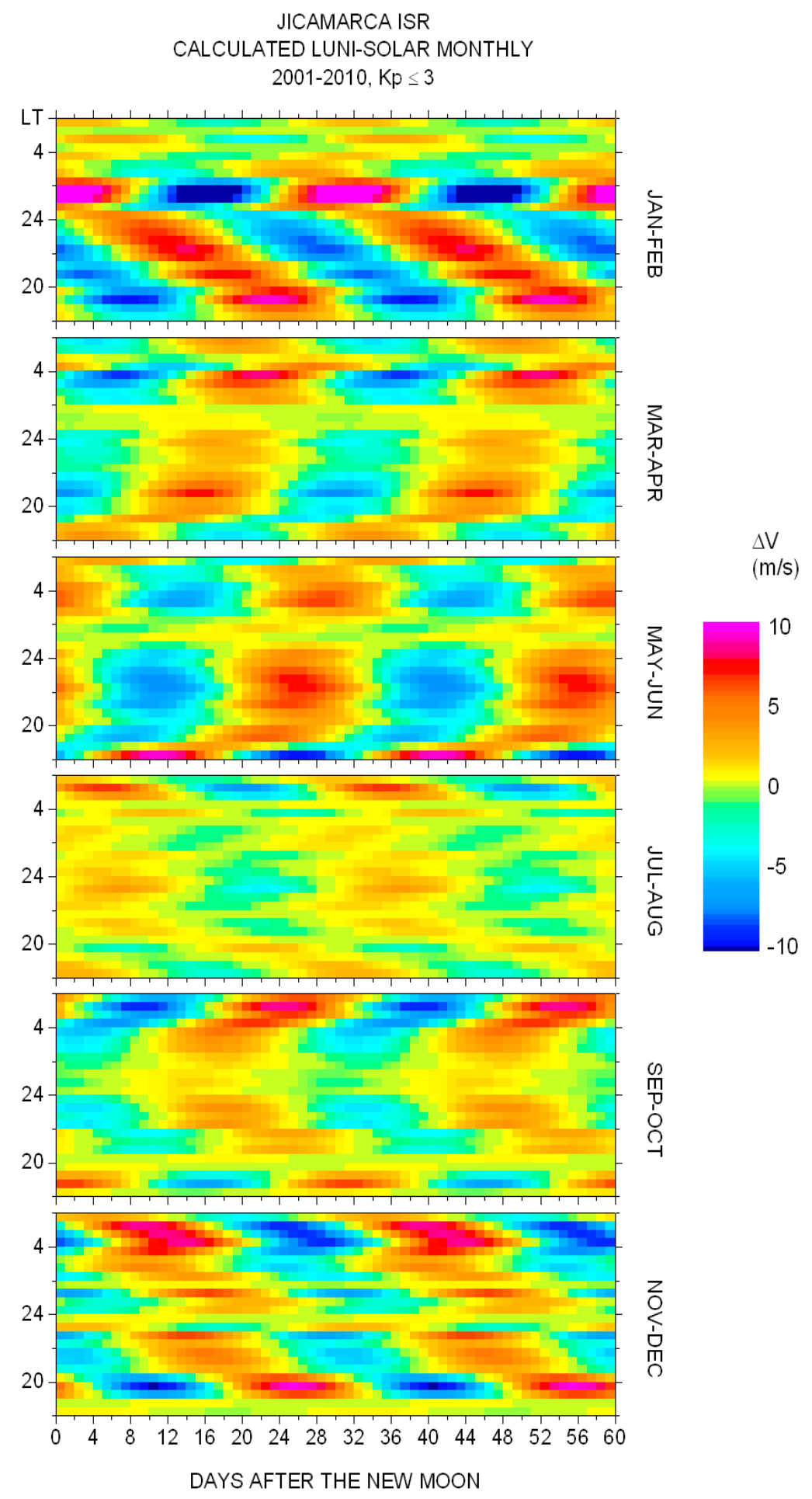

Figure 3-24. Nighttime maximum likelihood luni-solar monthly perturbation drifts as derived from ISR data for six bimonthly periods. 
interaction with other atmospheric tides would lead to the same slope, but different period, as the semidiurnal case. Figure 3-25 shows the January-February data from Figures 3-23 and 3-24 for two local time and lunar cycles, and the calculated and theoretical phase progressions. As in the semidiurnal case, a phase that increases in $\mathrm{L}_{\operatorname{MAX}}$ with an increase in local time will be defined as positive. The expected phase progression is seen clearest in January-February. Note, July-August again has a very steep slope. The monthly and semimonthly lunar tidal effects are seen to have similar phase progressions; compare Figures 3-10 and 3-11 with 3-23 and 3-24. Specifically, at night the semimonthly and monthly tidal phase progressions are positive during March-April and May-June, steepens during July-August, is transitioning during September-October, and is negative during November-December and January-February. January-February monthly phase progressions follows an s-shaped slope during the day similar to the semimonthly case; compare Figures 3-25 and 3-12. This s-shaped pattern is followed, to some extent, in all bimonthly periods, with the importance of each slope varying according to local time and bimonthly period. The negative slopes are an indication of other factors coupling with the lunar tides and more work should be done to determine the lunar tide's dependence on such things as solar flux and conductivity.

Figures 3-26 and 3-27 show the bimonthly average lunar monthly amplitudes and phases for 9-15 LT and 20-06 LT, respectively. In these data, the standard deviations were less than $1 \mathrm{~m} / \mathrm{s}$ and 0.5 day. The daytime amplitude is largest in December solstice and smallest in early June solstice. The nighttime amplitude is strongest in late December solstice and weakest in late June solstice. It is interesting to note the similarity between 


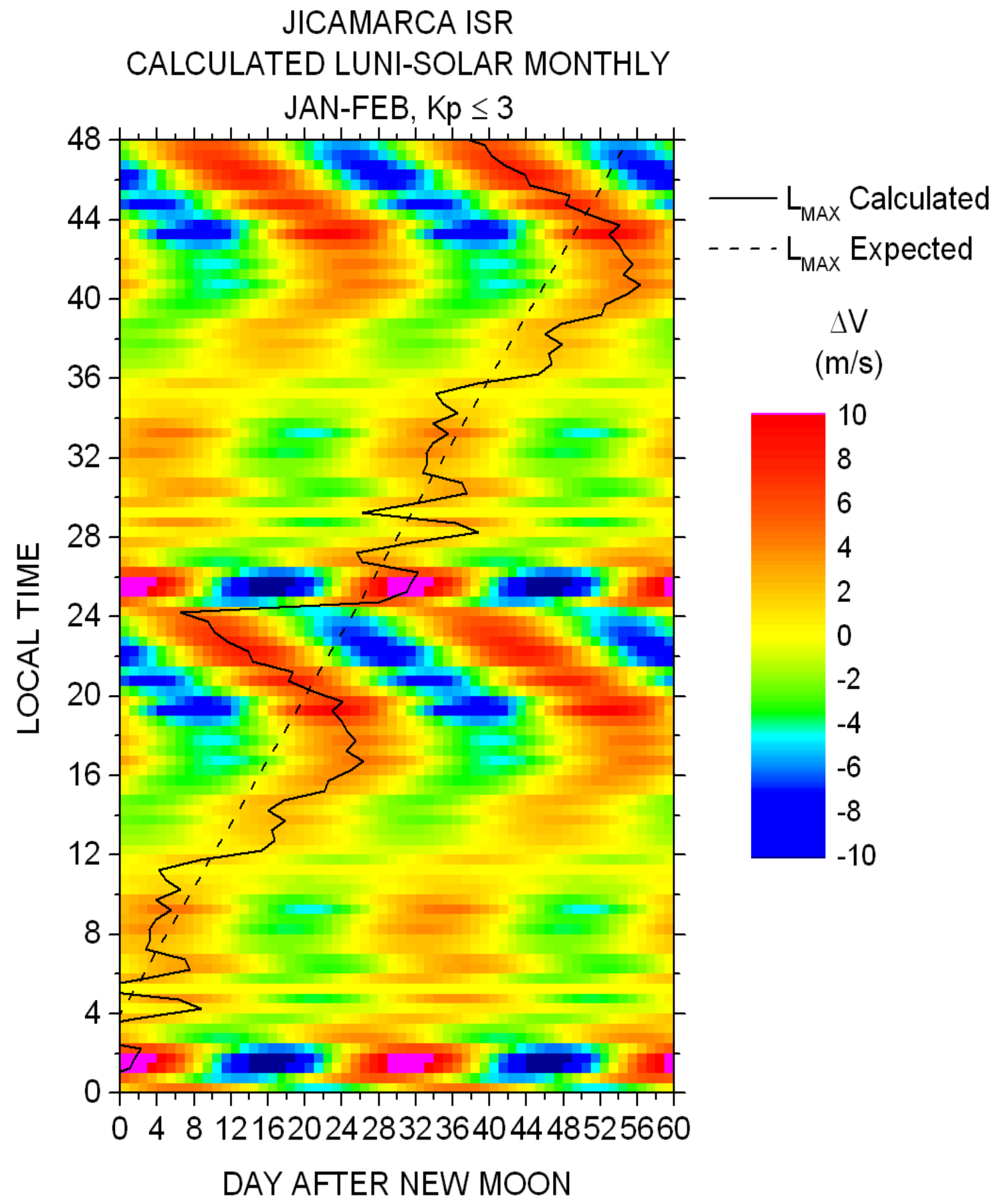

Figure 3-25. Day and nighttime maximum likelihood luni-solar monthly perturbation drifts as derived from ISR data for January-February and the calculated and expected phase. 


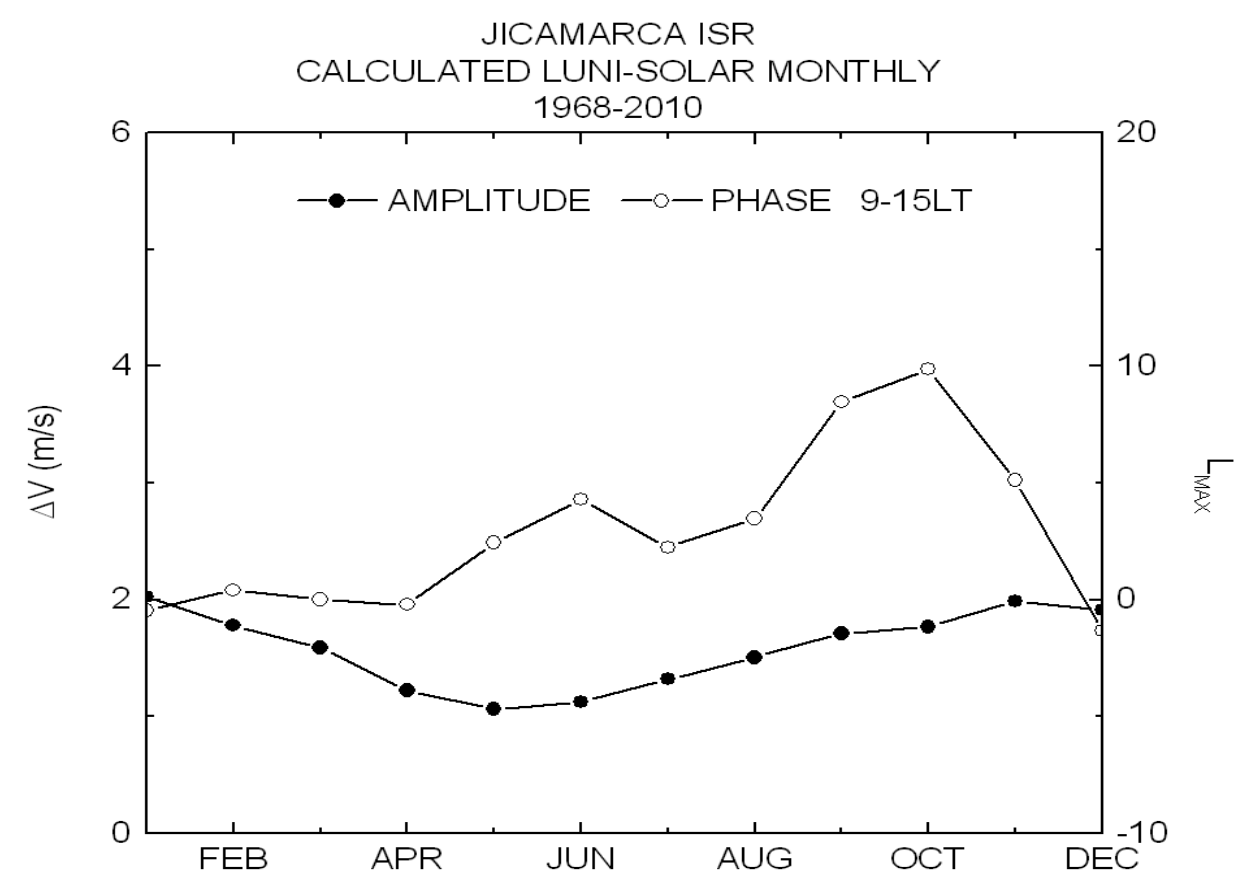

Figure 3-26. Bimonthly variation of the amplitudes and phases of daytime (9-15 LT) maximum likelihood luni-solar monthly vertical perturbation drifts as derived from ISR data.

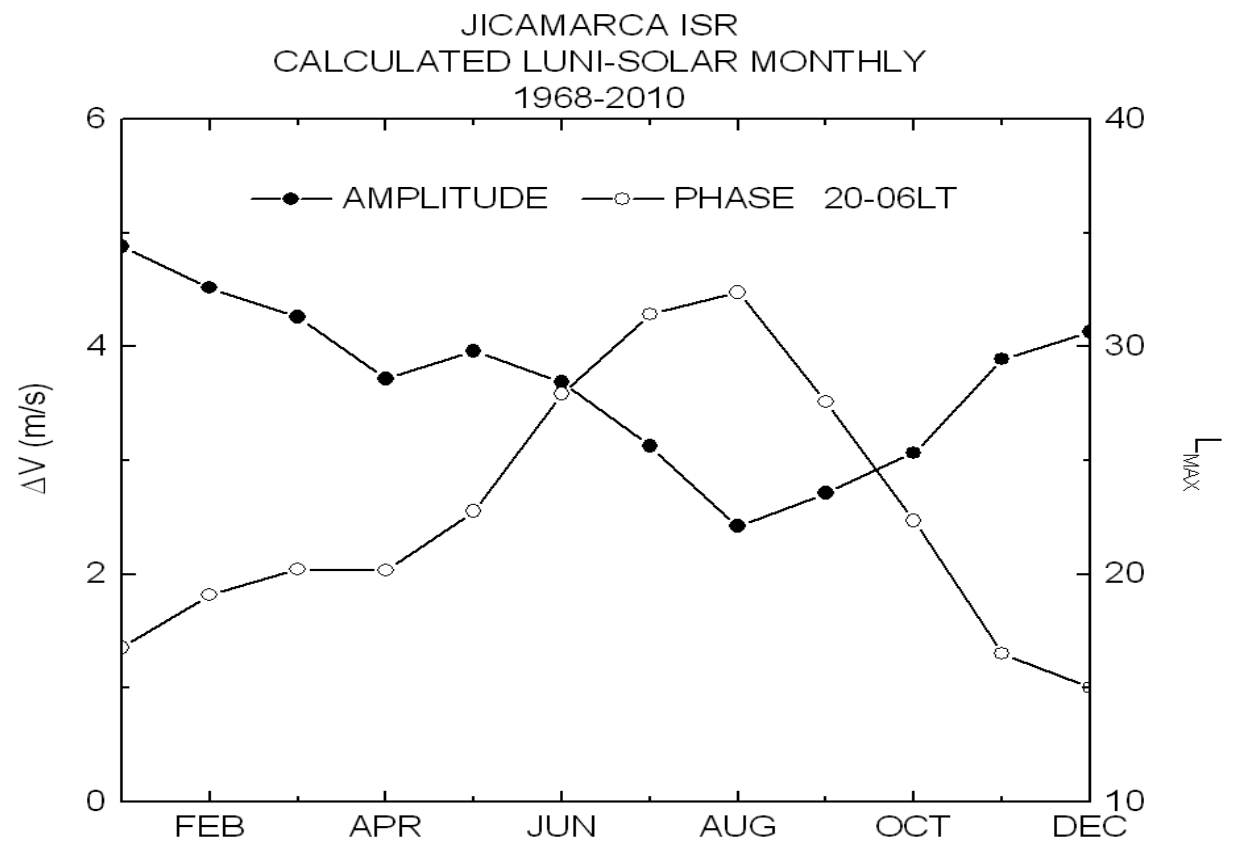

Figure 3-27. Bimonthly variation of the amplitudes and phases of nighttime (20-06 LT) maximum likelihood luni-solar monthly vertical perturbation drifts as derived from ISR data. 
the nighttime amplitudes derived here and the daytime semimonthly amplitudes derived earlier. Figure 3-28 shows the three-point smoothed average of the bimonthly lunar monthly and semimonthly amplitudes as a function of local time as derived from the ISR data. The monthly amplitude is larger during the night than at day, and only has moderate increases near dusk and dawn. The monthly amplitude is similar to the size of the semimonthly at night and about half of the size during the day.

Figure 3-29 shows good agreement between the bimonthly, monthly amplitudes as derived from ISR and JULIA and reasonable agreement between the phases except for

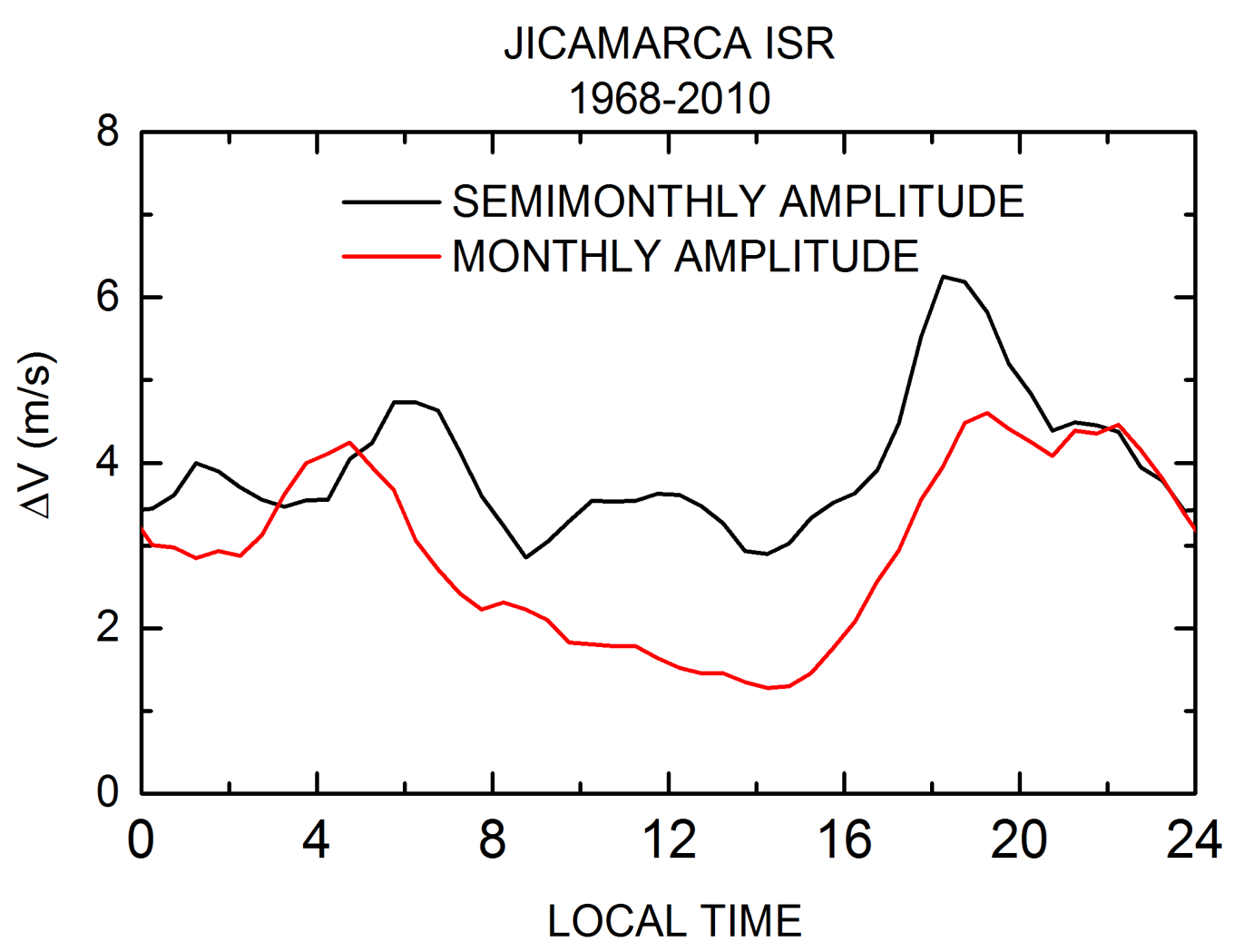

Figure 3-28. Local time variation of the average amplitudes of the luni-solar semimonthly and monthly perturbation drifts as derived from ISR data. These were found by computing the local time variation for each bimonthly period and then averaging the twelve bimonthly periods together. 


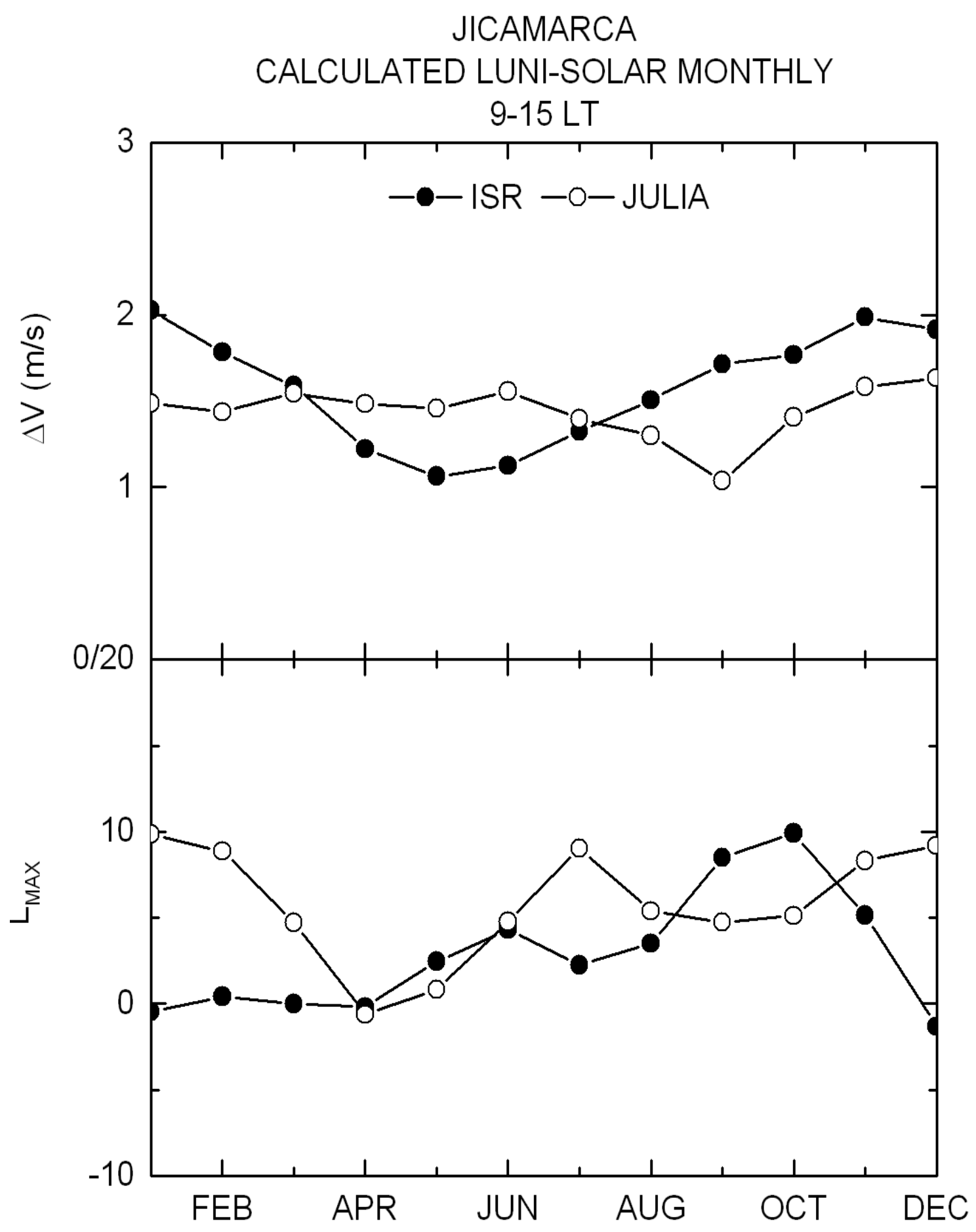

Figure 3-29. Comparison of the bimonthly variation of the amplitudes and phases of daytime (9-15 LT) maximum likelihood luni-solar monthly vertical perturbation drifts as derived from JULIA and ISR data. 
during December solstice. We believe the JULIA data to be more representative of the actual value.

\subsection{Lunar Tidal Effects During Sudden Stratospheric Warmings}

The low-latitude ionospheric response to sudden stratospheric warmings (SSWs) has been an area of extreme interest in recent years [e.g., Vineeth et al., 2009; Chau et al., 2009, 2010; Sridharan et al., 2009; Goncharenko et al., 2010a, b; Fejer et al., 2010, 2011; Yue et al., 2010; Rodrigues et al., 2011; Liu et al., 2011; Park et al., 2012; Yamazaki et al., 2012a, b]. These events are characterized by large-scale metereological changes in the winter polar atmosphere, driven by the rapid growth of upward propagating quasi-stationary planetary (Rossby) waves, rapid growth of waves from the polar troposphere, and their interaction with the mean circulation, that last for several days or even a few weeks [e.g., Matsuno, 1971; Andrews et al., 1987; Liu and Roble, 2002; Holton, 2004].

The initial studies on arctic SSW effects on the equatorial upper atmosphere found large, multiday mesospheric wind changes and afternoon reversals of the equatorial electrojet [e.g., Stening et al., 1996; Vineeth et al., 2009; Sridharan et al., 2009]. Chau et al. [2009] showed large daytime semidiurnal perturbations lasting for several days in the F-region vertical drift velocities over Jicamarca during the 2008 minor warming event. Similar velocity perturbations observed during following SSWs were associated with changes in low-latitude total electron content and peak electron densities [e.g., Goncharenko et al., 2010b; Chau et al., 2010; Yue et al., 2010]. Simulations using the TIME-GCM suggested observed velocity perturbations were due to large changes on the 
migrating and nonmigrating tides as a result of their nonlinear interaction with quasistationary planetary waves [Liu et al., 2010]. Fejer et al. [2010, 2011] pointed out these large semidiurnal electrodynamic perturbations shift to later local times with lunar age and suggested they result from strongly enhanced lunar semidiurnal tidal wave effects. Numerical simulations using the Whole Atmosphere Model (WAM) suggested initially the equatorial electrodynamic perturbations during the large 2009 SSW event were due to a large increase in the amplitude of the eight-hour terdiurnal low-atmospheric tide at the expense of the more typical semidiurnal tides [Fuller-Rowell et al., 2011].

Figure 3-30 shows the maximum likelihood lunar semimonthly drifts derived from the ISR data for November-February using the EM algorithm for periods with (bottom panel) and without (top panel) sudden stratospheric warmings. Figure 3-30 shows the semimonthly lunar tidal drifts associated with periods of SSW are much larger, but follow the same phase progression as the lunar tidal drifts from nonstratospheric warming periods. Figure 3-31 presents bihourly averaged Jicamarca daytime perturbation drifts, the climatological lunar semimonthly, the stratospheric temperatures at $10 \mathrm{hPa}$ (about 32 $\mathrm{km}$ ) over $90^{\circ} \mathrm{N}$, and zonally averaged zonal winds over $60^{\circ} \mathrm{N}$ winds during the $2010 \mathrm{SSW}$ event. In this case, the residual drifts data were obtained from incoherent scatter radar measurements up to the morning hours of February 4, and later from $150 \mathrm{~km}$ JULIA data; the stratospheric data were obtained from the National Center for Environmental Prediction (NCEP). In this period geomagnetic activity was low and the F10.7 index was about 80 . Figure 3-31 shows large quasi-two-day modulations on the vertical drifts, and enhanced multiday perturbations following closely the lunar semimonthly drifts after the 

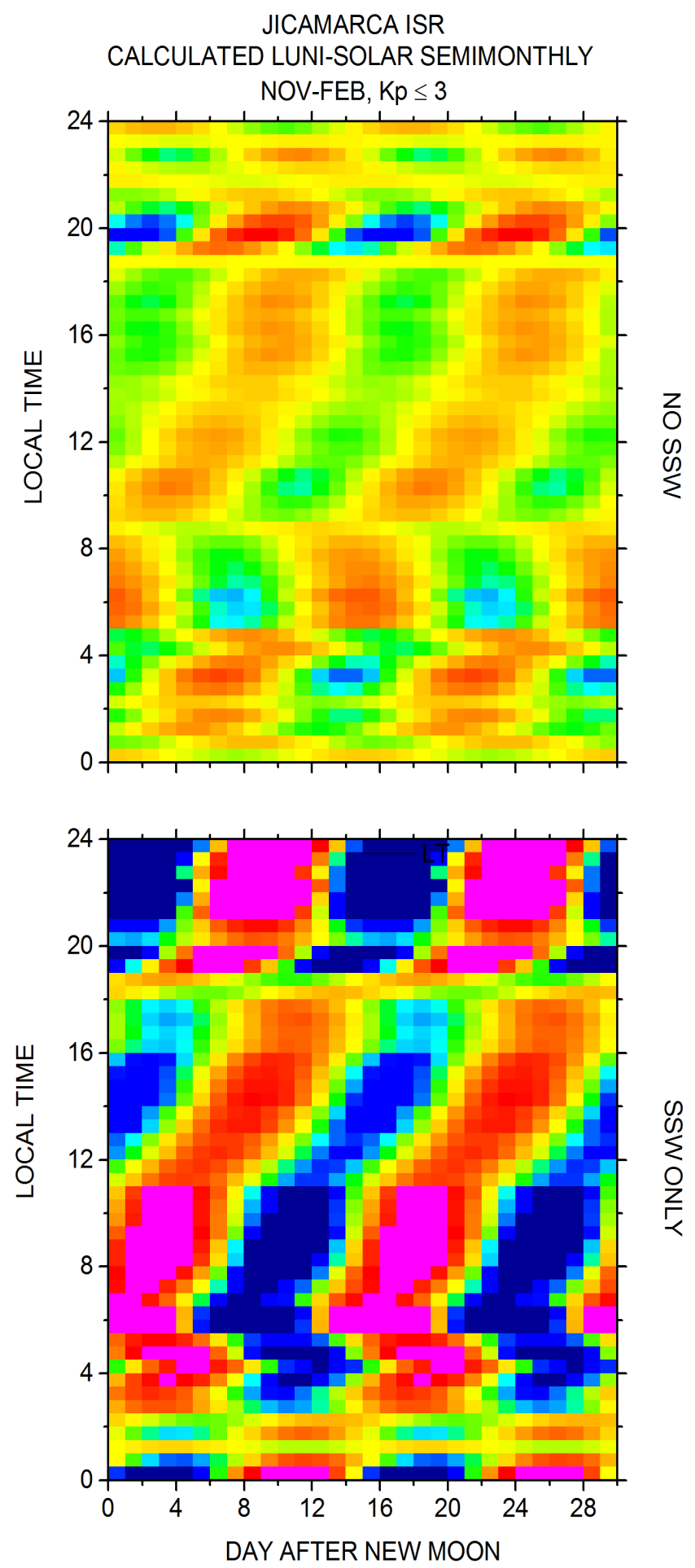

Figure 3-30. Day and nighttime maximum likelihood luni-solar semimonthly perturbation drifts as derived from ISR data for periods with (bottom panel) and without (top panel) ssw. 
warming onset. The onset of these large semimonthly perturbations occurs near new and full moon during northern winter warming periods. Early morning data in Figure 3-31 suggests the occurrence of an additional process, which downshifted the early morning perturbation drifts. Fejer et al. [2011] also reported largely enhanced lunar semimonthly vertical drift perturbations during other arctic winter low and high solar flux SSW events. This study suggested the amplitudes of the perturbation drifts are largest during early morning periods, as is the case for the lunar semimonthly drifts, and during low solar flux conditions.

Several more recent studies have presented ground-based and satellite measurements consistent with the suggestion enhanced lunar semidiurnal tidal effects play fundamentally important roles on low-latitude electrodynamic perturbations during SSW events [Liu et al., 2011; Park et al., 2012; Sumod et al., 2012; Yamazaki et al., 2012a, b].

Theoretical simulations showed the migrating lunar semidiurnal lunar tide is strongly enhanced during warmings [e.g. Stening et al., 1997]. Pedatella et al. [2012b] presented extensive Whole Atmosphere Community Climate Model (WACCM) simulations on the average mesosphere and lower thermosphere solar and lunar tidal response based on 23 moderate-to-strong SSWs. This study showed the changes in the equatorial vertical plasma drifts during solar maximum and minimum conditions SSWs are similar to observations only when the lunar tide is included in the simulations. The simulations also showed changes in the vertical drifts for solar minimum that were almost double those for solar maximum, which is consistent with the observations presented by Fejer et al. 


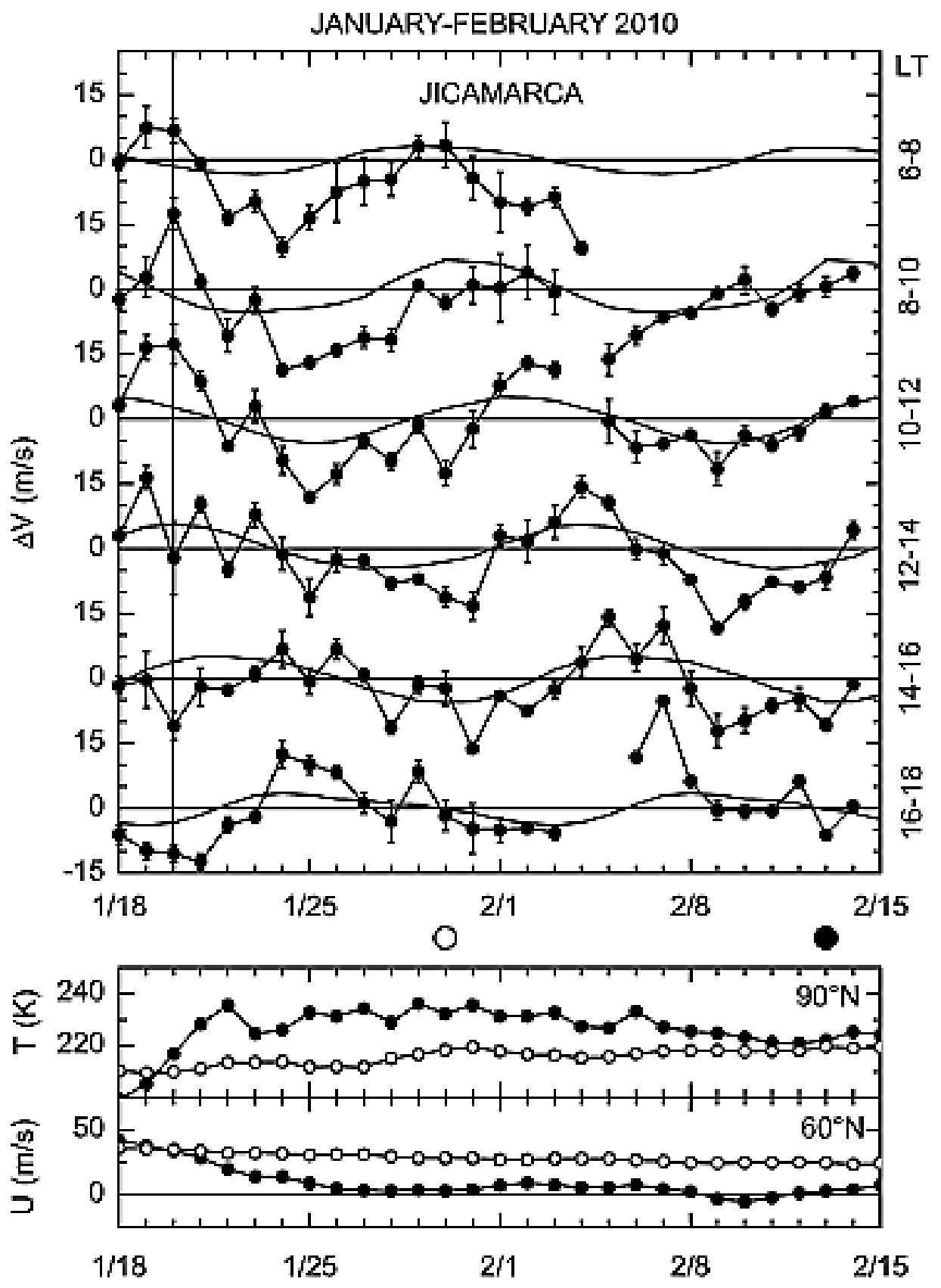

Figure 3-31. Jicamarca bimonthly averaged vertical plasma drift perturbations and highlatitude temperatures and winds during the 2010 SSW event. The smooth curves denote the climatological luni-solar semimonthly drifts. The closed and open circles below the top panel indicate the days of new and full moon, respectively. The vertical line indicates the SSW onset [after Fejer et al., 2011]. 
[2011]. Yamazaki et al. [2012b], on the other hand, did not find significant solar flux variation in the lunar tidal low-latitude magnetic field ionospheric response to SSWs.

Global studies of the low-latitude ionosphere during SSWs using ground-based and CHAMP satellite magnetic field measurements of the equatorial electrojet during arctic winter SSW events suggested the low-latitude ionospheric response varies with longitude [Fejer et al., 2010; Anderson and Araujo-Pradere, 2010]. Simulation studies indicate these SSW-induced changes in the vertical velocity occur at all longitudes with the largest perturbations in the 12-15 local time sector [Fang et al., 2012; Pedatella et al., 2012b].

SSW events are known to be much more common in the Northern than in the Southern Hemisphere due to the significantly stronger topographically forced planetary wave activity in the Northern Hemisphere [Holton, 2004]. The first recorded major Southern Hemisphere warming event occurred during September-October 2002. High-latitude middle atmosphere-mesosphere temperature perturbations during this warming were the subject of numerous experimental and model studies [Siskind et al., 2005; Coy et al., 2005; Liu and Roble, 2005]. Olson [2012] and Olson et al. [2013] presented the initial study on equatorial electrodynamic effects during this SSW event using magnetic field measurements from ground-based stations in Peru and from the CHAMP satellite. This study suggests multiday electrodynamic perturbations resembling those typically observed during Northern Hemisphere warming events occur in response to Southern Hemisphere equinoctial, but not to June solstice, events. These results further suggest the relationship between SSW events and enhanced lunar semidiurnal tidal effects as lunar semidiurnal tide effects are significantly larger during equinox than during June solstice. 


\subsection{Equatorial Spread F Short-Term Variability}

The solar cycle, season, longitude, and geomagnetic activity-dependent climatology of equatorial spread $\mathrm{F}$ has been fairly well understood for over two decades, but only modest progress has been made on the understanding and forecasting of its variability, especially under geomagnetically quiet conditions. Aveiro and Hysell [2010] used about 1500 nights of JULIA data to determine the climatology of spread F, its persistence (i.e., one-day lag correlation), and correlation with the phase of the moon. This analysis indicated during low geomagnetic activity and moderate solar flux equinoctial periods when the mean occurrence rate is about $50 \%$, the occurrence of premidnight topside spread F over Jicamarca follows the occurrence of the previous day $65 \%$ of the time. The correlations of day-to-day occurrences were negligible during the solstices and very small in the postmidnight sector for all seasons. Aveiro and Hysell [2010] also showed a high correlation between lunar phase and premidnight spread F occurrence during December solstice high solar flux quiet $(\mathrm{Kp}<4)$ conditions, with highest probability of occurrence close to full moon. This correlation was negligible at moderate and low solar flux values and other seasons. We have derived a similar relationship between the occurrence of strong spread F and lunar age using November-February incoherent scatter and JULIA data from 1968 to 2010. It is well known the evening height of the equatorial $\mathrm{F}$ layer (controlled by the vertical plasma drift velocity) plays a fundamental role in generation and evolution of spread F [e.g., Fejer et al., 1999]. Figure 3-32 compares the average vertical drifts during November-February centered over Jicamarca around the quarter moons, derived from the ROCSAT-1 data and the ISR data. Figure 3-32 clearly shows 
lunar monthly perturbation effects that are particularly large near sunset, which are consistent with a higher occurrence of strong and topside spread F following a full moon. The ROCSAT-1 daytime data shown in Figure 3-32 is in good agreement with the JULIA data shown above. In spite of the limitations mentioned earlier and the discrepancy in the daytime data, the Jicamarca incoherent scatter radar measurements suggest a similar relationship between the early night average vertical drifts as the ROCSAT-1 data.

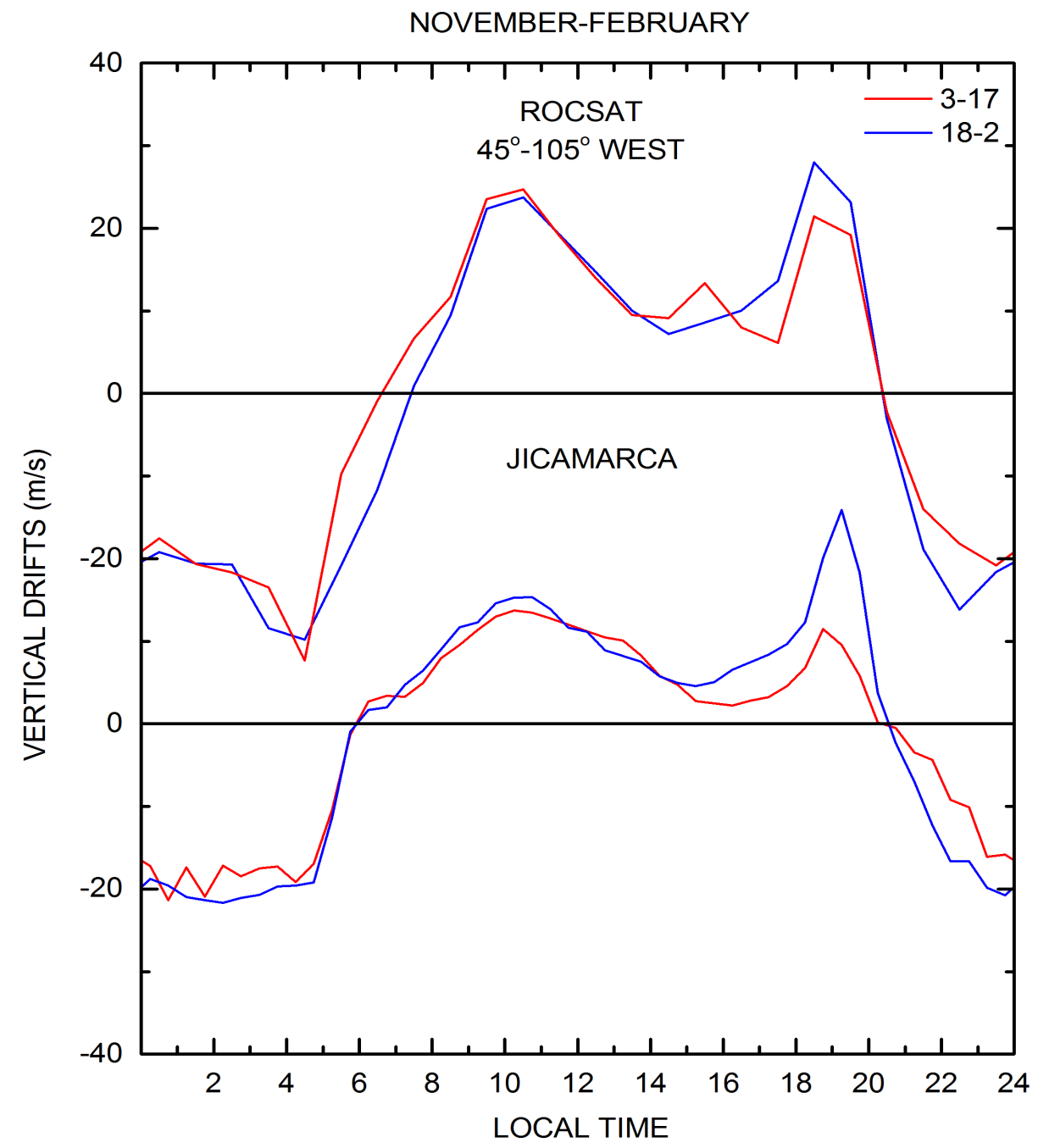

Figure 3-32. Average vertical plasma drifts (positive upward) derived from ROCSAT-1 (top panel) and ISR (bottom panel) measurements for periods starting close to the new and full moons, 3-17 and 18-2 days after the new moon, respectively. 


\section{CHAPTER 4}

\section{CONCLUSIONS}

We have discussed some recent results on the quiet-time variability of equatorial electrodynamic effects measured over Jicamarca. Our data confirm the importance of lunar semimonthly and monthly tidal effects on the equatorial vertical plasma drifts, which have been largely ignored in past studies. Lunar semimonthly effects are most important during December solstice when they significantly modulate the vertical plasma drifts and undergo large enhancements in response to SSW events. We have shown lunar monthly tidal effects can be easily detected, not only during the day, as suggested in earlier studies, but also in the early night period during December solstice when they modulate the occurrence of topside and strong equatorial spread $\mathrm{F}$.

This chapter summarizes our main results and also presents suggestions for future work.

\subsection{Summary of Results}

Vertical ion drift velocity data from Jicamarca have been analyzed for a lunar semimonthly tide using a maximum likelihood fitting method. Daytime (9-15LT) amplitudes range from $4 \mathrm{~m} / \mathrm{s}$ during November-April to $2 \mathrm{~m} / \mathrm{s}$ during June-September. Nighttime amplitudes are about $4 \mathrm{~m} / \mathrm{s}$, being slightly smaller during both equinoxes. The semimonthly amplitude decreases from morning to afternoon, has a large increase around dusk, and is fairly constant throughout the night. Phase progression as a function of local time was studied in detail for the first time. We confirmed the phase shift between day 
and night (about 5LT and 19LT) and pointed out the s-shaped curve of the daytime lunar semimonthly perturbation drifts. Further, we found the phase progression to be seasonally dependent, being steepest in June solstice. Some bimonthly periods that are commonly combined for seasonal studies have been found to have significant differences in their lunar tidal effects, such as March-April and September-October.

Vertical ion drift velocity data from Jicamarca have also been analyzed for a lunar monthly tide using a maximum likelihood fitting method. Daytime (9-15LT) amplitudes are about $1.5 \mathrm{~m} / \mathrm{s}$ throughout the year. Nighttime monthly amplitudes range from $5 \mathrm{~m} / \mathrm{s}$ during June solstice to $3 \mathrm{~m} / \mathrm{s}$ during autumn equinox. The diurnal amplitude decreases from morning to afternoon and evening to morning with slight increases at dusk and dawn. Phase progression as a function of local time has also been analyzed. Negative and positive slopes have been found that are local time and bimonthly dependent. The slopes are steepest during June solstice and often negative near dusk and dawn. There are large phase shifts around dusk, dawn, and 14LT for several bimonthly periods.

\subsection{Suggestions for Future Work}

We have shown the luni-solar monthly lunar tide phase progression has similarities to the phase progression of the luni-solar semimonthly lunar tide. Both of these experience large phase shifts near dusk and dawn and deviate slightly from the expected linear slope. We suggest further studies of the dependence of the phase of the lunar tidal effects on solar flux, conductivity, and altitude to help quantify the origin of these phase shifts. We further suggest modeling efforts of equatorial vertical plasma drifts that include lunar tidal coupling with other atmospheric tides to explain the local time 
dependence of the phase progression.

We have also shown the amplitudes of lunar monthly vertical drift modulation effects are similar in size to the semimonthly effects at night, and can significantly contribute to the development of ESF. The understanding of these important effects warrants detailed theoretical and modeling studies of the complex processes involved. We suggest modeling studies of the possible sources of a luni-solar lunar monthly tide.

We focused solely on lunar tidal effects on the vertical drifts in the Peruvian sector of the ionosphere. Preliminary studies using other databases have shown lunar tides to have longitude- and latitude-dependent effects and to be present in zonal drifts. We suggest similar studies to discover the lunar tidal effects on zonal drifts and the vertical and zonal lunar tidal perturbation drifts latitude and longitude dependence.

We have shown the lunar tide can be a significant portion of the quiet-time variability of the vertical drifts. We suggest an updated empirical model to take this variability into account since this would lead to highly improved low-latitude ionospheric forecast models. 


\section{REFERENCES}

Abdu, M. A., T. Maruyama, I. S. Batista, S. Saito, and M. Nakamura (2007), Ionospheric responses to the October 2003 superstorm: Longitude/local time effects over equatorial low and middle latitudes, J. Geophys. Res., 112, A10306, doi: $10.1029 / 2006$ JA012228.

Alken, P. (2009), A quiet time empirical model of equatorial vertical plasma drift in the Peruvian sector based on $150 \mathrm{~km}$ echoes, J. Geophys. Res., 114, A02308, doi:10.1029/2008JA013751.

Anderson, D., and E. A. Araujo-Pradere (2010), Sudden stratospheric warming event signatures in daytime ExB drift velocities in the Peruvian and Philippine longitude sectors for January 2003 and 2004, J. Geophys. Res., 115, A00G05, doi:10.1029/2010JA015337.

Anderson, D., A. Anghel, K. Yumoto, M. Ishitsuka, and E. Kudeki (2002), Estimating daytime vertical ExB drift velocities in the equatorial F-region using groundbased magnetometer observations, Geophys. Res. Lett., 29(12), 1596, doi:10.1029/2001GL014562.

Andrews, D. G., J. R. Holton, and C. B. Leovy (1987), Middle Atmosphere Dynamics, Academic, San Diego, Calif.

Aveiro, H. C., and D. L. Hysell (2010), Forecast assessment of topside spread F at Jicamarca, J. Geophys. Res., 115, A12331, doi:10.1029/2010JA015990.

Bartels, J., and H. F. Johnston (1940), Geomagnetic tides in horizontal intensity at Huancayo, Terr. Magn. Atmos. Electr., 45(3), 269-308, doi:10.1029/TE045i003p00269.

Batista, I. S., R. T. deMedeiros, M. A. Abdu, J. R. deSouza, G. J. Bailey, and E. R. dePaula (1996), Equatorial ionospheric vertical plasma drift model over the Brazilian region, J. Geophys. Res., 101(A5), 10887-10892, doi:10.1029/95JA03833.

Bertoni, F., I. S. Batista, M. A. Abdu, B. W. Reinisch, and E. A. Kherani (2006), A comparison of ionospheric vertical drift velocities measured by Digisonde and incoherent scatter radar at the magnetic equator, J. Atmos. Sol. Terr. Phys., 68, 669-678, doi:10.1016/j.jastp.2006.01.002.

Chapman, S., and J. Bartels (1940), Geomagnetism, VII, Clarendon, Oxford, U.K. 
Chapman, S., and R. S. Lindzen (1970), Atmospheric Tides: Thermal and Gravitational, Gordon and Breach, New York, N.Y.

Chau, J. L., and R. F. Woodman (2004), Daytime vertical and zonal velocities from 150km echoes: Their relevance to F region dynamics, Geophys. Res. Lett., 31, L17801, doi:10.1029/2004GL020800.

Chau, J. L., B. G. Fejer, and L. P. Goncharenko (2009), Quiet variability of equatorial E x B drifts during a stratospheric warming event, Geophys. Res. Lett., 36, L05101, doi:10.1029/2008GL036785.

Chau, J. L., N. A. Aponte, E. Cabassa, M. P. Sulzer, L. P. Goncharenko, and S. A. González (2010), Quiet time ionospheric variability over Arecibo during sudden stratospheric warming events, J. Geophys. Res., 115, A00G06, doi: $10.1029 / 2010 \mathrm{JA} 015378$.

Coley, W. R., and R. A. Heelis (1989), Low-latitude zonal and vertical ion drifts seen by DE-2, 1989, J. Geophys. Res., 94(A6), 6751-6761, doi:10.1029/JA004iA06p06751.

Coley, W. R., J. P. McClure, and W. B. Hanson (1990), Equatorial fountain effect and dynamo drift signatures from AE-E observations, J. Geophys. Res., 95(A12), 21285-21290, doi:10.1029/JA095iA12p21285.

Coy, L., D. Siskind, S. D. Ekermann, J. P. McCormack, D. R. Allen, and T. F. Hogan (2005), Modeling the August 2002 minor warming event, Geophys. Res. Lett., 32, L07808, doi:10.1029/2005GL022400.

Dempster, A. P., N. M. Laird, and D. B. Rubin (1977), Maximum likelihood from incomplete data via the EM algorithm, J. R. Stat. Soc., Ser. B, 39, 1-38.

Eccles, V., D. D. Rice, J. J. Sojka, C. E. Valladares, T. Bullett, and J. L. Chau (2011), Lunar atmospheric tidal effects in the plasma drifts observed by the low-latitude ionospheric sensor network, J. Geophys. Res., 116, A07309, doi: $10.1029 / 2010 \mathrm{JA} 016282$.

Fang, T. W., A. D. Richmond, J. Y. Liu, and A. Maute (2008), Wind dynamo effects on ground magnetic perturbations and vertical drifts, J. Geophys. Res., 113, A11313, doi: $10.1029 / 2008 \mathrm{JA} 013513$.

Fang, T.-W., H. Kil, G. Millward, A. D. Richmond, J.-Y. Liu, and S.-J. Oh (2009), Causal link of the wave-4 structures in plasma density and vertical plasma drift in the low-latitude ionosphere, J. Geophys. Res., 114, A10315, doi: $10.1029 / 2009$ JA014460. 
Fang, T.-W., T. Fuller-Rowell, R. Akmaev, F. Wu, H. Wang, and D. Anderson (2012), Longitudinal variation of ionospheric vertical drifts during the 2009 sudden stratospheric warming, J. Geophys. Res., 117, A03324, doi:10.1029/2011JA017348.

Fejer, B. G. (1997), The electrodynamics of the low-latitude ionosphere: Recent results and future challenges, J. Atmos. Sol. Terr. Phys., 59, 1465-1482, doi:10.1016/S1364-6826(96)00149-6.

Fejer, B. G. (2011), Low latitude ionospheric electrodynamics, Space Sci. Rev., 158(1), 145-166, doi:10.107/s11214-010-9690-7.

Fejer, B. G., and L. Scherliess (2001), On the variability of equatorial F region vertical plasma drifts, Atmos. Sol. Terr. Phys., 63, 893-897.

Fejer, B. G., and B. D. Tracy (2013), Lunar tidal effects in the electrodynamics of the low latitude ionosphere, J. Atmos. Sol. Terr. Phys., article in press. http://dx.doi.org/10.1016/j.jastp.2013.01.008.

Fejer, B. G., E. R. de Paula, S. A. Gonzales, and R. F. Woodman (1991), Average vertical and zonal F region plasma drifts over Jicamarca, J. Geophys. Res., 96(A8), 13901-13906, doi:10.1029/91JA01171.

Fejer, B. G., E. R. de Paula, R. A. Heelis, and W. B. Hanson (1995), Global equatorial ionospheric vertical plasma drifts measured by the AE-E satellite, J. Geophys. Res., 100(A4), 5769-5776.

Fejer, B. G., L. Scherliess, and E. R. de Paula (1999), Effects of the vertical plasma drift velocity on the generation and evolution of equatorial spread F, J. Geophys. Res., 104(A9), 19,859-19,869.

Fejer, B. G., J. R. Souza, A. S. Santos, and A. E. Costa Pereira (2005), Climatology of $F$ region zonal plasma drifts over Jicamarca, J. Geophys. Res., 110, A12310, doi:10.1029/2005JA011324.

Fejer, B. G., J. W. Jensen, and S.-Y. Su (2008), Quiet time equatorial $F$ region vertical plasma drift model derived from ROCSAT-1 observations, J. Geophys. Res., 113, A05304, doi:10.1029/2007JA012801.

Fejer, B. G., M. E. Olson, J. L. Chau, C. Stolle, H. Lühr, L. P. Goncharenko, K. Yumoto, and T. Nagatsuma (2010), Lunar-dependent equatorial ionospheric electrodynamic effects during sudden stratospheric warmings, J. Geophys. Res., 115, A00G03, doi:10.1029/2010JA015273. 
Fejer, B. G., B. D. Tracy, M. E. Olson, and J. L. Chau (2011), Enhanced lunar semidiurnal equatorial vertical plasma drifts during sudden stratospheric warmings, Geophys. Res. Lett., 38, L21104, doi:10.1029/2011GL049788.

Fejer, B. G., B. D. Tracy, and R. F. Pfaff (2013), Equatorial Zonal Plasma Drifts Measured by the C/NOFS Satellite During the 2008-2011 Solar Minimum, $J$. Geophys. Res., 118, doi:10.1002/jgra.50382.

Fesen, C. G., G. Crowley, R. G. Roble, A. D. Richmond, and B. G. Fejer (2000), Simulation of the pre reversal enhancement in the low latitude vertical ion drifts, Geophys. Res. Lett., 27(13), 1851-1854.

Fuller-Rowell, T., H. Wang, R. Akmaev, F. Wu, T.-W. Fang, M. Iredell, and A. Richmond (2011), Forecasting the dynamic and electrodynamic response to the January 2009 sudden stratospheric warming, Geophys. Res. Lett., 38, L13102, doi:10.1029/2011GL047732.

Goncharenko, L., J. Chau, H.-L. Liu, and A. J. Coster (2010a), Unexpected connections between the stratosphere and ionosphere, Geophys. Res. Lett., 37, L10101, doi:10.1029/2010GL043125.

Goncharenko, L. P., A. J. Coster, J. L. Chau, and C. E. Valladares (2010b), Impact of sudden stratospheric warmings on equatorial ionization anomaly, J. Geophys. Res., 115, A00G07, doi:10.1029/2010JA015400.

Hagan, M. E., and J. M. Forbes (2002), Migrating and nonmigrating diurnal tides in the middle and upper atmosphere excited by tropospheric latent heat release, $J$. Geophys. Res., 107(D24), 4754, doi:10.1029/2001JD001236.

Hagan, M. E., and J. M. Forbes (2003), Migrating and nonmigrating semidiurnal tides in the middle and upper atmosphere excited by tropospheric latent heat release, $J$. Geophys. Res., 108(A2), 1062, doi:10.1029/2002JA009466.

Hagan, M. E., A. Maute, R. G. Roble, A. D. Richmond, T. J. Immel, and S. L. England (2007), Connections between deep tropical clouds and the Earth's ionosphere, Geophys. Res. Lett., 34, L20109, doi:10.1029/2007GL030142.

Hartman, W. A., and R. A. Heelis (2007), Longitudinal variations in the equatorial vertical drift in the topside ionosphere, J. Geophys. Res., 112, A03305, doi:10.1029/2006JA011773.

Holton, J. R. (2004), An Introduction to Dynamic Meteorology, Elsevier Academic Press, New York, N.Y. 
Huang, C.-S., F. J. Rich, O. de La Beaujardiere, and R. A. Heelis (2010), Longitudinal and seasonal variations of the equatorial ionospheric ion density and eastward drift velocity in the dusk sector, J. Geophys. Res., 115, A02305, doi:10.1029/2009JA014503.

Huang, C. Y., P. A. Roddy, E. K. Sutton, R. Stoneback, R. F. Pfaff, L. C. Gentile, and S. H. Delay (2012), Ion-Neutral coupling during deep solar minimum, J. Atmos. Sol. Terr. Phys., http:dx.doi.org/10.1016/j.jastp.2012.11.009.

Huba, J. D., G. Joyce, and J. A. Fedder (2000), Sami2 is another model of the ionosphere (SAMI2): A new low-latitude ionosphere model, J. Geophys. Res., 105(A10), 23035-23053, doi:10.1029/2000JA000035.

Huba, J. D., G. Joyce, S. Sazykin, R. Wolf, and R. Spiro (2005), Simulation study of penetration electric field effects on the low- to mid-latitude ionosphere, Geophys. Res. Lett., 32, L23101, doi:10.1029/2005GL024162.

Immel, T. J., E. Sagawa, S. L. England, S. B. Henderson, M. E. Hagan, S. B. Mende, H. U. Frey, C. M. Swenson, and L. J. Paxton (2006), Control of equatorial ionospheric morphology by atmospheric tides, Geophys. Res. Lett., 33, L15108, doi:10.1029/2006GL026161.

Jensen, J. W., and B. G. Fejer (2007), Longitudinal dependence of middle and low latitude zonal plasma drifts measured by DE-2, Ann. Geophys., 25, 2551-2559.

Kelley, M. C. (2009), The Earths Ionosphere; Plasma Physics and Electrodynamics, Academic Press, New York, N.Y.

Kil, H., E. R. Talaat, S.-J. Oh, L. J. Paxton, S. L. England, and S.-J. Su (2008), Wave structures of the plasma density and vertical $\mathbf{E} \times \mathbf{B}$ drift in low-latitude $\mathrm{F}$ region, J. Geophys. Res., 113, A09312, doi:10.1029/2008JA013106.

Kudeki, E., and C. D. Fawcett (1993), High resolution observations of $150 \mathrm{~km}$ echoes at Jicamarca, Geophys. Res. Lett., 20, 1987-1990, doi:10.1029/93GL01256.

Liu, H.-L., and R. G. Roble (2002), A study of a self-generated stratospheric sudden warming and its mesospheric-lower thermospheric impacts using the coupled TIME-GCM/CCM3, J. Geophys. Res., 107(D23), 4695, doi:10.1029/2001JD001533.

Liu, H.-L., and R. G. Roble (2005), Dynamical coupling of the stratosphere and mesosphere in the 2002 Southern Hemisphere major stratospheric sudden warming, Geophys. Res. Lett., 32, L13804, doi:10.1029/2005GL022939. 
Liu, H.-L., W. Wang, A. D. Richmond, and R. G. Roble (2010), Ionospheric variability due to planetary waves and tides for solar minimum conditions, J. Geophys. Res., 115, A00G01, doi:10.1029/2009JA015188.

Liu, H., M. Yamamoto, S. Tulasi Ram, T. Tsugawa, Y. Otsuka, C. Stolle, E. Doornbos, K. Yumoto, and T. Nagatsuma (2011), Equatorial electrodynamics and neutral background in the Asian sector during the 2009 stratospheric sudden warming, $J$. Geophys. Res., 116, A08308, doi:10.1029/2011JA016607.

Lühr, H., T. A. Siddiqui, and S. Maus (2012), Global characteristics of the lunar tidal modulation of the equatorial electrojet derived from CHAMP observations, Ann. Geophys., 30, 527-536, doi:10.5194/angeo-30-527-2012.

Maruyama, N., S. Sazykin, R. W. Spiro, D. Anderson, A. Anghel, R. A. Wolf, F. R. Toffoletto, T. J. Fuller-Rowell, M. V. Codrescu, A. D. Richmond, and G.H. Millward (2007), Modeling storm-time electrodynamics of the low-latitude ionosphere-thermosphere system: Can long lasting disturbance electric fields be accounted for? J. Atmos. Sol. Terr. Phys., 69, 1182-1199.

Matsuno, T. (1971), A dynamical model of the stratospheric sudden warming, J. Atmos. Sci., 28, 1479-1494.

Matsushita, S. (1967), Solar quiet and lunar daily variation fields, in Physics of Geomagnetic Phenomena, edited by S. Matsushita and W. Campbell, pp. 301424, Academic, New York, N.Y.

Maynard, N. C., T. L. Aggson, F. A. Herrero, M. C. Liebracht, and J. L. Saba (1995), Average equatorial zonal and vertical ion drifts determined from San Marco D electric field measurements, J. Geophys. Res., 100(A9), 17,465-17,479.

Millward, C. G., I. C. F. Muller-Wodarg, A. D. Aylward, T. J. Fuller-Rowell, A. D. Richmond, and R. J. Moffet (2001), An investigation into the influence of tidal forcing on $\mathrm{F}$ region equatorial vertical ion drift using a global ionospherethermosphere model with coupled electrodynamics, J. Geophys. Res., 106(A11), 24,733-24,744.

Moon, T. K., and W. C. Stirling (2000), Mathematical Methods and Algorithms for Signal Processing, Prentice Hall, Upper Saddle River, N.J.

Oberheide, J., Q. Wu, T. L. Killeen, M. E. Hagan, and R. G. Roble (2006), Diurnal nonmigrating tides from TIMED Doppler Interferometer wind data: Monthly climatologies and seasonal variations, J. Geophys. Res., 111, A10S03, doi:10.1029/2005JA011491. 
Olson, M.E. (2012), Variations of equatorial electrodynamics during sudden stratospheric warming events, Ph.D. dissertation, Utah State University, Logan, Utah.

Olson, M. E., B. G. Fejer, C. Stolle, H. Lühr, and J. L. Chau (2013), Equatorial ionospheric electrodynamic perturbations during Southern Hemisphere stratospheric warming events, J. Geophys. Res. Space Physics, 118, 1190-1195, doi:10.1002/jgra.50142.

Parish, H. F., J. M. Forbes, and F. Kamalabadi (1994), Planetary wave and solar emission signatures in the equatorial electrojet, J. Geophys. Res., 99(A1), 355-368, doi:10.1029/93JA02096.

Park, J., H. Lühr, M. Kunze, B. G. Fejer, and K. W. Min (2012), Effect of sudden stratospheric warming on lunar tidal modulation of the equatorial electrojet, $J$. Geophys. Res., 117, A03306, doi:10.1029/2011JA017351.

Pedatella, N. M., and J. M. Forbes (2010), Global structure of the lunar tide in the ionospheric total electron content, Geophys. Res. Lett., 37, L06103, doi:10.1029/2010GL042781.

Pedatella, N. M., H.-L. Liu, and A. D. Richmond (2012a), Atmospheric semidiurnal lunar tide climatology simulated by the whole atmosphere community climate model, J. Geophys. Res., 117, A06327, doi:10.1029/2012JA017792.

Pedatella, N. M., H.-L. Liu, A. D. Richmond, A. Maute, and T.-W. Fang (2012b), Simulations of solar and lunar tidal variability in the mesosphere and lower thermosphere during sudden stratosphere warmings and their influence on the low-latitude ionosphere, J. Geophys. Res., 117, A08326, doi: $10.1029 / 2012$ JA017858.

Rastogi, R. G. (1974), Lunar effects in the counter electrojet near the magnetic equator, $J$. Atmos. Terr. Phys., 36, 167-170.

Rastogi, R. G., and N. B. Trivedi (1970), Luni-solar tides in H at stations within the equatorial electrojet, Planet. Space Sci., 18(3), 367-377.

Richmond, A. D. (1995a), The ionospheric wind dynamo: Effects of its coupling with different atmospheric regions, in The Upper Mesosphere and Lower Thermosphere: A Review of Experiment and Theory, Geophys. Monogr. Ser., vol. 87, edited by R. M. Johnson and T. L. Killeen, pp. 49-65, AGU, Washington, D.C.

Richmond, A. D. (1995b), Ionospheric electrodynamics, in Handbook of Atmospheric 
Electrodynamics, vol. 2, edited by H. Volland, pp. 249-290, CRC Press, Boca Raton, Fla.

Richmond, A. D., C. Peymirat, and R. G. Roble (2003), Long-lasting disturbances in the equatorial ionospheric electric field simulated with a coupled magnetosphereionosphere-thermosphere model, J. Geophys. Res., 108, 1118, doi:10.1029/2002JA009758, A3.

Rodrigues, F. S., G. Crowley, S. M. I. Azeem, and R. A. Heelis (2011), C/NOFS observations of the equatorial ionospheric electric field response to the 2009 major sudden stratospheric warming event, J. Geophys. Res., 116, A09316, doi:10.1029/2011JA016660.

Sagawa, E., T. J. Immel, H. U. Frey, and S. B. Mende (2005), Longitudinal structure of the equatorial anomaly in the nighttime ionosphere observed by IMAGE/FUV, $J$. Geophys. Res., 110, A11302, doi:10.1029/2004JA010848.

Sastri, J. H. (1996), Longitudinal dependence of equatorial F region vertical plasma drifts in the dusk sector, J. Geophys. Res., 101(A2), 2445-2452, doi: $10.1029 / 95 \mathrm{JA} 02759$.

Scherliess, L., and B. G. Fejer (1999), Radar and satellite global equatorial F-region vertical drift model, J. Geophys. Res., 104(A4), 6829-6842.

Scherliess, L., R. W. Schunk, J. J. Sojka, and D. C. Thompson (2004), Development of a physics-based reduced state Kalman filter for the ionosphere, Radio Sci., 39, RS1S04, doi:10.1029/2002RS002797.

Scherliess, L., R. W. Schunk, J. J. Sojka, D. C. Thompson, and L. Zhu (2006), Utah State University Global Assimilation of Ionospheric Measurements Gauss-Markov Kalman filter model of the ionosphere: Model description and validation, $J$. Geophys. Res., 111, A11315, doi:10.1029/2006JA011712.

Scherliess, L., D. C. Thompson, and R. W. Schunk (2008), Longitudinal variability of low-latitude total electron content: Tidal influences, J. Geophys. Res., 113, A01311, doi:10.1029/2007JA012480.

Schunk, R. W., and A. F. Nagy (2009), Ionospheres: Physics, Plasma Physics, and Chemistry, Cambridge University Press, Cambridge, U.K.

Schunk, R. W., L. Scherliess, and J. J. Sojka (2002), Ionospheric Specification and Forecast Modeling, Journal of Spacecraft and Rockets, 39(2), pp. 314-324, doi: $10.2514 / 2.3815$. 
Schwiderski, E. W. (1979), Global Ocean Tides, II, The semidiurnal principal lunar tide $\left(\mathrm{M}_{2}\right)$, atlas of tidal charts and maps Rep. NSWC TR 79-414, 87 Nav. Surface Weapons Cent., Silver Spring, Va.

Siskind, D. E., L. Coy, and R. Espy (2005), Observations of stratospheric warmings and mesospheric coolings by the TIMED SABER instrument, Geophys. Res. Lett., 32, L09804, doi:10.1029/2005GL022399.

Sridharan, S., S. Sathishkumar, and S. Gurubaran (2009), Variabilities of mesospheric tides and equatorial electrojet strength during major stratospheric warming events, Ann. Geophys., 27, 4125-4130.

Stening, R. J. (1989), A diurnal modulation of the lunar tide in the upper atmosphere, Geophys. Res. Lett., 16, 307-310, doi:10.1029/GL016i004p00307.

Stening, R. J. (2011), Lunar tide in the equatorial electrojet in relation to stratospheric warmings, J. Geophys. Res., 116, A12315, doi:10.1029/2011JA017047.

Stening, R. J., and B. G. Fejer (2001), Lunar tide in the equatorial F region vertical ion drift velocity, J. Geophys. Res., 106(A1), 221-226, doi:10.1029/2000JA000175.

Stening, R. J., C. E. Meek, and A. H. Manson (1996), Upper atmosphere wind system during reverse equatorial electrojet events, Geophys. Res. Lett., 23, 3243-3246, doi:10.1029/96GL02611.

Stening, R. J., J. M. Forbes, M. E. Hagan, and A. D. Richmond (1997), Experiments with lunar atmospheric tidal model, J. Geophys. Res., 102, 13,465-13,471, doi:10.1029/97JD00778.

Sumod, S. G., T. K. Pant, L. Jose, M. M. Hossain, and K. K. Kumar (2012), Signatures of sudden stratospheric warming on the equatorial ionosphere-thermosphere system. Planetary and Space Sci., 63, 49-55.

Tarpley, J. D., and B. B. Balsley (1972), Lunar variations in the Peruvian electrojet, J. Geophys. Res., 77, 1951-1958.

Vial, F., and J. M. Forbes (1994), Monthly simulations of the lunar semi-diurnal tide, J. Atmos. Terr. Phys., 56, 1591-1607.

Vichare, G., and A. D. Richmond (2005), Simulation study of the longitudinal variation of the evening vertical ionospheric drifts at the magnetic equator during equinox, J. Geophys. Res., 110, A05304, doi:10.1029/2004JA010720.

Vineeth, C., T. K. Pant, and R. Sridharan (2009), Equatorial counter electrojets and 
polar stratospheric sudden warmings: A classical example of high latitude-low latitude coupling? Ann. Geophys., 27, 3147-3153.

Woodman, R. F. (1970), Vertical drift velocities and east-west electric fields at the magnetic equator, J. Geophys. Res., 75(31), 6249-6259, doi:10.1029/JA075i031p06249.

Woodman, R. F. (1972), East-west ionospheric drifts at the magnetic equator, Space Res., 12, 969-974.

Wu, C. F. J. (1983), On the convergence properties of the EM algorithm, Ann. Statist., 11(1),95-103.

Yamazaki, Y., A. D. Richmond, and K. Yumoto (2012a), Stratospheric warmings and the geomagnetic lunar tide: 1958-2007, J. Geophys. Res., 117, A04301, doi:10.1029/2012JA017514.

Yamazaki, Y., K. Yumoto, D. McNamara, T. Hirooka, T. Uozumi, K. Kitamura, S. Abe, and A. Ikeda (2012b), Ionospheric current system during sudden stratospheric warming events, J. Geophys. Res., 117, A03334, doi:10.1029/2011JA017453.

Yue, X., W. S. Schreiner, J. Lei, C. Rocken, D. C. Hunt, Y.-H. Kuo, and W. Wan (2010), Global ionospheric response observed by COSMIC satellites during the January 2009 stratospheric sudden warming event, J. Geophys. Res., 115, A00G09, doi: $10.1029 / 2010 \mathrm{JA} 015466$. 
APPENDIX 
Figures 2-1, 2-2, 2-4 through 2-15, and 3-31 are copyrighted by the American Geophysical Union and reproduced with permission. Pages 96-107 contain an outline of permissions given by AGU to use the mentioned figures. Figure 1-1 was published by Elsevier in Kelley [2009]. Permission to reproduce this figure was obtained, and is included on pages 108-112.

The copyright notices appearing in the AGU articles are reproduced here as required by the terms and conditions.

The Fejer et al. [1991] paper Copyright 1991 by the American Geophysical Union.

The Scherliess and Fejer [1999] paper:

Copyright 1999 by the American Geophysical Union.

The Fejer et al. [2005] paper:

Copyright 2005 by the American Geophysical Union.

The Fejer et al. [2008] paper:

Copyright 2008 by the American Geophysical Union.

The Fejer et al. [2011] paper:

Copyright 2011 by the American Geophysical Union.

The Fejer et al. [2013] paper:

C2013. American Geophysical Union. All Rights Reserved. 


\section{JOHN WILEY AND SONS LICENSE} TERMS AND CONDITIONS

This is a License Agreement between Brian D Tracy ("You") and John Wiley and Sons ("John Wiley and Sons") provided by Copyright Clearance Center ("CCC"). The license consists of your order details, the terms and conditions provided by John Wiley and Sons, and the payment terms and conditions.

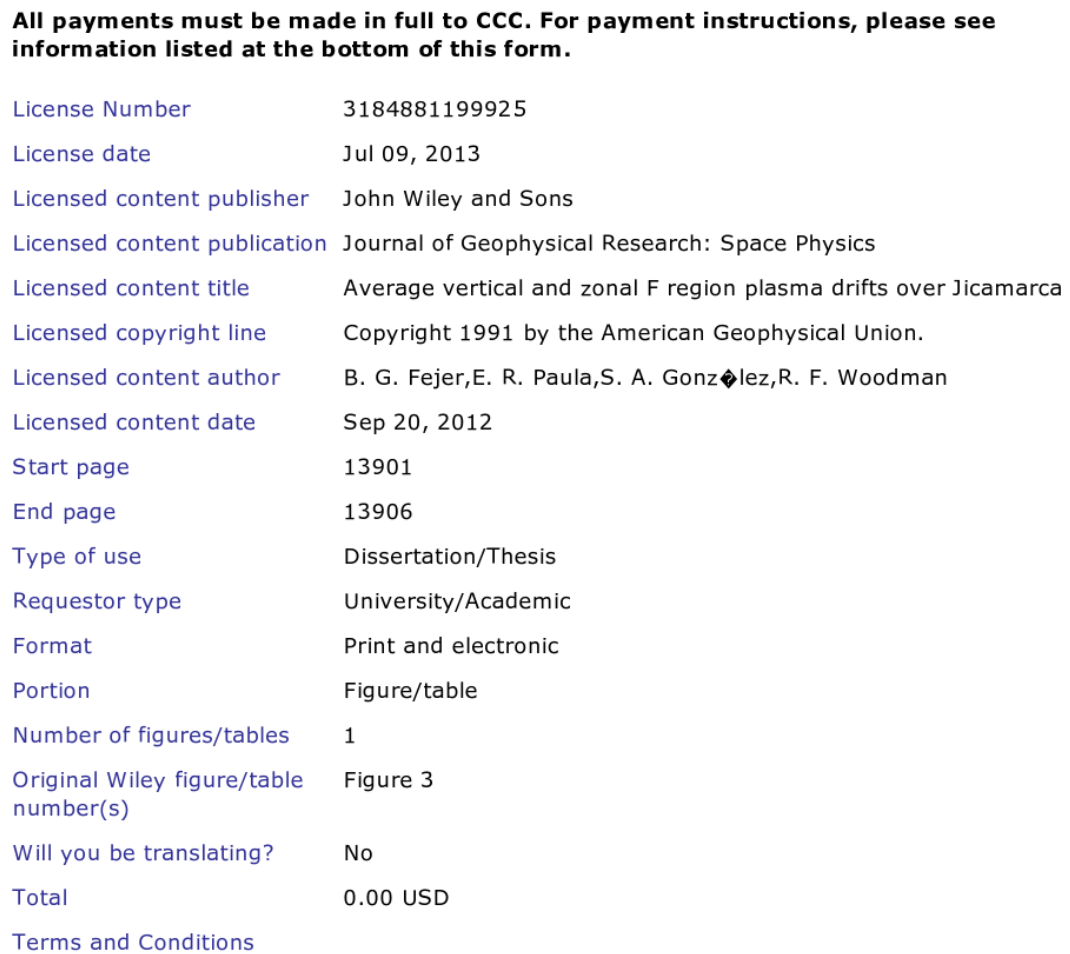




\section{JOHN WILEY AND SONS LICENSE} TERMS AND CONDITIONS

This is a License Agreement between Brian D Tracy ("You") and John Wiley and Sons ("John Wiley and Sons") provided by Copyright Clearance Center ("CCC"). The license consists of your order details, the terms and conditions provided by John Wiley and Sons, and the payment terms and conditions.

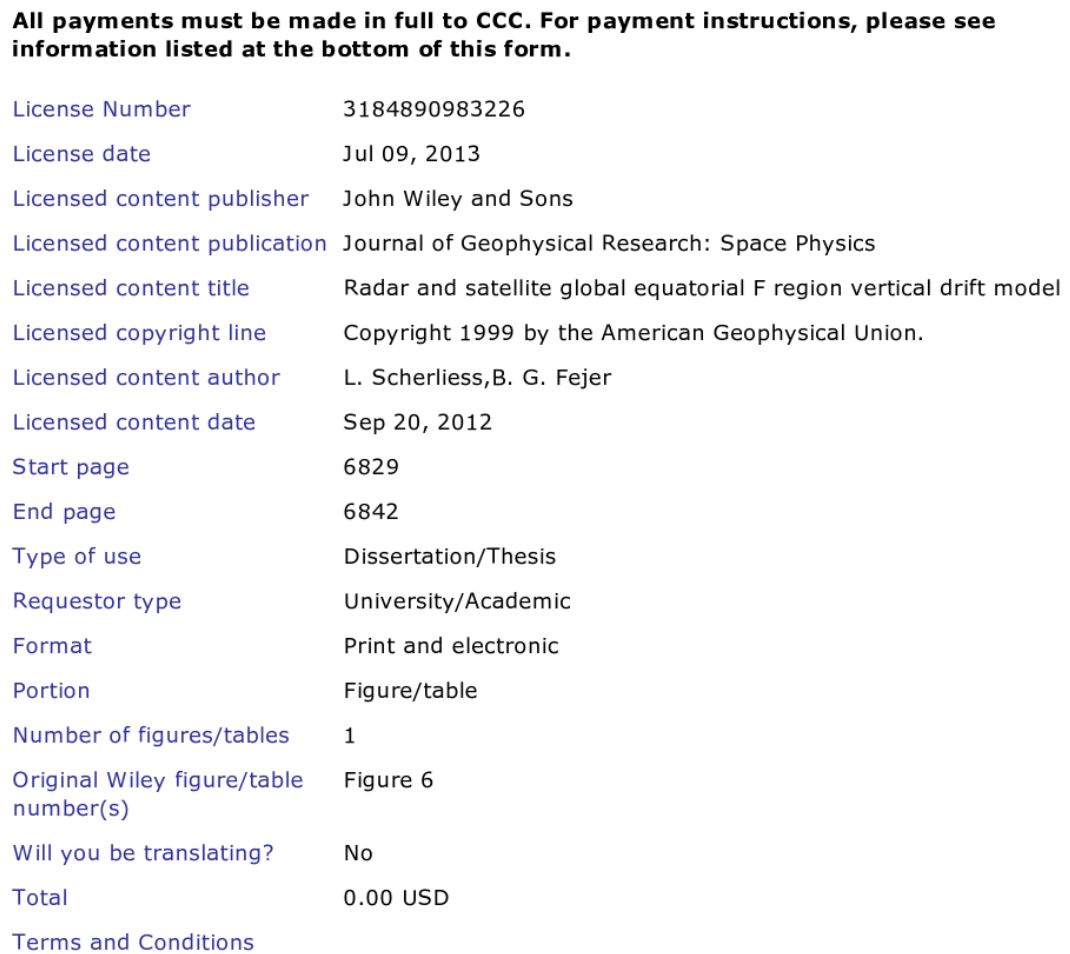




\section{JOHN WILEY AND SONS LICENSE} TERMS AND CONDITIONS

This is a License Agreement between Brian D Tracy ("You") and John Wiley and Sons ("John Wiley and Sons") provided by Copyright Clearance Center ("CCC"). The license consists of your order details, the terms and conditions provided by John Wiley and Sons, and the payment terms and conditions.

\begin{tabular}{|c|c|}
\hline License Number & 3184890091728 \\
\hline License date & Jul 09, 2013 \\
\hline Licensed content publisher & John Wiley and Sons \\
\hline Licensed content publication & Journal of Geophysical Research: Space Physics \\
\hline Licensed content title & Climatology of $\mathrm{F}$ region zonal plasma drifts over Jicamarca \\
\hline Licensed copyright line & Copyright 2005 by the American Geophysical Union. \\
\hline Licensed content author & B. G. Fejer,J. R. Souza,A. S. Santos,A. E. Costa Pereira \\
\hline Licensed content date & Dec 21, 2005 \\
\hline Start page & $\mathrm{n} / \mathrm{a}$ \\
\hline End page & $\mathrm{n} / \mathrm{a}$ \\
\hline Type of use & Dissertation/Thesis \\
\hline Requestor type & University/Academic \\
\hline Format & Print and electronic \\
\hline Portion & Figure/table \\
\hline Number of figures/tables & 2 \\
\hline $\begin{array}{l}\text { Original Wiley figure/table } \\
\text { number(s) }\end{array}$ & Figure 1 and Figure 4 \\
\hline Will you be translating? & No \\
\hline Total & 0.00 USD \\
\hline
\end{tabular}


This is a License Agreement between Brian D Tracy ("You") and John Wiley and Sons ("John Wiley and Sons") provided by Copyright Clearance Center ("CCC"). The license consists of your order details, the terms and conditions provided by John Wiley and Sons, and the payment terms and conditions.

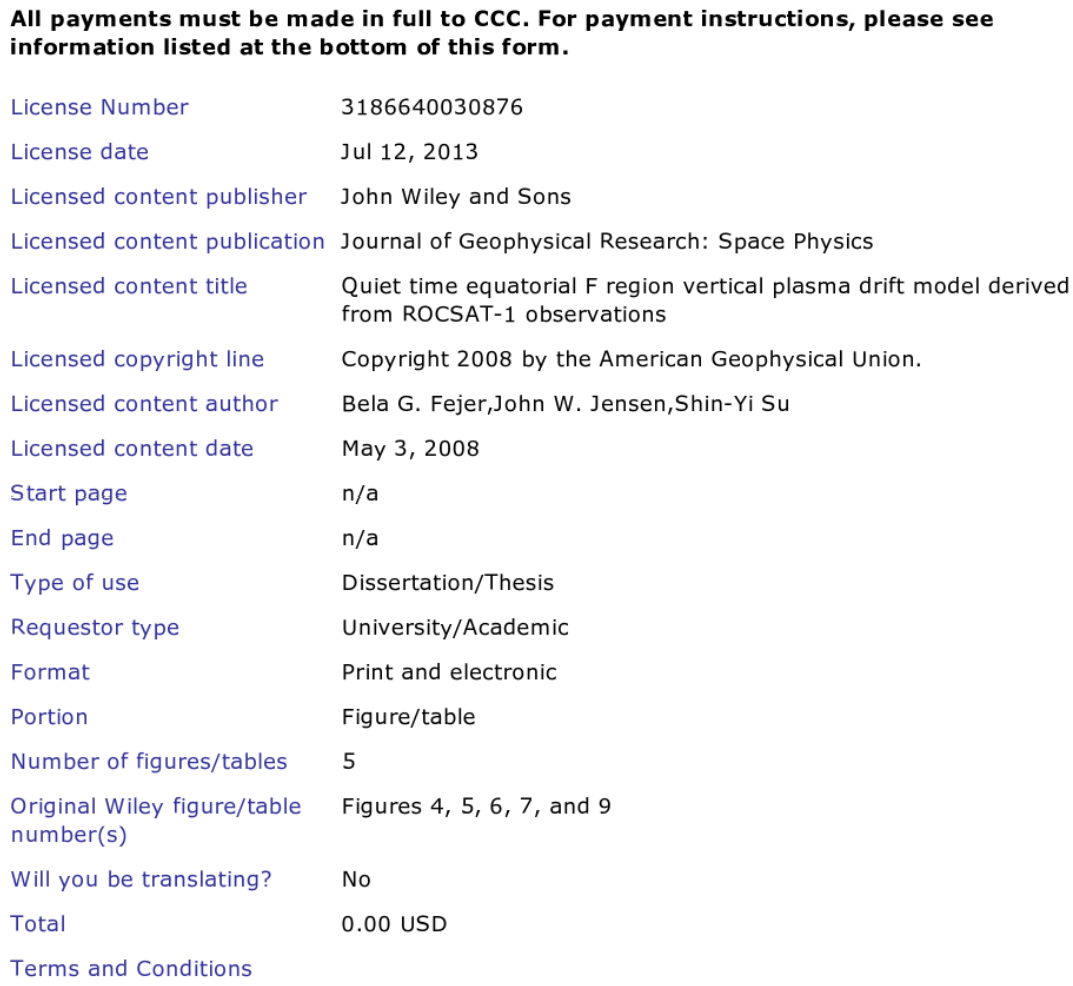

\section{TERMS AND CONDITIONS}

This copyrighted material is owned by or exclusively licensed to John Wiley \& Sons, Inc. or one of its group companies (each a "Wiley Company") or a society for whom a Wiley Company has exclusive publishing rights in relation to a particular journal (collectively "WILEY"). By clicking "accept" in connection with completing this licensing transaction, you agree that the following terms and conditions apply to this transaction (along with the billing and payment terms and conditions established by the Copyright Clearance Center Inc., ("CCC's Billing and Payment terms and conditions"), at the time that you opened your 
This is a License Agreement between Brian D Tracy ("You") and John Wiley and Sons ("John Wiley and Sons") provided by Copyright Clearance Center ("CCC"). The license consists of your order details, the terms and conditions provided by John Wiley and Sons, and the payment terms and conditions.

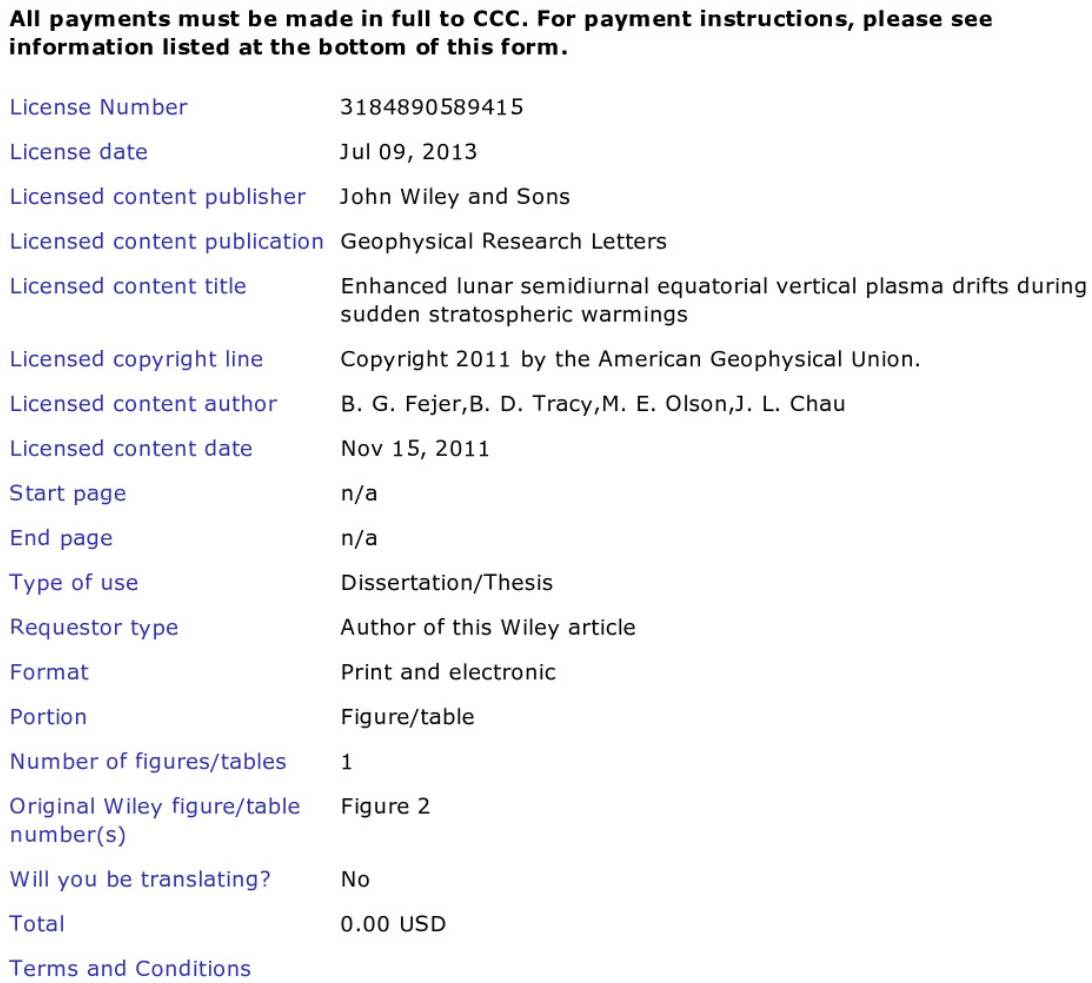

\section{TERMS AND CONDITIONS}

This copyrighted material is owned by or exclusively licensed to John Wiley \& Sons, Inc. or one of its group companies (each a "Wiley Company") or a society for whom a Wiley Company has exclusive publishing rights in relation to a particular journal (collectively "WILEY"). By clicking "accept" in connection with completing this licensing transaction, you agree that the following terms and conditions apply to this transaction (along with the billing and payment terms and conditions established by the Copyright Clearance Center Inc., ("CCC's Billing and Payment terms and conditions"), at the time that you opened your 
This is a License Agreement between Brian D Tracy ("You") and John Wiley and Sons ("John Wiley and Sons") provided by Copyright Clearance Center ("CCC"). The license consists of your order details, the terms and conditions provided by John Wiley and Sons, and the payment terms and conditions.

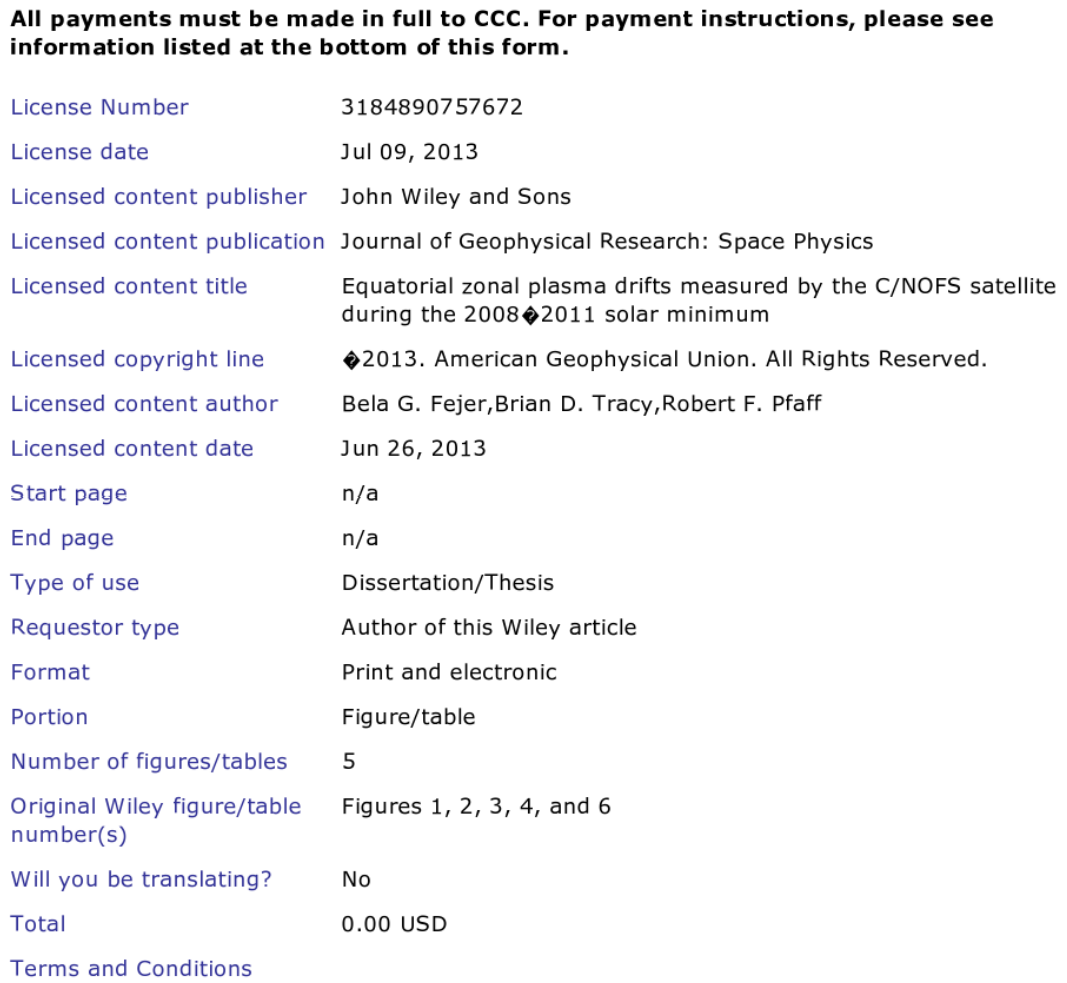

\section{TERMS AND CONDITIONS}

This copyrighted material is owned by or exclusively licensed to John Wiley \& Sons, Inc. or one of its group companies (each a "Wiley Company") or a society for whom a Wiley Company has exclusive publishing rights in relation to a particular journal (collectively "WILEY"). By clicking "accept" in connection with completing this licensing transaction, you agree that the following terms and conditions apply to this transaction (along with the billing and payment terms and conditions established by the Copyright Clearance Center Inc., ("CCC's Billing and Payment terms and conditions"), at the time that you opened your 


\section{TERMS AND CONDITIONS}

This copyrighted material is owned by or exclusively licensed to John Wiley \& Sons, Inc. or one of its group companies (each a "Wiley Company") or a society for whom a Wiley Company has exclusive publishing rights in relation to a particular journal (collectively "WILEY"). By clicking "accept" in connection with completing this licensing transaction, you agree that the following terms and conditions apply to this transaction (along with the billing and payment terms and conditions established by the Copyright Clearance Center Inc., ("CCC's Billing and Payment terms and conditions"), at the time that you opened your RightsLink account (these are available at any time at http://myaccount.copyright.com).

\section{Terms and Conditions}

1. The materials you have requested permission to reproduce (the "Materials") are protected by copyright.

2.You are hereby granted a personal, non-exclusive, non-sublicensable, non-transferable, worldwide, limited license to reproduce the Materials for the purpose specified in the licensing process. This license is for a one-time use only with a maximum distribution equal to the number that you identified in the licensing process. Any form of republication granted by this license must be completed within two years of the date of the grant of this license (although copies prepared before may be distributed thereafter). The Materials shall not be used in any other manner or for any other purpose. Permission is granted subject to an appropriate acknowledgement given to the author, title of the material/book/journal and the publisher. You shall also duplicate the copyright notice that appears in the Wiley publication in your use of the Material. Permission is also granted on the understanding that nowhere in the text is a previously published source acknowledged for all or part of this Material. Any third party material is expressly excluded from this permission.

3. With respect to the Materials, all rights are reserved. Except as expressly granted by the terms of the license, no part of the Materials may be copied, modified, adapted (except for minor reformatting required by the new Publication), translated, reproduced, transferred or distributed, in any form or by any means, and no derivative works may be made based on the Materials without the prior permission of the respective copyright owner. You may not alter, remove or suppress in any manner any copyright, trademark or other notices displayed by the Materials. You may not license, rent, sell, loan, lease, pledge, offer as security, transfer or assign the Materials, or any of the rights granted to you hereunder to any other person.

4. The Materials and all of the intellectual property rights therein shall at all times remain the exclusive property of John Wiley \& Sons Inc or one of its related companies (WILEY) or their respective licensors, and your interest therein is only that of having possession of and the right to reproduce the Materials pursuant to Section 2 herein during the continuance of this Agreement. You agree that you own no right, title or interest in or to the Materials or any of the intellectual property rights therein. You shall have no rights hereunder other than the license as provided for above in Section 2. No right, license or interest to any trademark, 
trade name, service mark or other branding ("Marks") of WILEY or its licensors is granted hereunder, and you agree that you shall not assert any such right, license or interest with respect thereto.

5. NEITHER WILEY NOR ITS LICENSORS MAKES ANY WARRANTY OR REPRESENTATION OF ANY KIND TO YOU OR ANY THIRD PARTY, EXPRESS, IMPLIED OR STATUTORY, WITH RESPECT TO THE MATERIALS OR THE ACCURACY OF ANY INFORMATION CONTAINED IN THE MATERIALS, INCLUDING, WITHOUT LIMITATION, ANY IMPLIED WARRANTY OF MERCHANTABILITY, ACCURACY, SATISFACTORY QUALITY, FITNESS FOR A PARTICULAR PURPOSE, USABILITY, INTEGRATION OR NON-INFRINGEMENT AND ALL SUCH WARRANTIES ARE HEREBY EXCLUDED BY WILEY AND ITS LICENSORS AND WAIVED BY YOU.

6. WILEY shall have the right to terminate this Agreement immediately upon breach of this Agreement by you.

7. You shall indemnify, defend and hold harmless WILEY, its Licensors and their respective directors, officers, agents and employees, from and against any actual or threatened claims, demands, causes of action or proceedings arising from any breach of this Agreement by you.

8. IN NO EVENT SHALL WILEY OR ITS LICENSORS BE LIABLE TO YOU OR ANY OTHER PARTY OR ANY OTHER PERSON OR ENTITY FOR ANY SPECIAL, CONSEQUENTIAL, INCIDENTAL, INDIRECT, EXEMPLARY OR PUNITIVE DAMAGES, HOWEVER CAUSED, ARISING QUT OF OR IN CONNECTION WITH THE DOWNLOADING, PROVISIONING, VIEWING OR USE OF THE MATERIALS REGARDLESS OF THE FORM OF ACTION, WHETHER FOR BREACH OF CONTRACT, BREACH OF WARRANTY, TORT, NEGLIGENCE, INFRINGEMENT OR OTHERWISE (INCLUDING, WITHOUT LIMITATION, DAMAGES BASED ON LOSS OF PROFITS, DATA, FILES, USE, BUSINESS OPPORTUNITY OR CLAIMS OF THIRD PARTIES), AND WHETHER OR NOT THE PARTY HAS BEEN ADVISED OF THE POSSIBILITY OF SUCH DAMAGES. THIS LIMITATION SHALL APPLY NOTWITHSTANDING ANY FAILURE OF ESSENTIAL PURPOSE OF ANY LIMITED REMEDY PROVIDED HEREIN.

9. Should any provision of this Agreement be held by a court of competent jurisdiction to be illegal, invalid, or unenforceable, that provision shall be deemed amended to achieve as nearly as possible the same economic effect as the original provision, and the legality, validity and enforceability of the remaining provisions of this Agreement shall not be affected or impaired thereby.

10. The failure of either party to enforce any term or condition of this Agreement shall not constitute a waiver of either party's right to enforce each and every term and condition of this Agreement. No breach under this agreement shall be deemed waived or excused by either party unless such waiver or consent is in writing signed by the party granting such waiver or consent. The waiver by or consent of a party to a breach of any provision of this Agreement shall not operate or be construed as a waiver of or consent to any other or subsequent breach by such other party. 
11. This Agreement may not be assigned (including by operation of law or otherwise) by you without WILEY's prior written consent.

12. Any fee required for this permission shall be non-refundable after thirty (30) days from receipt

13. These terms and conditions together with CCC's Billing and Payment terms and conditions (which are incorporated herein) form the entire agreement between you and WILEY concerning this licensing transaction and (in the absence of fraud) supersedes all prior agreements and representations of the parties, oral or written. This Agreement may not be amended except in writing signed by both parties. This Agreement shall be binding upon and inure to the benefit of the parties' successors, legal representatives, and authorized assigns.

14. In the event of any conflict between your obligations established by these terms and conditions and those established by CCC's Billing and Payment terms and conditions, these terms and conditions shall prevail.

15. WILEY expressly reserves all rights not specifically granted in the combination of (i) the license details provided by you and accepted in the course of this licensing transaction, (ii) these terms and conditions and (iii) CCC's Billing and Payment terms and conditions.

16. This Agreement will be void if the Type of Use, Format, Circulation, or Requestor Type was misrepresented during the licensing process.

17. This Agreement shall be governed by and construed in accordance with the laws of the State of New York, USA, without regards to such state's conflict of law rules. Any legal action, suit or proceeding arising out of or relating to these Terms and Conditions or the breach thereof shall be instituted in a court of competent jurisdiction in New York County in the State of New York in the United States of America and each party hereby consents and submits to the personal jurisdiction of such court, waives any objection to venue in such court and consents to service of process by registered or certified mail, return receipt requested, at the last known address of such party.

\section{Wiley Open Access Terms and Conditions}

Wiley publishes Open Access articles in both its Wiley Open Access Journals program [http://www.wileyopenaccess.com/view/index.html] and as Online Open articles in its subscription journals. The majority of Wiley Open Access Journals have adopted the Creative Commons Attribution License (CC BY) which permits the unrestricted use, distribution, reproduction, adaptation and commercial exploitation of the article in any medium. No permission is required to use the article in this way provided that the article is properly cited and other license terms are observed. A small number of Wiley Open Access journals have retained the Creative Commons Attribution Non Commercial License (CC BY-NC), which permits use, distribution and reproduction in any medium, provided the original work is properly cited and is not used for commercial purposes.

Online Open articles - Authors selecting Online Open are, unless particular exceptions 
apply, offered a choice of Creative Commons licenses. They may therefore select from the CC BY, the CC BY-NC and the Attribution-NoDerivatives (CC BY-NC-ND). The CC BY-NC-ND is more restrictive than the CC BY-NC as it does not permit adaptations or modifications without rights holder consent.

Wiley Open Access articles are protected by copyright and are posted to repositories and websites in accordance with the terms of the applicable Creative Commons license referenced on the article. At the time of deposit, Wiley Open Access articles include all changes made during peer review, copyediting, and publishing. Repositories and websites that host the article are responsible for incorporating any publisher-supplied amendments or retractions issued subsequently.

Wiley Open Access articles are also available without charge on Wiley's publishing platform, Wiley Online Library or any successor sites.

Conditions applicable to all Wiley Open Access articles:

- The authors' moral rights must not be compromised. These rights include the right of "paternity" (also known as "attribution" - the right for the author to be identified as such) and "integrity" (the right for the author not to have the work altered in such a way that the author's reputation or integrity may be damaged).

- Where content in the article is identified as belonging to a third party, it is the obligation of the user to ensure that any reuse complies with the copyright policies of the owner of that content.

- If article content is copied, downloaded or otherwise reused for research and other purposes as permitted, a link to the appropriate bibliographic citation (authors, journal, article title, volume, issue, page numbers, DOI and the link to the definitive published version on Wiley Online Library) should be maintained. Copyright notices and disclaimers must not be deleted.

- Creative Commons licenses are copyright licenses and do not confer any other rights, including but not limited to trademark or patent rights.

- Any translations, for which a prior translation agreement with Wiley has not been agreed, must prominently display the statement: "This is an unofficial translation of an article that appeared in a Wiley publication. The publisher has not endorsed this translation."

\section{Conditions applicable to non-commercial licenses (CC BY-NC and CC BY-NC-ND)}

For non-commercial and non-promotional purposes individual non-commercial users may access, download, copy, display and redistribute to colleagues Wiley Open Access articles. In addition, articles adopting the CC BY-NC may be adapted, translated, and text- and data-mined subject to the conditions above. 


\section{Use by commercial "for-profit" organizations}

Use of non-commercial Wiley Open Access articles for commercial, promotional, or marketing purposes requires further explicit permission from Wiley and will be subject to a fee. Commercial purposes include:

- Copying or downloading of articles, or linking to such articles for further redistribution, sale or licensing;

- Copying, downloading or posting by a site or service that incorporates advertising with such content;

- The inclusion or incorporation of article content in other works or services (other than normal quotations with an appropriate citation) that is then available for sale or licensing, for a fee (for example, a compilation produced for marketing purposes, inclusion in a sales pack)

- Use of article content (other than normal quotations with appropriate citation) by for-profit organizations for promotional purposes

o Linking to article content in e-mails redistributed for promotional, marketing or educational purposes;

- Use for the purposes of monetary reward by means of sale, resale, license, loan, transfer or other form of commercial exploitation such as marketing products

- Print reprints of Wiley Open Access articles can be purchased from: corporatesales@wiley.com

The modification or adaptation for any purpose of an article referencing the CC BY-NC-ND License requires consent which can be requested from RightsLink@wiley.com .

Other Terms and Conditions:

BY CLICKING ON THE "I AGREE..." BOX, YOU ACKNOWLEDGE THAT YOU HAVE READ AND FULLY UNDERSTAND EACH OF THE SECTIONS OF AND PROVISIONS SET FORTH IN THIS AGREEMENT AND THAT YOU ARE IN AGREEMENT WITH AND ARE WILLING TO ACCEPT ALL OF YOUR OBLIGATIONS AS SET FORTH IN THIS AGREEMENT. 
If you would like to pay for this license now, please remit this license along with your payment made payable to "COPYRIGHT CLEARANCE CENTER" otherwise you will be invoiced within 48 hours of the license date. Payment should be in the form of a check or money order referencing your account number and this invoice number RLNK501061914.

Once you receive your invoice for this order, you may pay your invoice by credit card. Please follow instructions provided at that time.

Make Payment To:

Copyright Clearance Center

Dept 001

P.0. Box 843006

Boston, MA 02284-3006

For suggestions or comments regarding this order, contact RightsLink Customer Support: customercare@copyright.com or +1-877-622-5543 (toll free in the US) or +1-978-646-2777.

Gratis licenses (referencing $\$ 0$ in the Total field) are free. Please retain this printable license for your reference. No payment is required. 
This is a License Agreement between Brian D Tracy ("You") and Elsevier ("Elsevier") provided by Copyright Clearance Center ("CCC"). The license consists of your order details, the terms and conditions provided by Elsevier, and the payment terms and conditions.

All payments must be made in full to CCC. For payment instructions, please see information listed at the bottom of this form.

\begin{tabular}{|c|c|}
\hline Supplier & $\begin{array}{l}\text { Elsevier Limited } \\
\text { The Boulevard,Langford Lane } \\
\text { Kidlington,Oxford,OX5 1GB,UK }\end{array}$ \\
\hline $\begin{array}{l}\text { Registered Company } \\
\text { Number }\end{array}$ & 1982084 \\
\hline Customer name & Brian D Tracy \\
\hline \multirow[t]{2}{*}{ Customer address } & 11104 N 5550 W \\
\hline & AMERICAN FORK, UT 84003 \\
\hline License number & 3163741384913 \\
\hline License date & Jun 07, 2013 \\
\hline Licensed content publisher & Elsevier \\
\hline Licensed content publication & Elsevier Books \\
\hline Licensed content title & International Geophysics, Volume 96 \\
\hline Licensed content author & Vivien Gornitz \\
\hline Licensed content date & 2009 \\
\hline Number of pages & 26 \\
\hline Start Page & 1 \\
\hline End Page & 26 \\
\hline Type of Use & reuse in a thesis/dissertation \\
\hline Portion & figures/tables/illustrations \\
\hline $\begin{array}{l}\text { Number of figures/tables } \\
\text { /illustrations }\end{array}$ & 1 \\
\hline Format & both print and electronic \\
\hline $\begin{array}{l}\text { Are you the author of this } \\
\text { Elsevier chapter? }\end{array}$ & No \\
\hline Will you be translating? & No \\
\hline \multicolumn{2}{|l|}{ Order reference number } \\
\hline $\begin{array}{l}\text { Title of your } \\
\text { thesis/dissertation }\end{array}$ & $\begin{array}{l}\text { Lunar Tidal Effects in the Electrodynamics of the Low Latitude } \\
\text { Ionosphere }\end{array}$ \\
\hline Expected completion date & Jun 2013 \\
\hline $\begin{array}{l}\text { Estimated size (number of } \\
\text { pages) }\end{array}$ & 118 \\
\hline
\end{tabular}




$\begin{array}{ll}\text { Elsevier VAT number } & \text { GB 494 6272 12 } \\ \text { Permissions price } & 0.00 \text { USD } \\ \text { VAT/Local Sales Tax } & 0.00 \text { USD / 0.00 GBP } \\ \text { Total } & 0.00 \text { USD } \\ \text { Terms and Conditions } & \end{array}$

\section{INTRODUCTION}

1. The publisher for this copyrighted material is Elsevier. By clicking "accept" in connection with completing this licensing transaction, you agree that the following terms and conditions apply to this transaction (along with the Billing and Payment terms and conditions established by Copyright Clearance Center, Inc. ("CCC"), at the time that you opened your Rightslink account and that are available at any time at http://myaccount.copyright.com).

\section{GENERAL TERMS}

2. Elsevier hereby grants you permission to reproduce the aforementioned material subject to the terms and conditions indicated.

3. Acknowledgement: If any part of the material to be used (for example, figures) has appeared in our publication with credit or acknowledgement to another source, permission must also be sought from that source. If such permission is not obtained then that material may not be included in your publication/copies. Suitable acknowledgement to the source must be made, either as a footnote or in a reference list at the end of your publication, as follows:

"Reprinted from Publication title, Vol /edition number, Author(s), Title of article / title of chapter, Pages No., Copyright (Year), with permission from Elsevier [OR APPLICABLE SOCIETY COPYRIGHT OWNER]." Also Lancet special credit - "Reprinted from The Lancet, Vol. number, Author(s), Title of article, Pages No., Copyright (Year), with permission from Elsevier."

4. Reproduction of this material is confined to the purpose and/or media for which permission is hereby given.

5. Altering/Modifying Material: Not Permitted. However figures and illustrations may be altered/adapted minimally to serve your work. Any other abbreviations, additions, deletions and/or any other alterations shall be made only with prior written authorization of Elsevier Ltd. (Please contact Elsevier at permissions@elsevier.com)

6. If the permission fee for the requested use of our material is waived in this instance, please be advised that your future requests for Elsevier materials may attract a fee.

7. Reservation of Rights: Publisher reserves all rights not specifically granted in the combination of (i) the license details provided by you and accepted in the course of this licensing transaction, (ii) these terms and conditions and (iii) CCC's Billing and Payment terms and conditions. 
8. License Contingent Upon Payment: While you may exercise the rights licensed immediately upon issuance of the license at the end of the licensing process for the transaction, provided that you have disclosed complete and accurate details of your proposed use, no license is finally effective unless and until full payment is received from you (either by publisher or by CCC) as provided in CCC's Billing and Payment terms and conditions. If full payment is not received on a timely basis, then any license preliminarily granted shall be deemed automatically revoked and shall be void as if never granted. Further, in the event that you breach any of these terms and conditions or any of CCC's Billing and Payment terms and conditions, the license is automatically revoked and shall be void as if never granted. Use of materials as described in a revoked license, as well as any use of the materials beyond the scope of an unrevoked license, may constitute copyright infringement and publisher reserves the right to take any and all action to protect its copyright in the materials.

9. Warranties: Publisher makes no representations or warranties with respect to the licensed material.

10. Indemnity: You hereby indemnify and agree to hold harmless publisher and CCC, and their respective officers, directors, employees and agents, from and against any and all claims arising out of your use of the licensed material other than as specifically authorized pursuant to this license.

11. No Transfer of License: This license is personal to you and may not be sublicensed, assigned, or transferred by you to any other person without publisher's written permission.

12. No Amendment Except in Writing: This license may not be amended except in a writing signed by both parties (or, in the case of publisher, by CCC on publisher's behalf).

13. Objection to Contrary Terms: Publisher hereby objects to any terms contained in any purchase order, acknowledgment, check endorsement or other writing prepared by you, which terms are inconsistent with these terms and conditions or CCC's Billing and Payment terms and conditions. These terms and conditions, together with CCC's Billing and Payment terms and conditions (which are incorporated herein), comprise the entire agreement between you and publisher (and CCC) concerning this licensing transaction. In the event of any conflict between your obligations established by these terms and conditions and those established by CCC's Billing and Payment terms and conditions, these terms and conditions shall control.

14. Revocation: Elsevier or Copyright Clearance Center may deny the permissions described in this License at their sole discretion, for any reason or no reason, with a full refund payable to you. Notice of such denial will be made using the contact information provided by you. Failure to receive such notice will not alter or invalidate the denial. In no event will Elsevier or Copyright Clearance Center be responsible or liable for any costs, expenses or damage incurred by you as a result of a denial of your permission request, other than a refund of the amount(s) paid by you to Elsevier and/or Copyright Clearance Center for denied permissions.

\section{LIMITED LICENSE}


The following terms and conditions apply only to specific license types:

15. Translation: This permission is granted for non-exclusive world English rights only unless your license was granted for translation rights. If you licensed translation rights you may only translate this content into the languages you requested. A professional translator must perform all translations and reproduce the content word for word preserving the integrity of the article. If this license is to re-use 1 or 2 figures then permission is granted for non-exclusive world rights in all languages.

16. Website: The following terms and conditions apply to electronic reserve and author websites:

Electronic reserve: If licensed material is to be posted to website, the web site is to be password-protected and made available only to bona fide students registered on a relevant course if:

This license was made in connection with a course,

This permission is granted for 1 year only. You may obtain a license for future website posting,

All content posted to the web site must maintain the copyright information line on the bottom of each image,

A hyper-text must be included to the Homepage of the journal from which you are licensing at http://www.sciencedirect.com/science/journal/xxxxx or the Elsevier homepage for books at http://www.elsevier.com, and

Central Storage: This license does not include permission for a scanned version of the material to be stored in a central repository such as that provided by Heron/XanEdu.

17. Author website for journals with the following additional clauses:

All content posted to the web site must maintain the copyright information line on the bottom of each image, and the permission granted is limited to the personal version of your paper. You are not allowed to download and post the published electronic version of your article (whether PDF or HTML, proof or final version), nor may you scan the printed edition to create an electronic version. A hyper-text must be included to the Homepage of the journal from which you are licensing at http://www.sciencedirect.com/science/journal/xxxxx . As part of our normal production process, you will receive an e-mail notice when your article appears on Elsevier's online service ScienceDirect (www.sciencedirect.com). That e-mail will include the article's Digital Object Identifier (DOI). This number provides the electronic link to the published article and should be included in the posting of your personal version. We ask that you wait until you receive this e-mail and have the DOI to do any posting.

Central Storage: This license does not include permission for a scanned version of the material to be stored in a central repository such as that provided by Heron/XanEdu.

18. Author website for books with the following additional clauses:

Authors are permitted to place a brief summary of their work online only.

A hyper-text must be included to the Elsevier homepage at http://www.elsevier.com . All content posted to the web site must maintain the copyright information line on the bottom of each image. You are not allowed to download and post the published electronic version of 
your chapter, nor may you scan the printed edition to create an electronic version.

Central Storage: This license does not include permission for a scanned version of the material to be stored in a central repository such as that provided by Heron/XanEdu.

19. Website (regular and for author): A hyper-text must be included to the Homepage of the journal from which you are licensing at http://www.sciencedirect.com/science/journal /xxxxx. or for books to the Elsevier homepage at http://www.elsevier.com

20. Thesis/Dissertation: If your license is for use in a thesis/dissertation your thesis may be submitted to your institution in either print or electronic form. Should your thesis be published commercially, please reapply for permission. These requirements include permission for the Library and Archives of Canada to supply single copies, on demand, of the complete thesis and include permission for UMI to supply single copies, on demand, of the complete thesis. Should your thesis be published commercially, please reapply for permission.

\section{Other Conditions:}

v1.6

If you would like to pay for this license now, please remit this license along with your payment made payable to "COPYRIGHT CLEARANCE CENTER" otherwise you will be invoiced within $\mathbf{4 8}$ hours of the license date. Payment should be in the form of a check or money order referencing your account number and this invoice number RLNK501038599.

Once you receive your invoice for this order, you may pay your invoice by credit card. Please follow instructions provided at that time.

Make Payment To:

Copyright Clearance Center

Dept 001

P.o. Box 843006

Boston, MA 02284-3006

For suggestions or comments regarding this order, contact RightsLink Customer Support: customercare@copyright.com or +1-877-622-5543 (toll free in the US) or +1-978-646-2777.

Gratis licenses (referencing $\$ 0$ in the Total field) are free. Please retain this printable license for your reference. No payment is required. 